\title{
Novel insights into the pathophysiology and treatment of the overactive bladder syndrome
}

Citation for published version (APA):

Dambros, M. (2006). Novel insights into the pathophysiology and treatment of the overactive bladder syndrome. [Doctoral Thesis, Maastricht University]. Universiteit Maastricht. https://doi.org/10.26481/dis.20060223md

Document status and date:

Published: 01/01/2006

DOI:

10.26481/dis.20060223md

Document Version:

Publisher's PDF, also known as Version of record

\section{Please check the document version of this publication:}

- A submitted manuscript is the version of the article upon submission and before peer-review. There can be important differences between the submitted version and the official published version of record.

People interested in the research are advised to contact the author for the final version of the publication, or visit the DOI to the publisher's website.

- The final author version and the galley proof are versions of the publication after peer review.

- The final published version features the final layout of the paper including the volume, issue and page numbers.

Link to publication

\footnotetext{
General rights rights.

- You may freely distribute the URL identifying the publication in the public portal. please follow below link for the End User Agreement:

www.umlib.nl/taverne-license

Take down policy

If you believe that this document breaches copyright please contact us at:

repository@maastrichtuniversity.nl

providing details and we will investigate your claim.
}

Copyright and moral rights for the publications made accessible in the public portal are retained by the authors and/or other copyright owners and it is a condition of accessing publications that users recognise and abide by the legal requirements associated with these

- Users may download and print one copy of any publication from the public portal for the purpose of private study or research.

- You may not further distribute the material or use it for any profit-making activity or commercial gain

If the publication is distributed under the terms of Article $25 \mathrm{fa}$ of the Dutch Copyright Act, indicated by the "Taverne" license above, 
Novel insights into the pathophysiology and treatment of the Overactive Bladder Syndrome 
Novel insights into the pathophysiology and treatment of the Overactive Bladder Syndrome

\section{Proefschrift}

ter verkrijging van de graad van doctor aan de Universiteit Maastricht, op gezag van de Rector Magnificus, Prof. mr. G.P.M.F. Mols volgens het besluit wan het College van Decanen, in het openbaar te verdedigen op donderdag 23 Februari 2006 om 14:00 uur

door

Miriam Dambros 
Promotores:

- Prof. Dr. Ph. E.V. Van Kerrebroeck

- Prof. Dr. Paulo C.R. Palma (University of Campinas, Brasil)

Co-promotor:

- Dr. Gommert A. Van Koeveringe

Beoordelingcommissie:

- Prof. Dr. K. Leunissen (voorzitter)

- Prof. Dr. A. Bast

- Prof. Dr. L. Cardozo (University of London)

- Prof. Dr. A.A.B. Lyklama a Nijeholt (University of Leiden)

- Prof. Dr. J. de Mey

- Prof. Dr. H. Steinbush

Finanancial support :

WAMU foundation Maastricht

Apsen farmacêutica S/A 


\section{Contents}

\section{Chapter 1}

General Introduction and outline of the thesis

\section{Chapter 2}

The effect of ovariectomy and estradiol replacement on collagen and elastic fibers in the bladder of rats

Published in Int Urogynecol J 14: 108-112, 2003

\section{Chapter 3}

Relexant effects of estradiol through non-genomic pathways in male and female pig bladder smooth muscle

Published in Pharmacology 72:121-127, 2004.

\section{Chapter 4}

The Flavonoid galangin prevents smooth muscle fatigue of pig urinary bladder

Published in J Pharm Pharmacol 57(5):617-622, 2005.

\section{Chapter 5}

Galangin protects pig detrusor nerves from anoxia-glucopenia injuries due to repetitive field stimulation

Published in Urology 66(6):1327-31, 2005

\section{Chapter 6}

Multiple-signaling pathways are involved in the inhibitory effects of galangin on urinary bladder contractility

Published in Neurourol Urodyn 24(4):369-73, 2005.

\section{Chapter 7}

The inhibitory effect of the flavonoid galengin on urinary bladder smooth muscle contractility is mediated in part by modulation of $\mathrm{Ca}^{2+}$ release from intracellular stores Published in Planta Med 71(10): 962-964, 2005. 


\section{Chapter 8}

General discussion and future perspectives

Samenvatting

References

Acknowledgements

133

Curriculum vitae/List of publications 


\section{Chapter I}

Outline of the thesis and general Introduction 


\section{Outline of the thesis}

Lower urinary tract symptoms are common in the population, and particularly among the elderly. Some reports estimate the prevalence as $5 \%$ in the general population and $10 \%$ among individuals aged over 70 years.

Disturbances of bladder function leading to symptoms of urgency, frequency, and eventually incontinence have been termed overactive bladder (OAB) syndrome (ICS, 2002), defined as the symptoms of urgency, with or without urge incontinence, usually with frequency and nocturia. The appearance of this condition is accompanied by changes in the cell physiology of the detrusor and the associated motor nerves. However, it remains unclear whether such alterations are ubiquitouls and are causal in the appearance of abnormal function or merely a secondary development.

Therefore, a better understanding of normal bladder physiology and treatments for the condition is meeded. At present, the therapeutic options are dominated by suppression of the parasympathetic innervation of the bladder, through the use of anticholinergic agents. These agents can reduce urgency, reduce detrusor overactivity and increase bladder capacity. The clinical use of antimuscarinic agents is, however, limited by the well-known anticholinergle side effects of dry mouthi, blurred vision and constipation.

The limitations on the current drugs for treating lower urinary symptoms have diverted interest to new targets for pharmacological intervention and to further investigation of the pathophysiological basis of lower urinary tract function and dysfunction. Desplte promising effects in animal models; few new treatment principles for overactive bladder have passed the proofi-of-concept stage.

From this perspective, the present thesis focuses on some pathophysiological points of action regarding the detrusor muscle such as the roles of estradiol on the lower urinary tract and the flavonoid galangin on bladder smooth muscle contractility.

In the first part of this thesis, our current understanding of the problem of overactive bladider symptoms is reviewed. In chapter $\mathrm{I}$, the action of estradiol and flavonoids on the smooth muscle of the bladder are discussed.

The second part of this thesis involves preclinical research on the role of estradiol and flavonoids. 
The postmenopausal period is associated with high incidence of lower urinary tract symptoms. The most significant change caused by the menopause is estrogen deprivation. This has led to the use of hormone replacement among postmenopausal women with lower urinary tract dysfunction. However, the ralle of estradiol in the treatment of overactive bladder syndrome is still undefined and contradictory evidence can be found in the literature. Collagen and elastin are important components of the bladder wall and participate in bladder function. Collagen provides tensile strength, but over accumulation may inhibit bladder contractility and conduction of electrical impulses through the wall. Our knowledge of connected tissue alterations in the genitourinary tract and their hormonal regulation potential is limited. Since bladder wall connective tissue is crucial for the mechanical properties of the genitournary regions, it is important to characterize the possible changes related to estrogen status. Therefore, in chapter II, the influence of estradiol on collagen and elastic fibers in the bladder wall of rats is studied. Its protective activity is assessed in ovariectomized rats with and without estradiol replacement. Besides the considerable contradictory dlata published in the llterature on the specific effects af estrogen administration on the bladder wall morphology, there are also many doubts about the role of estradiol on bladder contractility as well as whether estrogen receptars are necessary for mediation of its effect on muscle contractility. In chapter III, the role of acute administration of estradiol in the organ bath in relation to detrusor contractile response is investigated. Furthermore, in a group of experiments, a specific estradiol antagonist was added to the organ bath to distinguish between genomic and non-genomic mechanisms of estradiol on detrusor muscle cells,

Filawonoids are a large group of polyphenolic compounds with a broad spectrum of physiological and pharmacological effects. Some flavonoids induce a bimodal effect on vascular tissue, with the boosting of muscle contraction at concentrations lower than $1 \mu$ mol/, while at higher concentrations their effect on smooth muscle relaxation prevails. The effects of galangin at submicromolar concentrations on detrusor smooth muscle contractility are investigated in chapters IV and $V$. Chapter IV shows the protective effects of the flavonoid galangin on the progressive decrease in bladder smooth muscle contractile responses, during Repetitive Field Stimulation (a model for muscle fatigue). Chapter $\mathrm{V}$ also deals with galangin, with regard to its use as a protector against 
detrusor damage induced by hypoxia/reoxygenation. In vivo ischaemia in animal models results in bladder overactivity and in humans, bladders from patients with bladder overactivity show patchy denervation "suggesting that periodic ischaemia and neuronal death may predispose to overactivity. Repetitive Field Stimulation as well as hypoxia and reoxygenation have demonstrated to increased lipid peroxidation and impaired smooth muscle contractility. The damage to cells on reperfusion after ischaemia is thought to be caused by calcium overload resulting from increased calcium entry. Therefore, we suggest that radical scavengers, like galangin, capable of limiting the $\mathrm{Ca}^{2 *}$ influlu into the cells might be used as effective drugs for the prevention of tissue damage by ischemiareperfusion injury. In chapters $I V$ and $V$ we test the hypothesis that the flavonoid galangin can counteract the detrusor damage caused by a period of ischaemia.

Chapters VI and VII investigate the mechanism for galangin action at higher micromolar concentrations on pig bladder smooth muscle. An attempt has been made to characterize its potential as an alternative inhibitor of bladder smooth muscle contraction.

Following this, an overview of the mast important results described in this thesis is presented in chapter VIII. 


\section{General introduction}

\section{Overactive bladder syndrome - an overview}

Overactive bladder is a symptom complex that includes urinary urgency with or without urgencyincontinence, urinary frequency and nocturia (ICS, 2002). The International Continence Society classlfies overactlve bladder as a syndrome for which no precise cause has been identified, with local abnormalities ruled out by diagnostic evaluation.

Although these lower urinary tract symptoms are rarely life-threatening, they are very common in the general population and, in particular, among the elderly. Some estimates have put the prevalence at about $5 \%$ in the general population and 7 to $12 \%$ among individuals aged over 70 years (Temml et al., 2000). Apart from being a major factor in reducing the quality of life, especially among the elderly, overactive bladder is also a very costly burden on the health services.

The pathological condition underlying overactive bladder is not completely understood but it is almost certainly multifactorial.

Injury to or diseases of the nervous system in adults can disrupt voluntary control of voiding. causing the reemergence of reflex voiding, resulting in bladder hyperactivity and urge incontinence. Because of the complexity of central nervous system control of the lower urinary tract, urge incontinence can develop as a result of various neurological disorders and aging. In addition, urge incontinence may be due to intrinsic detrusor myogenic abnormalities, resulting in detrusor overactlivity (Brading, 1997).

Urethral dysfunction can also cause urge incontinence. Increased bladder outlet urethral resistance in men with benign prostatic hyperplasia causes secondary bladder changes. In this situation the bladder wall can be subjected to gross ischaemia during micturition, compounded by an increased metabolic demand. It has been suggested that perlodic bladder ischaemia during obstructive micturition, may result in the partial denervation of the detrusor smooth muscle, through ischaemia and reperfusion injury to the post-ganglionic parasympathetic (Brading, 2004). Furthermore, recent studies have introduced the concept that reactive oxygen species may function as a major factor in 
the progressive deterioration of bladder contractility induced by benign prostatic hyperplasia (Masick et al., 2001). Brading's hypothesis is that bladder wall ischaiemia is a predisposing factor for bladder overactivity.

Overactivity of the detrusor muscle, whether neurogenic or idiopathic, can result in urgency or urge incontinence, depending on the response of the sphincter (Fisser et al., 2003). Detrusor overactivity may also have a myogenic origin. However, detrusor contractions may be weak as a result of impaired contractility. Urodynamic testing has Indicated that up to half of elderly patients with detrusor overactivity empty less than one third of their bladder contents through involuntary bladder contraction (Resnick \& Yalla, 1987). Incomplete emptying can contribute towards urinary frequency by lowering the functional capacity of the bladder.

The optimal therapy for overactive bladder depends on thorough evaluation, followed by treatment of all the likely causes and contributory factors. The genesis of overactive bladder symptom is commonly multifactorial, and multimodal therapy that includes nonpharmacological as well as pharmacollogical interventions may be indicated.

The limitations on the currently used drugs that have documented efficacy have stimulated research on alternative models. However, few new treatment principles for the treatment of overactive blladder have passed the proof-of-concept stagie.

Innervation, physlology, pharmacology and pathophysiology of the bladder

Innervation

The nervous mechanisms for bladder emptying and urine storage involve a complex pattern of

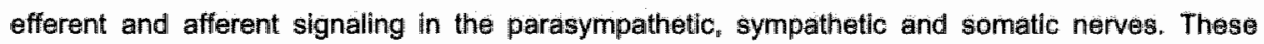
nerves constitute reflex pathways that either maintain the bladder in a relaxed state, thereby enabling urine storage at low intravesical pressure, or alternatively iniflate micturition by relaxation of the outflow region area and contraction of the bladder simoath muscle. 
The bladder is innervated by sacral parasympathetic nerves and thoracolumbar sympathetic nerves. Parasympathetic innervation originates via the mervi erigentes from the second to the fourth sacral segment. The sympathetic fibers are derived from the ninth to the twelfth thoracic and the first and second lumbar segments via the hypogastric plexus.

Contraction of the detrusor smooth muscle and relaxation of the outflow area result from activation of parasympathetic neurons. The axons pass through the pelvic nerve and synapse with the postganglionic nerve in the pelvic plexus, in ganglia on the surface of the bladder, or within the walls of the bladder and urethra (Owens \& Karram, 1998; Fletcher \& Bradley, 1978).

Most of the sympathetic innervation of the bladder and urethra originates from the intermedialateral nuclei in the thoracolumbar region of the spinal cord. The axons travel either through the inferior mesenteric ganglia and the hypogastric nerve, or pass through the paravertebral chain and enter the pelvic nerve. Thus, sympathetic signals are conveyed in both the hypogastric nerve and the pelwic nerve (Lincoln \& Burnstock, 1993). Sympathetic preganglionic transmission, like parasympathetic preglanglionic transmission, is predominantly mediated by acetylcholine acting on nicotinic receptors. The predominant effects of sympathetic innervation of the lower urinary tract in humans are inhibition of the parasympathetic pathways at the spinal and ganglion levels, and mediation of bladder base and urethra contraction.

Most of the sensory innervation of the bladder and urethra reaches the spinal cord via the pelvic nerve and dorsal root ganglia. In addition, some afferents travel in the hypogastric nerve. The most important afferents for the micturition process are myelinated $A \delta$-fibers and unmyelinated C-fibers traveling in the pelvici nerve to the sacral spinal cord, thereby conveying information from receptors in the bladder wall to the spinal cord (Kuru, 1965).

A separate nonadrenergic, noncholinergic component of the autonomic nerwous system participates in activating the detrusor, although the neurotransmitter has not been identified.

Nitric oxide synthase (NOS)-containing neurons have been identified in the detrusor, particularly at the bladder neck, where they may facilitate relaxation during micturition. The trigonal muscle is innervated by adrenergic and NOS-containing neurons. Like the bladder neck, it relaxes during 
micturition. Afferent innervation from the bladder travels both with sympathetic and parasympathetic nerves to reach cell bodies in the dorsal root ganglia at the thoracolumbar and sacral levels.

Under normal conditions, there is a negative-reciprocal relationship between the activity in the detrusor and the activity in the outlet area.

\section{Physiology and pharmacology}

Smooth muscle contraction differs profoundly from contraction in skeletal muscle, even though it is based on the same basic mechanism of myosim and actin fillament interaction, activated by high $\mathrm{Ca}^{2+}$ levels. In the normal human bladder, acetylcholine is the predominant neurotransmitter that causes bladder contraction (figure 1). Acetylcholine interacts with $M_{3}$ muscarinic receptors and typically results in the raising of intracellular $\mathrm{Ca}^{2+}$ concentrations, which may involve both mobilization from intracellular stores and influx from the extracellular space. For the intracellular stores, two molecularly distinct intracellular $\mathrm{Ca}^{2 *}$ release mechanisms have been lidentifled in smooth muscle; an inositol trisphosphate $\left(\mathrm{IP}_{3}\right)$ process and a $\mathrm{Ca}^{2+}$ and ryanodine-sensitive, $\mathrm{Ca}^{2+}$ induced $\mathrm{Ca}^{2+}$ release (RyR-CICR) process (Somlyo \& Somlyo, 1994). Activation of the chollinergic pathway induces the activation of phospholipase $\mathbb{C}$ through coupling with G-proteirn, which stimulates the production of $\mathrm{IP}_{3}$, in turn releasing $\mathrm{Ca}^{2+}$ from the sarcoplasmic reticulum (Eglen et al., 1994). M2 receptors may contribute to blaidder contraction by inhilbiting adenylate cyclase activity and decreasing intracellular cyclic adenosine monophosphate (AMP) levels, which mediate bladder relaxation. Stimulation of $\beta_{3}$-adrenergic receptors may also lead to relaxation of bladder smooth muscle.

A variety of efferent and afferent neural pathways, reflexes, and central and peripheral neurotransmitters are involved in urine storage and bladdler emptying. The relationships between these factors are not completely understood.

Glutamate is an excitatory neurotransmitter in the pathways that cantrol the lower urinary tract. Serotonergic activity facilitates urine storage by enhancing the sympathetic reflex pathway and 
Inhibiting the parasympathetic woiding pathway. Dopaminergic pathways may exert both inhibitory and facilitatory effects on voiding. Dopamine $D_{4}$ receptors appear to have a role in suppressing bladder activity ${ }_{i}$ whereas dopamine $D_{2}$ receptors appear to facilitate voiding. Other neurotransmitters, such as y-aminobutyric acid and enkephalin, inhibit voiding in animals.

\section{Filgure 1}

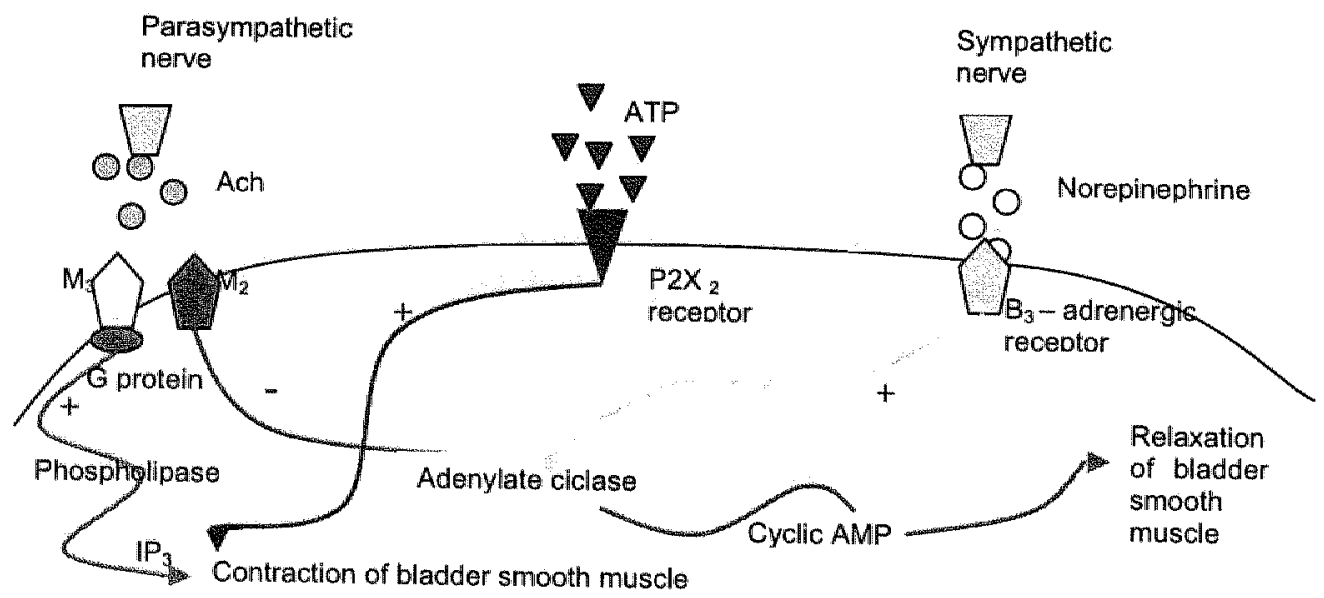




\section{Pathophysiology}

The urinary bladder is a smooth muscle organ that has the function of collecting and storing urine at low intravesical pressures and then periodically expelling it via a highly coordinated sustained contraction (Sterling et al., 1983). To a large extent, urinary bladder function is dependent on the underlying structure of the organ as a whole, relying on the interrelationships between the smooth muscle, connective tissue and epithelial elements. An increase in the ratio of connective tissue to smooth muscle would be expected to reduce compliance and capacity and give rise to structural impairment of the bladder's ability to empty efficiently and fully, thereby resulting in increased residual urine. Thus, a change in structural compartmentation can affect bladder function independently of the contractile capabilities of the smooth muscle elements (Wein et al., 1991).

Apart from their contractile functions, smooth muscle cells generate and organize many different extracelliular matrix (ECM) compounds. These provide a supporting, structural framework for smooth muscle tissue that is essential for its integrity and makes it compliant with stretching. Under certain physiological conditions and in diseased smooth muscle tissue, the generation of ECM compounds may predominate. SMCs may contribute towards tissue remodeling and repair by increased proliferation and synthesis of more or different ECM components.

The two predominant ECM proteins in smooth muscle tissue are collagen and elastin, but proteoglycans and structural glycoproteins also contribute to the functional properties of this structural lattice (Jacob et al. , 2001).

Elastin is essential for maintaining the structural Integrity of smooth muscle tissue by providing the elasticity to cope with constantly changing pressure. Elastin represents $90 \%$ of the elastic fibers of smooth muscle tissue, while the remaining $10 \%$ is constituted by fibrillin and microfibrillarm associated glycoproteins (Jacob et al., 2001).

Apart from their structural functions, the components of the ECM also relay signals that control the behavior of the SMC with respect to proliferation, migration, differentiation, and survival (Pickering, 2001). 
Smooth muscle and ECM of the urinary bladder are types of specialized tissue that enabile the collection and storage of urine at low intravesical pressures and the subsequent periodic expulsion of the urine via a thighly coordinated contraction. Urination can be influenced by both the nervous system and the anatomical components of the lower urinary tract itself. Disorders of any of these structures may contribute towards symptoms of an overactive bladder. On this basis, better understanding of modulators (for example, hormones) of the composition and function of ECM and smooth muscle of the bladder are required in order to develop new approaches for the treatment of different types of bladder dysfunctions.

The neurogenic regulation of the lower urinary tract is complex and still the subject of research (Firy \& Wu, 1998). An intact neural axis from the cerebral cortex, through the brainstem, spinal cord, sacral micturition center and peripheral nerves innervating the bladder is crucial for normal bladder function. Many different neurotransmitter pathways are involved, modulating proper voluntary control over the storage and voiding function of the detrusor and the opening and closing of the urethra. When voluntary control is lost or disfupted due to neurologicall disease or damage, aberrant reflexes can take over, thereby resulting in incontinence, abnormal frequency of urination or urinary retention.

Experimental models for obtaining morphometric estimates for connective tissue and studying the contractile function of the bladder

\section{Morptiometric analysis}

A frequent problem in cell biology is to obtain morphometric information on certain cell types that can be related to cell function. To describe the cell features, one wants to know their number, their mean volume, and their composition in terms of organelle volumes, membrane surfaces, or granule numbers, to mention only a few examples (Haies et al. "1981).

The purpose of the study described in chapter II was to provide information on the properties of the bladder"s connective tissue, in relation to estrogen levels. The experimental model used to quantify 
the collagen and elastic fibers was stereology. Point counting is the best method for estimating the volumetric density of a cell type within a tissue (Cruz-Orive \& Weibel, 1990). The use of an automatic image analyzer or computer-assisted tracing system is very rarely an advantage (Mathieu et at, 1981). If tissue blocks are properly sampled and sufficient in number, then the number of test points to be counted per animal in a tissue component does not need to exceed 200.

The Picrosirius-polarization method is a specific histochemical procedure for collagen detection in tissue sections. Interstitial collagen displays a variety of birefringence-interference colors and intensities in tissue sections studied with the aid of the Picrosirius-polarization method. This procedure is therefore also useful for studying the differential distribution of structurally distinct collagen types in routinely fixed, paraffin-mbedded organs (Montes, 1996). On this basis, the Sirius red polarization method was used to evaluate the collagen fibers in the experiments that are described in chapter $\mathrm{H}_{\text {. }}$

Although several reports have described the occurrence of different types of elastic system fibers in tissues and organs, it has been difficult to obtain distinct Identification, specific localization and precise quantification of these fibers. Montes (1996) demonstrated that Weigert's resorcin-fuchsin oxidation method is a reliable method for evaluating elastic fibers. Furthermore, Weigert's resorcinfuchsin with and without oxidation is more sensitive and thus also stains elaunin and oxytalan fibers (Montes, 1992).

In vitro studies

A commonly used experimental setup is the standard organ bath technique, in which a strip of tissue is suspended in a physiological solution so that the isotonic contraction can be measured (figure 2). The system has a number of advantages: it is relatively straightforward to set up, thus allowing multiple preparations to be used simultaneously. The tissue strips can be continuously bathed in a superfusate of known composition and controlled temperature (Fry, 2004). Stimulation 
of the preparation may be done electrically, via electrodes in the organ bath, or by direct exposure to agonists.

However, the arrangement has a number of disadvantages that include the relatively large size of the preparation, and consequent difficulty in meastring specific variables that often require smaller preparations (Glerum \& van Mastrigt "1990).

We used organ bath methodology to study bladder contractile function, using experimental preparations that are described in chapters III, IV, V, VI and VII. During the preparation of the detrusor muscle strips for the in vifro recordings, care was taken to remove the serosal and mucosal layers of the bladder because the mucosal lining can have a negative inotropic effect on the preparation (Longhurst \& Uvellus, 2001) and may prevent rapid diffusion of pharmacological agents to the tissue. In view of possible differences in functional response from the strips depending on their location within the biladder, care was taken to obtain material from the dome of the bladder in all experiments. 


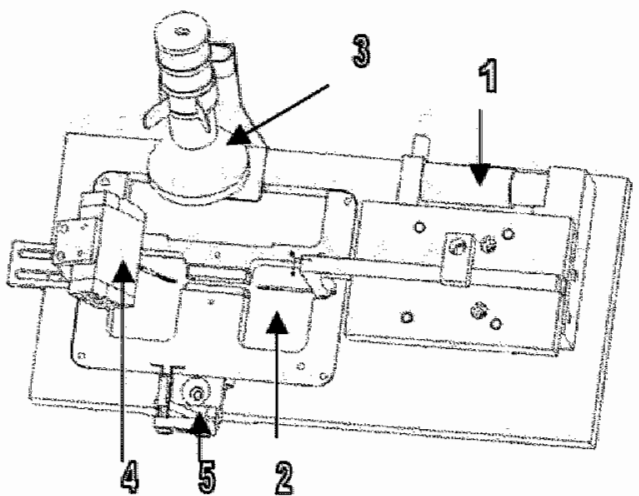

Figure 2: $\quad$ Schematic layout of a horizontal trough for use with small muscle preparations to record isometric contractions. (Custom made organ bath (IDEE(B) University Maastricht). This organ bath was used in the experiments described in chapter III.

1: translation stage M111,1DG regulated by a Mercury Controller C860, Physic Instrumente@.

2: Tweezer for mounting the muscle strip.

3: Halogen lamp, Philips $\otimes, 12 \mathrm{~V}, 20 \mathrm{~W}, 6^{\circ}$ for warming the organ bath.

4: KG4 force transducer with tweezer connected to the BAM4C amplifier ( Scientific instruments $($ Heidelberg)

5: Movable arm with double needle system for an instantaneous fluid exchange.

\section{Role of Estrogens on the lower urinary tract}

There is no doubt that the physiology of the female urinary tract is influenced by sex hormones. The physiological changes during pregnancy have been well documented. Many women also notice a deterioration in their ability to malntain continence just prior to menstruation. The prevalence of urinary tract symptoms also increases with age, particularly around the time of the menopause (losif \& Bekassy, 1984). The combined effect of genitourinary diseases and hypoestrogenism makes incontinence more likelly. Therefore if the hormone deficit is corrected a more favorable clinical 
respionse may be obtained. In this context, estrogens have been used for over 40 years to treat urinary symptoms.

Several epidemiological reports have implicated estrogen deficiency in the etiology of a number of different urinary complaints. Approximately $40 \%$ of premenopausal women with regular mensirual periods complain that their urinary symptoms change with the menstrual cycle. The time just before a menstrual period is identified as the most bothersome. The prevalence of detrusor overactivity seen on cystometry also increases significantly with time from the last menstrual period and may reflect increases in the circulating progesterone levels following ovulation. losif \& Bekassy (1984) studied 2200 women aged 61 years and found the prevalence of lower urinary tract disorders was high, with $49 \%$ of women having some symptoms.

Early uncontrolled case series analyses suggested a benefit of estrogen, in various forms, on urinary tract symptoms and urodynamic findings. However, clinical trials of the effect of estrogen therapy on UI have had mixed results. Most were small and of short duration, and the majority showed no improvement in the number of incontinent episodes per week. (Wilson et al., 1987; Jackson et all., 1999; Rufford el all. 2003) In some of these trials, various combinations of pharmacological agents along with estrogen were used to treat $U I_{\text {, }}$ and benefit could be attributed to combination therapy, not simply to estrogen alone. (Ahlstrom et al., 1990).

Although basic science in this area is limited, animal studies have shown that estradiol reduces the amplitude and frequency of spontaneous rhythmic contractions and that pretreatment with estrogen reduces the contractile response of isolated rat detrusor muscle. There is also some evidence to suggest that, in women, the sensory threshold of the bladder may be raised by estrogen supplementation. Cyclic variations in sex steroid levels during the menstrual cycle may lead to both symptomatic and urodynamic changes

Apart from the effects of estrogen on detrusor function, this hormone influences collagen synthesis and directly affects collagen metabolism in the lower genital tract. Urogenital atrophic changes in women may result from an alteration in systemic collagenase activity, and stress urinary incontinence and urogenital prolapse are associated with reduced vaginal and periurethral collagen. Skin collagen content reduces after the menopause: the rectus muscle fascia become less elastic 
with increasing age, so that less energy is required to cause irreversible damage. Collagen composition also changes: the hydroxyproline content in connective tissue from women with stress urinary incontinence is $40 \%$ lower than in continent control subjects. On the other hand, recent placebo-controlled, randomized clinical trial of estrogen alone sheds light on this issue. Women receiving $2 \mathrm{mg}$ of oral estradiol valerate over 6 months showed significant decreases in total periurethral collagen (Jackson et al., 2002). Profound effects on collagen metabollsm were observed and included stimulation of collagen degradation via increased matrix metalloproteinase-2 activity. Urethral closure is dependent on the integrated action of the suburethral vaginal wall, the pubo-urethral ligaments, the pubococcygeus muscles, and the paraurethral connective tissues.

For all of these structures, connective tissue is a crucial element. Consequently, research evaluating the effects of estrogen on various biological mechanisms, such as collagen, elastic and smooth muscle fibers of the bladder and urethra wall as well "may provide important addifional insights on the mechanisms of action of these preparations on the lower urinary tract symptons.

In a recent meta-analysis $s_{\text {; }}$ the hormone and urogenital therapy committee demonstrated that estrogen therapy may be effective in alleviating symptoms suggestive of overactive bladder (Cardozo et al., 2004). Furthermore, the systematic review showed that local administration may be the most beneficial administration route. Thus, they suggested that supplementary vaginal therapy may provide additional urogenital benefit for those women who are already receiving adequate systemic estrogen replacement therapy.

Results from a large, double-blind, placebo-controlled, randomized clinical trial, conducted in several centers with an ethnically diverse group of healthy postmenopausal women, indicate that menopausal hormone therapy use does not confer protection against any type of urinary incontinence (UI). On the contrary, both conjugated equine estrogen $(0.625 \mathrm{mg} / \mathrm{d})$ alone and conjugated equine estrogen $(0.625 \mathrm{mg} / \mathrm{d})$ plus medroxyprogesterone acetate $(2.5 \mathrm{mg} / \mathrm{d})$ increased risk of new onset UI among continent women and worsened the characteristics of UI among symptomatic women (Hendrix et al., 2005). 
Based on the data that can be found in the literatura, considerations regarding the use of homone therapy by post-menopausal women for any duration should incorporate the current findings into the established risks and benefits of these agents.

\section{Flavonolds}

Flavonolds are a subclass of polyphenols, which are characterized as containing two or more aromatic rings, each bearing at least one aromatic hydroxyl and connected with a carbon bridge. For flavonoids, this bridge consists of three carbons that combines with an oxygen and wo carbons of one of the aromatic rings ( $A$ ring) to form a third 6-member ring [C ring (Figure 3)] (Heijnen et al., 2002): The flavonoids are further divided into subclasses based on the connection of the $B$ ring to the $C$ ring, as well as the oxidation state and functional groups of the $C$ ring. Within each subclass, individual flavonoids and isoflavones are identified and characterized by hydroxylation and conjugation patterns of the $B$ ring, as well as the conjugation patterns of hydroxyls on the $A$ and $C$ rings. Structures of flavonoids common to foods have been widely published. Most flavonoids are present in nature as glycosides and other conjugates (flavanols are an exception), which contribute to their complexity and the large number of individual molecules that have been identified $(>5000)$ (van Acker et al., 1996).

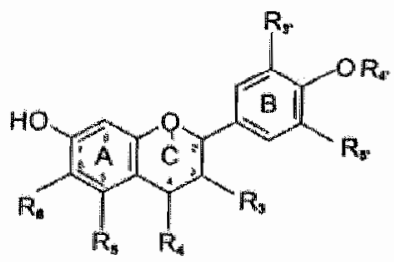

Figure 3: Geneiral structure and numbering pattern for common food flavonoids

The flavonolds are a large group of naturally occurring phenylchromones found in fruits, vegetables, grains, roots, stems, flowers, tea, and wine. Their beneficial effects will be dependent upon their uptake and disposition in tissues and cells. The metabolism and pharmacokinetics of flavonoids has been an area of active research in the last decade. Only limited information is avallable on the 
absorption, distribution, metabalism, and excretion of these compounds in man. Some compounds are absorbed, and measurable plasma concentrations are achleved which could have pharmacological relevance. Absorbtion in the small intestine ranges from 0 to $60 \%$ of the dose and elimination half-lives (T1/2) range from 2 to $28 \mathrm{~h}$ (Walle, 2004)

Consumption of total flavonoids ranges from about $20 \mathrm{mg} / \mathrm{d}$ (United States, Denmark, Finland) to $>70 \mathrm{mg} / \mathrm{d}$ (Holland). These values are considerably lower than earlier estimates (several hundred $\mathrm{mg} / \mathrm{d})$, which were based on limited analyses of only a few foods. Also contributing to the disagreement of consumption data may be the lack of comprehensive food composition data for one or more flavonoid subclasses (and all of the tannin subclasses) among the countries.

A variety of in vitro and in vivo experiments have shown that selected flavonoids possess antiallergic, antiinflammatory, antiviral and antloxidant activities (Kuehnau, 1976; Havsteen, 1983; Gulati et al., 1985). Moreover, acting by several different mechanisms, particular flavonoids can exert significant anticancer activity including anticarcinogenic properties and even a prodifferentiative activity, amongst other modes of action. Certain flavonoids possess potent inhibitory activity against a widle array of enzymes, but of particullar note is their inhibitory effects on several enzyme systems intimately connected to cell activation processes such as protein kinase $\mathrm{C}$, protein tyrosine kinases, phospholipase A2, and others (Galati \& O'Brien, 2004). Evidence suggests that only activated cells are susceptible to the modulating effects of flawonoids, i.e. cells which are responding to a stimulus. The stimulated activities of numerous cell types, including mast cells, basophils, neutrophils, eosinophils, T \& B lymphocytes, macrophages, platelets, smooth muscle, hepatocytes, and others, can be influenced by perticular flavonoids (Galatl \& O'Brien, 2004). On balance, a considerable body of evidence suggests that plant flavonoids may be health-promoting. disease-preventing dietary compounds.

Although anti-oxidative activities are considered beneflcial, some filavonols such as quercetin, morin and myricetin act as pro-oxidants under certain conditions (Myara et al., 1993). Thus, these flavonoids with various effects on oxidation may have dual biochemical and pharmacological actions. (Galati \& O'Brien, 2004). Thus, it is important to remember that the consumption of large 
amounts of flavonoids in the form of a concentrated supplement might not be considered safe until their in vivo potential for oxidative stress is evaluated.

\section{Flavonoids and smooth muscle contractility}

Flavonoids have longl been recognized to have a broad spectrum of biological activities, and the effects of polyphenolic compounds on smooth muscle contractility have been the subject of some reports.

Some important influences that flavonoids have on smooth muscle are their abilities to reduce small and large intestinal transit time in mice (Di Carlo et al., 1994), to cause intestinal smooth muscle relaxation (Hammad A Abdalla, 1997) and to prevent castor oil-induced diarrhea (Galvez et al., 1993): These properties are consistent with the use of flavonoids as antidiarrheal drugs in traditional medicine. Moreover, several flavonoids have been shown to relax isolated segments of Illeum following contraction induced by acetylcholine ${ }_{n} \mathrm{KCl}_{\mathrm{r}}$ histamine and prostaglandin $\mathrm{E}_{2}$ (Hammad \& Abdalla, 1997; Macander, 1986).

The mechanism by which flavonoids imhibit intestinal propulsion is not fully understood. Apart from their possible interaction with intracellular mediators of smooth muscle contractility (Abdel-Latif, 2001), there is no information about the possible effects of flavonoids on enteric neuratransmission. A recent study has demonstrated that flavonoids suppress peristaltic motility in the small intestine of guinea pigs through a variety of mechanisms (Gharzouli \& Holzer 2004 ). Quercetin and naringenin reduce distention sensitivity but hardly affect peristaltic action, which seems to be related to stimulation of inhibitory enteric pathways that evoke peristalsis. In contrast, the effect of apigenin and genistein in attenuating both distention sensitivity and peristaltic action appears to result from inhibition of muscle activation or muscle activity.

Another smooth muscle activity of flavonoids is related to the vascular tone, Several epidemiological studies (Hertog et al., 1993; Knekt et al., 1996) have revealed an inverse association between fllavonoid intake and reduced occurrence of cardiovascular diseases such as myocardial infarction. 
Quercetin, an important flavonoid found in several plant products such as red wine and grape juice has been shown to cause endothelium-dependent relaxation in the rat aorta (Fitzpatrick et al.s 1993). The relaxant effects of flavonoids are reported to have the following order of potency: flavonols>flavones>flavanols (Duarte et al., 1993). The relaxant effects of the flavonols have recently been demonstrated to be endothelium-dependent at concentrations lower than 30 4M (Chan et al., 2000). This implies that, at lower concentrations, the relaxant effects of the flavonoids are probably mediated by the release of $\mathrm{NO}$ and $P \mathrm{PI}_{2}$ from the endothelium.

Recently, a study demonstrated that the flavonol galangin inhibited the contractile response of rat detrusor muscle to electrical field stimulation (EFS) without modifying the contractions produced by exogenous acetylcholine. The response to electrical stimulation was almost completely abolished by tetrodotoxin. From this, the authors concluded that the mechanism for galangin action on rat detrusor smooth muscle contraction was due to a presynaptic effect (Capasso \& Tavares, 2002).

A recent publication by Capasso \& Mascolo (2003) demonstrated the inhibitory effect of galangin on EFS-induced contractions in rat vas deferens. These authors performed some experiments in order to investigate the mechanism by which galangin inhibited electrically induced contractions. They identified that the inhibitory effects of galangin could involve a direct or indirect activation of prejunctional receptors (e.g. vanilloid, oploid or 2-adrenergic receptors), which are known to have an inhibitory role on vas deferens neuromuscular transmission (Hughes et al., 1975; Maggi et al., 1993).

Galangin: structure and activity

Galangin is a flavonol derivative that does not have any hydroxyl group in the B-ring, but has a 2,3double bond with a 3-hydroxyl group in the C-ring and 5,7-dihydroxyl groups in the A-ring (figure 4). Galangin is the most lipophilic compound among similar flavonol compounds such as quercetin, kaempferol, 5-hydroxy group into 7-hydroxyflavone enhances the inhibitory potentials relative to 7 hydroxyflavone. The flawones (li.e. acacetin and diosmetin which have 2,3-double bond in the Cring, 5,7-dihydroxyl in the A-ring and monohydroxyl in the B-ring) are more potent inhibitors than the 
flavanones (ie, eriodictyol, hesperetin, homoeriodictyol and naringenin) in conveying selectivity for the different cytochrome P450 enzymes. Galarigin with the 3,5,7-trihydroxyl groups increases the intibition of CYP1A2 to the greatest extent. This suggests that hydrogen bond formation by the 3 and 5-hydroxy groups with the flavone binding site of CYP $1 \mathrm{A2}$ significantly contributes to the observed inhibition.<smiles>O=c1c(O)c(-c2ccccc2)oc2cc(O)cc(O)c12</smiles>

Figure 4: Chemical structure of galangin

Galangin, a member of the flavonol class of flavonoids, is present in high concentration both in Alpinia officinarum, a plant used as a spice and as a herbal medicine for a variety of ailments in Asia, and in propolis which is a natural composite balsam produced by honey bees. Galangin has been demonstrated to possess anti-mutagenic activity, anti-oxidative and radical scavenging activity due to its redox properties. Moreover, galangin has been recently proposed as a candidate for cancer chemoprevention (Heo et al., 2001). More recently, its inhibitory effect on rat bladder contractility has been investigated (Capasso \& Tavares 2002).

Among polyphenol compounds tested galangin has the lowest oxidative potential which means the highest anti-oxidative activity compared with other polyphenols (van Acker et al., 1996). Moreover, studies have reported that galangin has anti-oxidalive activity and free radical scavening effect with a weak pro-oxidant effect (Silva et al., 2000; Heo at al., 2001). Besides that, galangin is the most Hpophilic compound among similar flavonol compounds such as quercetin, kaempferol etc., thus, this flavonol can easily penetrate the mucosa (llmamura et al., 2000).

These chemical attributes of galangin may account for its in vitro as well as in vivo studies as an anti-oxidant and an inhibitor of bladder smooth muscle contractility. 


\section{Chapter II}

The effect of ovariectomy and estradiol replacement on collagen and elastic fibers in the bladder of rats.

Míriam Dambros, Paulo CR Palma, Carlos A Mandarim-de-Lacerda ; Ricardo Miyacka and Nelson R Netto Jr.

Int Urogynecol J 14:108-112, 2003 
The effect of ovariectomy and estradiol replacement on collagen and elastic fibers in the bladder of rats

\section{Abstract}

The authors quantified the collagen and elastic fibers in the bladder wall of ovariectomized rats with and without estradiol replacement. This study was conducted on 60 Wistar rats (three months old). Group 1: remained intact; Group 2: underwent bilateral ovariectomy and were sacrificed after 30 days; Group 3: sham operated and sacrificed after 30 days: Group 4: bilateral ovariectomy and after 30 days was started subcutaneous injection of $17 \mathrm{~B}$ - estradiol ( $10 \mu \mathrm{g} / \mathrm{Kg}$ body weight) for 90 days: Group 5: sham operated and after 30 days was started subcutaneous sesame oil replacement $(0,2 \mathrm{ml}$ per day $)$ for 90 days; Group 6: bilateral ovariectomy and after 30 days was started subcutaneous sesame oil replacement $(0,2 \mathrm{mll}$ per day) for 90 days. Sirius red and Weigert's resorcin-fuchsin were used to stain collagen and elastic fibers on paraffin rat bladder sections. The M-42 grid system was used to quantitatively analyze the fibers. Ovariectomy had no effect on the volumetric density and absolute volume of the collagen and elastic fibers in the bladder wall of rats as well as on the weight of the bladder. Estradiol replacement in castrated animals did not demonstrate any significant difference in the stereological parameters when compared to the castrated group without hormonal replacement.

\section{Introductlon}

The presence of estrogen receptors has been demonstrated in the human lower urinary tract. Estrogen receptors are present in the bladder trigone and urethra ${ }^{2}$. However, the concentration of receptors in the urethra is less than the concentration in the uterus and lesser still in the bladder 
body. This differentiated distribution of estrogen receptors makes the urethra more sensitive than the bladder to estrogen infiuence of depletion and/or repletion ${ }^{3}$.

The postmenopausal period is associated with a high incidence of symptoms in the lower urinary tract ${ }^{4}$. The main urological bladder symptoms are urge incontinence and recurrent urinary tract, infections. It is hard to separate the influence of aging from that of menopause when studying the etiology of dysfunction in elderly women. The most significant result of menopause is estrogen deprivation. This fact has led to the use of hormonal replacement in postmenopausal women with lower urinary tract dysfunction. However, the best treatment in terms of type, dosage and method of estrogen administration has still not been defined ${ }^{5}$.

Previous investigations performed in animals regarding the influence of ovarian hormones on bladder function and structure presented contradictory results ${ }^{4,6}$ "The choice of treatment in these studies varied. Some studies compared only intact controls and intact animals treated with estrogen. Others used ovariectomized animals with and without estrogen treatment, but without intact controls. Moreover, in most of the studies, the animals were castrated and/or treated with hormones for only short periods, and therefore their relevance to long-term hormonal changes that occurred with aging was not clear:

Collagen and elastin are important components of the bladder wall and participate in bladder function. Collagen provides tensile strength, but over accumulation may inhibit bladder contractility and conduction of electrical impulses through the wall ${ }^{\dagger}$. Elastin provides tissue elasticity, which helps in compliance. The collagen content of the detrusor muscle in a postmortern study was found to increase significantly more in female above the age of 50 than in younger female or male at same age

Our knowledge of connected tissue alterations in the genitourinary tract and their hormonal regulation potential is limited. Since bladder wall connective tissue is crucial for the mechanical properties of the genitourinary regions, it is important to characterize the possible changes related to estrogen status. We analyzed the effects of ovariectomy and estradiol replacement on the extracellular matrix in the urinary bladder of rats. 


\section{Materials and Methods}

\section{Animals}

Thils study was conducted on 60 female virgin Wistar rats, three months old and weighing between $250 \mathrm{~g}-300 \mathrm{~g}$. The animals were maintained in a controlled environment $\left(25 \pm 2^{\circ} \mathrm{C}\right.$; exposed to dailly light cycle for 12 hours) and had ad libitum access to water and Purina(e ration. The study was conducted in accordance with the Guide for the Care and Use of Laboratory Animals published by the US National Health Institute (NHI Publication $n^{\circ} 85-23$, revised 1985) and the Animal protection Committee of the State University of Campinas approved the protocols.

The animals were randomly divided into 6 groups, with 10 animals in each group, and underwent the following procedures: Group 1- remained intact; Group 2 - bilateral ovariectomy and sacrifficed after 30 days; Group 3 - sham operated and sacrificed after 30 days; Group 4 - bilateral ovariectomy and after 30 days, subcutaneous injection of 173 - estradiol $110 \mu g / K g$ body weight (Galenica Laboratory, Sào Paulo, Brasil)] for 90 days; Group 5 - sham operated and after 30 days subcutaneous sesame oil replacement [0,2mi per day (Galenica Laboratory)] for 90 days; Group 6 billateral ovariectomy and after 30 days subcutaneous sesame oil replacement $(0,2 \mathrm{ml}$ per day for 90 days. Ovariectomy was performed using the anesthesia sodium thiopental ( $40 \mathrm{mg} / \mathrm{Kg}$ weight) bilaterally via the dorsolumbar region.

\section{Estradial Dosage}

The estradiol serum dosage was measured Just before the animals were sacrificed [Veterinary Protocol, (limmunotech Cat \#2464, radioimmunoassay Kit, Sảo Paulo, Brazil)]. 


\section{Tissue Sample Collection}

An intraperitoneal injection of sodium thiopental was used to sacrifice the animals $(60 \mathrm{mg} / \mathrm{Kg}$ body weight). The bladder was sectioned at the neck and the anterior wall was longitudinally opened from the neck to the bladder fundus. The organ was then weighed using the Scherle method, suspended by a thread and immersed in physiological solution in a vessel on the plate of the scale $^{* 0}$, after which it was spread out on a cork sheet and held down with pins so that a microscoplic examination could be performed. The bladders were then immediately fixed in a $10 \%$ formaldehyde $(\mathrm{pH}=7.2)$ for 48 hours. Subsequently, the material was dehydrated in a series of increasing concentrations of alcohol solution and diaphanized in xylol. In order to get a cross section of the bladdler wall, $5 \mu \mathrm{m}$ and $7 \mu \mathrm{m}$ sections were obtained from the paraffin embedded tissue samples. The $7 \mu \mathrm{m}$ sections were stained with Sirius red and analyzed under a polarized light and (figure 1) the $5 \mu \mathrm{m}$ sections were stained using Weigert's resorcin-fuchsin techniquen (figure 2) with and without previous peracetic acid oxidation".

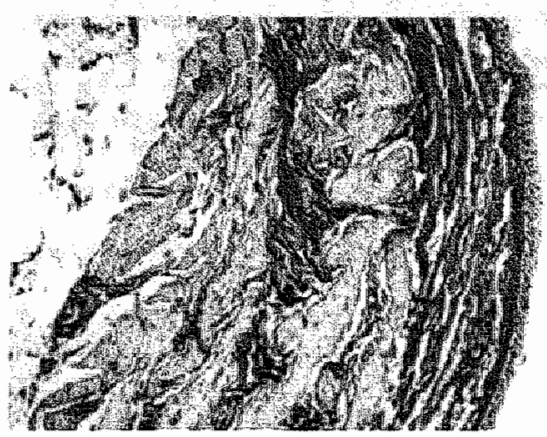

A

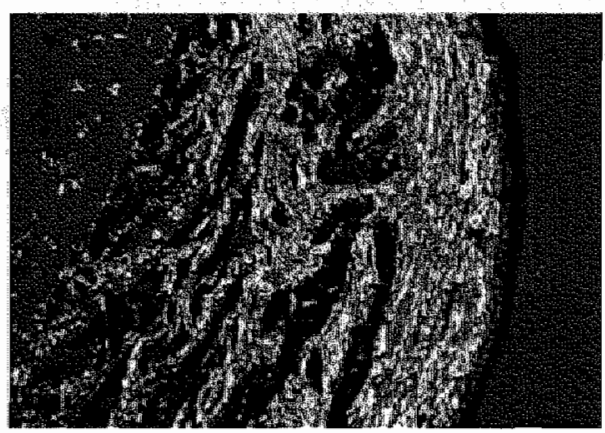

B

Fig 1. Photomicnograph of the bladder wall of the rat 7 in Group 1. (A) In a chaar field, the collagen (red) can bas sean distributed in all the layers of the bladder. (B) In a dark field (polarlzed light), the same area can be sean with blrothingence of collagen and the fibers to be identifed more precisely (Sirius ned, 350 X). 


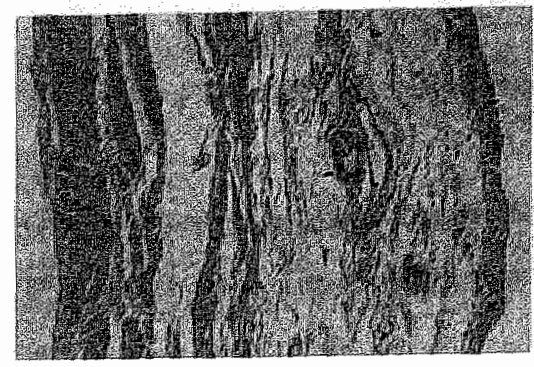

Fle 2. The section stainied with Weigent's resoncin-fuchsir showed that the ellastic fibers were present in a smaller number intermingled with smooth muscle fibers and collagen $(350)$ ).

\section{Morphometric Quantification}

The stereological count of the absolute volume and the volumetric density of the collagen and elastic fibers was determined by superimposing the M-42 grid systern on the morphological image". The volumetric density is the relative density accupied by these structures in the tissue and the absolute volume is the total volume of these structures. The stereological method determines three-dimensional quantitative parameters of anatomic structures based on two dimensional sections. Hence, it is based on Delesse's principle, which states that the relationship between the areas of a determined structure at the surface where the organ was sectioned is the same as the relationship that exists between the volume of the structure and the total volume of the $\operatorname{organ}^{12}$.

The formula $V v=P p \quad \times 100 \%$

Pt

was used to calculate the volumetric density of the collagen and ellastic fibers, where Wv is volumetric density; $\mathrm{Pp}$ is the number of points on the structure being studied (collagen or elastic fibers) and $\mathrm{Pt}$ the point test number ( 42 in this case). The absolute volume was obtained using the formula:

Absolute volume of fibers $=$ Volumetric density of fibers $\mathrm{X}$ Volume of the bladder 
The volume of the bladder was considered as the same as weight of the bladder because the bladder weight was checked using the Scherle method ${ }^{10}$ which is:

\section{Volume of the bladder $=$ Weilght of the bladder}

specific gravity

The specific gravity of the saline solution was approximately 1.0048 .

The quantitative measurements were obtained using the Olympus BX 50 microscope. Quantification was performed at a final magnification of $400 X$ using an $M-42$ test (Tonbridge(8). Ten microscopic fields were randomly analyzed in each group so that the collagen fibers could be analyzed $^{13}$. Quantification of elastic fibers involved the analysis of 50 random fields in each group because of the small quantity of elastic fibers intermingled with the smooth muscle ${ }^{13}$.

\section{Statistical Analysis}

As the sterealogical results presented a discreet variability, the Kruskal-Wallis nonparametric test was used to check the differences between the independent samples (Statistics for Windows. Statsoftt, Inc, 1995). A probability of $p<0,05$ was taken as the criterion of significance.

\section{Results}

\section{General Characteristics}

A quick look at the results showed that there were no major differences regarding the thickness and macroscopy of the control bladders and the ovariectomized bladders with or without estradiol rreplacement.

All the animals showed an increase in weight during the experiment. The average weight gained was $62 \mathrm{gm}$ for all the groups (table 1). 
Ovariectomy and estradiol treatment had no effect on bladder volume. The Table 2 demonstrates that clespite the varied procedure, the volume remained the same for all the groups.

The distribution of the connective tissue components within the bladder wall remained essentially unchanged in all the groups. The collagen fibers were found arranged in all the layers of the bladder wall and were the main components of the extracellular matrix. The sections stained with Weigert's resorcin-fuchsin showed that the elastic fibers were present mainly in the walls of the blood vessels and a smaller number intermingled with smooth muscle fibers and collagen. Therefore it was necessary to analyze a greater number of microscopic fields.

Table 1: Weight gain and serum estradial levels in groups.

\section{Groups}

\begin{tabular}{|c|c|c|c|c|c|c|}
\hline & \multicolumn{2}{|c|}{ Weight before experiment } & \multicolumn{2}{|c|}{ Weight after experiment } & \multicolumn{2}{|c|}{ Serum estradiol before sacrifice } \\
\hline & Median (gm) & $\mathrm{Cl} 95 \%$ & Median (gm) & $\mathrm{Cl} 95 \%$ & Median $(\mathrm{pg} / \mathrm{ml})$ & C\| $95 \%$ \\
\hline 1 & 260 & $250-268$ & 325 & $315-331$ & 74 & $68-79$ \\
\hline 2 & 273 & $269-280$ & 332 & $324-341$ & $17^{\star}$ & \\
\hline 3 & 291 & $284-300$ & 360 & $351-372$ & 80 & $71-87$ \\
\hline 4 & 282 & $277-288$ & 344 & $338-353$ & 78 & $70-84$ \\
\hline 5 & 270 & $263-278$ & 325 & $317-332$ & 72 & $66-78$ \\
\hline 6 & 268 & $260-275$ & 330 & $322-340$ & $17^{*}$ & \\
\hline
\end{tabular}

" p<0,05. The concentration of the estradiol in these groups was lower

\section{Estradiol Serum}

The concentrations just before sacrifice in the ovariectomized groups without estradiol replacement were below $17 \mathrm{pg} / \mathrm{ml}$, which is the lower limit of sensitivity of the method applied. In the non- 
ovariectomized and ovariectomized groups that underwent hormonal replacement; the average hormonal concentration was $76 \mathrm{pg} / \mathrm{ml}$ (varying between $66 \mathrm{pg} / \mathrm{ml}-87 \mathrm{pg} / \mathrm{ml}$ ) (table 1).

\section{Stereological Parameters}

The table 2 presents the stereological results. The volumetric density and the absolute volume of the collagen and elastic fibers did not show a significant difference when the groups were compared.

Estradiol replacement for 90 days (Group 4) did not alter the volumetric density and absolute volume of fibers in comparison with the sham operated and castrated groups (Groups 5 and 6 , respectively).

Table 2- Descriptive Stereological Parameter Statistics of the extracellular matrix in the blactder wall af rats.

\begin{tabular}{|c|c|c|c|c|c|c|c|c|c|}
\hline \multirow[t]{2}{*}{ Groups } & $\begin{array}{l}\text { Volumetric density } \\
\text { (collagen fibers) \% }\end{array}$ & \multicolumn{2}{|c|}{$\begin{array}{l}\text { Volumetric density } \\
\text { (elastic system) } \%\end{array}$} & \multicolumn{2}{|c|}{ Volume (bladder) min 3} & \multicolumn{2}{|c|}{$\begin{array}{l}\text { Absolute wolume } \\
\text { (collagen fibers) } \mathrm{mm} 3\end{array}$} & \multicolumn{2}{|c|}{$\begin{array}{l}\text { Absolute volume } \\
\text { (elastic system) mam3 }\end{array}$} \\
\hline & Madian & Median & $\mathrm{Cl} 95 \%$ & Median & $\operatorname{col} 95 \%$ & Median & $\mathrm{Cl} 95 \%$ & Median & $\mathrm{Cl} 95 \%$ \\
\hline 1 & $44,04 \quad 35,30-55,63$ & 4,32 & $3,71-4,80$ & 62,00 & $58,41-67,58$ & 27.56 & $21,35-36,44$ & 2,70 & $2,43-3,01$ \\
\hline 2 & $42,85 \quad 35,64-52,44$ & 4,81 & $4,38-5,12$ & 77,00 & $70,77-80,62$ & $31_{1} 76$ & $26,14-40,91$ & 3,12 & $2,90 \cdot 3,4,1$ \\
\hline 3 & $44,04 \quad 37,03 i-52,00$ & 4,99 & $4,52-5,38$ & 67,50 & $60,23-71,76$ & 29,94 & $23,39-36,34$ & 282 & $2,50-2,08$ \\
\hline 4 & $39,28 \quad 34,51-51,19$ & 5,02 & $4,79-5,33$ & 71,50 & $58,68-76,31$ & 28,36 & $21,89-32,40$ & 2,69 & $2,28-3,03$ \\
\hline 5 & $40,47 \quad 36,89-48,34$ & 4,48 & $4,21-4,78$ & 61,50 & $55,68-64,71$ & 23,17 & $20,15 \cdot 28,30$ & 2,23 & $3,96-2,4,8$ \\
\hline 6 & $40,12 \quad 31,97-51,34$ & 4,73 & $4,49-4,94$ & 67,50 & $62,88-84,11$ & 28,80 & $21,850-32,41$ & 2,79 & $2,36-3,02$ \\
\hline$V_{h}$ & 0,24 & 0,09 & & 0,23 & & 0,12 & & 0,32 & \\
\hline
\end{tabular}

\section{Discussion}

Estrogen receptors have been detected in the urethra muscles of animals ${ }^{44}$ and humans ${ }^{2}$. These observations have led to the hypothesis that hypoestrogenism plays a role in urethral and bladder dysfunctions. Evidence has been found of the 
direct influence of estrogen on bladder function and structure. However the results obtained are contradictory and the hormonal effect is more evident in the urethra ${ }^{3}$.

The extracellular matrix is made up of fibrous and amorphous components. The fibers are of two types: collagen fibers and elastic fibers. Collagen is a source of tensile strength for the tissues, while elastin is essential for matrix resiliency ${ }^{3}$. It has been suggested that the extracellular bladder matrix has an effect on the passive properties of the bladder wall and that the collagen and elastic fibers, probably, also play an important role in interceliular active force transmission ${ }^{x}$. Therefore, a change in the extracellular matrix concentration might, also affect the contractile properties of the smooth muscle. The most cammon collagen types found in the bladder are: type 1, which supplies resistance against tension and type 111 responsible for structural maintenance of the expansible organs $^{a}$. It has been assumed that loss of compliance is due to bladder fibrosis resulting from excessive or abnormal deposit of collagen ${ }^{8}$. The effect of estrogen levels on the extracellular matrix is still not clear. While some studies show an increased deposit of collagen fibers among the bladder muscle fascicles ${ }^{\prime}$, others associate the postmenopausal period to an increased collagen turnover resulting in reduction ${ }^{15}$.

The purpose of this study is to contribute information on the behavior of the bladder connective tissue in relation to estrogen levels. The experimental model used in this study was previously used In studies concerning the influence of sexual hormones on the lower urinary tract in rats ${ }^{16}$, but in this study the animals were deprived of hormones for long periods because some studies demonstrated a change in the bladder function and structure only 4 weeks after castration ${ }^{17}$. The ovarlectomized group was thus maintained without estradiol replacement for 16 weeks so that fiber behevior could be assessed after a long period of estrogenic deprival. The low estradiol levels in this group and in the group analyzed 4 weeks after ovariectomy demonstrated that it was effective in producing a hypoestrogenic condition in rats. Estradiol replacement was maintained for 12 weeks so that any transitory reactions to low hormonal levels did not influence the final assessment of the stereological parameters, although some studies suggest that after five days of estradial replacement, modifications occur in bladder function ${ }^{16}$. The dose, frequency and method of administering the medication were based on previous studies, although various schemes and 
periods of use are available ${ }^{1,16}$. The experimental model used in this study was previously used in studies concerning the influence of sexual hormones on the lower urinary tract in rats ${ }^{16}$, but in this study the animals were deprived of hormones for long periods because some studies demonstrated a change in the bladder function and structure only 4 weeks after castration ${ }^{17}$. It was observed that in the groups that received hormonal replacement, the dosage and method of administering estradiol in this experiment effectively attained normal serum levels of the hormone; similar to those encountered in animals that were not ovariectomized. Young rats were chosen to perform the study ( 3 months old) in order to assess the behavior of the collagen and elastin fibers only in relation to serum estradiol. The use of old rats could present an alteration in the quantity of these fibers that resulted not from hormone levels but from senile changes that were not assessed in this study (myogenic, nervous, ...) and could induce wrong interpretations.

The results of our study demonstrate that ovariectomy in rats did not affect the concentration of collagen and elastic fibers in the bladder wall. Stereology was chosen to obtain these morphometric fiber estimates. Point counting is the best method for estimating the volumetric density of a cell type within a tissue ${ }^{18}$. The use of an automatic image analyzer or of a computer assisted tracing sysiem is very rarely an advantage ${ }^{19}$. The Sirius red polarization method was used to evaluate the collagen fibers because it is a specific histochemical procedure for the detection of collagen in tissue sections ${ }^{8}$, while the Weigert's resorcin-fuchsin oxidation method is more sensitive to elastic fibers ${ }^{3}$. We do not belleve that the absence of statistical significance in our study is due to the experimental method adopted or the inadequate size of the sample because the number of animals used in each group was based on stereological principles ${ }^{1,13,17}$. Nevertheless, a new experiment could be conducted utilizing a larger number of animals and another quantitative analytical methodology to werify the stability of these findings.

The use of estradiol did not affect the quantitative behavior of the main elements of the connective tissue in castrated animals. It was observed that the animals that remained under the influence of low hormonal levels for long periads presented characteristics that were statistically similar to the pattern of the collagen and elastic fibers deposited in the group of rats exposed to normal estradiol 
levels. Hence, there was no relationship found between estrogen serum levels and bladder extracellular matrix in rats.

A wide variety of estrogen induced structural changes are reported in the literature. A hypothesis that could explain these changes is that the methodologies used as well as the mulliple tissues investigated for the effect of estrogen are not standardized. A recent study on rats showed that epithelium of the bladder and the urethra express subtype beta mRNA receptors while the connective tissue in the bladder expresses sub-type alpha mRNA receptors ${ }^{14}$. Therefore, the homone may present differing actions according to the tissue being analyzed and the animal species being studied. A study on rabblts analyzed the collagen fibers in the bladder wall regarding the estrogenic status and observed that ovariectomy had no effect on collagen tissue concentrations ${ }^{4}$. A similar research on postmenopausal women detected that estrogen replacement therapy resulted in a lower concentration of collagen in the paraurethral connective tissue ${ }^{20}$. A study on rabbits detected a significant association between low estrogen levels and the response pattern of the detrusor muscle to nerve reactions, electric stimulus and a variety of medication but alterations in the mechanical properties or structural composition of the bladder did not occur ${ }^{4}$. It has been suggested that the effect of estrogens on the llower urinary tract may be mediated by a variety of alterations involving neurotransmitters and modifications in the hormonal receptor response in virtue of the low levels of circulating estrogen.

Therefore the discrepancy between the clinical and experimental study results and the evidences that demonstrate a variable estrogenic action in accordance with the organ and animal being studied demand extreme caution when extrapolating research results with reglard to the human boing.

As clinical and experimental studies show a discrepancy in results concerning the influence of estrogen on the lower urinary tract, there is reason to believe that changes associated with decreased estrogen levels occurring after menopause have a subtle effect on the urinary bladder. However, in order to prove this hypothesis, there is a need for clinical and laboratory experimentation that include functional and structural parameters symptoms of the lower urinany tract, objective status documentation and appropriate determination of the outcome. 


\section{Conclusion}

The conclusion reached is that estrogen depletion had no effect on collagen and elastic fiber concentration in the bladder wall of rats. Estrogen treatment did not influence any of the parameters studied.

\section{Acknowledgement}

This study was supported by grants from the Foundation for Research Support ${ }^{\text {State of São Paulo }}$ - FAPESP (Proc. 00/02194-7).

\section{References}

1. Eika $B$, Salling LN, Christensen $L L$ et al. Long-term observation of the detrusor smooth muscle in rats: itts relationship to ovariectomy and estrogen treatment. Urol Res $1990 ; 18: 439-442$.

2. Blakeman $P J$. Hilton $P$, Bulmer $J N$. Oestrogen and progesterone receptor expression in the female lower urinary tract, with reference to oestrogen status. BJU Int 2000; 86(1): 32-38.

3. Ekström J, losif CS and Maimberg L. Effects of long-term treatment with estrogen and progesterone on in vitro muscle responses of the female rabbit urinary bladder and urethra to autonomic drugs and nerve stimulation. J Urol 1993: 150: 1284-88.

4. Persson K, Svane D, Glavind B. et al. Effects of ovariectomy on mechanical properties and collagen content in rabbit llower urinary tract smooth muscle. Scand J Urol Nephrol $1996 ; 30(1): 7-$ 14.

5. Cardozo LD and Kelleher CJ. Sex hormones, the menopause and urinary problems. Gynecol Endocrinol 1995; $9(1) ; 75-84$. 
6. Sanchez-Ortiz R F, Wang Z, Menon $C$ et al. Estrogen modulates the expression of myosin heavy chain in detrusor smooth muscle. Am J Physiol 2001; 280(3): C433-40.

7. Susset JG and Regnier $\mathrm{CH}$. Viscoelastic properties of bladder strips: standardization of a technique. Invest Ural $1981 ; 18(8): 445-50$.

8. Montes GS. Structural biology of the fibers of the collagenous and elastic systems. Cell Biol Inter $1996 ; 20(1): 15-27$

9. Susset JG, Servot-Viguier D, Lamy $F$ et al. Collagen in 155 human bladders. Invest Urol 1978; 16(3): 204-206.

10. Scherle W. A simple method for volumetry of organs in quantitative stereology. Mikroskopie 1970; $26: 57-63$.

11. Weibel ER, Kistler GS and Scherle WF. Practical stereological methods for morphometric cytology. ل Cell Biol 1966; 30: 23-38:

12. Delesse M. Procédé mécanique pour déterminer la composition des roches. Ann Mines 1848; 13: $379-85$

13. Hally A. A counting method for measuring the volumes of tissue components in microscopical sections. Quaterly J Microsc Sci 1964; 105: 503-517.

14. Makela S, Strauss L, Kuiper $G$ et al. Differential expression of estrogen receptors alpha and beta in aduit rat accessory sex glands and lower urinary tract. Mol Cell Endocrinol 2000; 164(1-2): $109-16$

15. Hassager $C_{k}$ Jensen LT, Podenphant $J$ et al. Collagen synthesis in postmenopausal women during therapy with anabolic steroid or female sex hormones. Metabolism 1990; 39(11): 1167-69.

16. Palea $S$ and Angel I. The effect of ovariectomy on the contractile response of the rat isolated detrusor muscle and urethra. Life Sci 1997; 61(1): PL21-26.

17. Diep $N$ and Constantinou $C E$. Age dependent response to exogenous estrogen on micturition, contractility and cholinergic receptors of the rat bladder. Life Sci 1999; 64(23): PL279-89.

18. Cruz-Orive L M and Weibel ER. Recent stereological methods for cell biology: a brief survey. Am J Physiol 1990; 258: L148-56. 
19. Mathieu $O$, Cruz-Orive $L M$, Hoppeler $H$ et al. Measuring error and sampling variation in stereology: comparison of the efficiency of various methods for planar image analysis. I Microsc $1981 ; 121: 75-88$.

20. Falconer $C$, Ekman-Ordeberg $G$, Blomgren $B$ et al. Paraurethral connective tissue in stressincontinent women after menopause. Acta Obstet Gynecol Scand 1998; 77(1): 95-100. 


\section{Chapter III}

Relaxant effects of estradiol through non-genomic pathways in male and female pig bladder smooth muscle

Mriam Dambrors, Gommert van Koeveringe, Aalt Bast, Philip van Kerrebroeck.

Pharmacology $72: 121-127,2004$ 


\section{Relaxant effects of estradiol through non-genomic pathways in male and female plig bladder smooth muscile}

\section{Abstract}

The precise effect of low estrogen levels on urinary bladder contractility remains controversial. The present study was designed to analyse the effect of $17-\beta$-estradiol in bladder smooth muscle contractility and the involvement of specific estrogen receptor stimulation in this effect. Castrated male and female pig detrusor strips were mounted for tension recording in an organ bath, super fused with Krebs solution at $37^{\circ} \mathrm{C}$ and stimulated electrically and pharmacologically. In order to verify the acute effect of $17-\beta$-estradiol on muscle contractility the strips were incubated with different concentrations of the hormone. Muscle contractions were induced by potassium chloride, acetylcholine chloride and electrical field-stimulation. The involvement of the estrogen receptor in the effects of $17-\beta$-estradiol was assessed by incubation of some strips with the selective estrogen receptor antagonist $\mathrm{ICI} 182.780$ before estradiol was applied. Estradiol at a dose of $30 \mu \mathrm{mol} /$ elicited a lower amplitude of contractions induced by EFS, Ach and $\mathrm{KCl}$ in female as well as in castrated male pig bladder smooth muscle strips. The effects of $17-\beta$-estradiol were stronger in contractions induced by potassium chloride than those induced by other forms of stimulation. Pretreatment with the pure estrogen receptor antagonist had no effect on $17-\beta$-estradlol-induced inhibition of muscle contractility. These observations suggest that 17 - $\beta$-estradiol induces lower amplitude of contraction of female as well as castrated male pig detrusor which is not mediated by the classic estrogen receptor. Furthermore, we can conclude that estradiol has a stronger inhibitory effect on the depolarisation of muscle cell membrane compared to a muscarinic receptor-induced contraction. 


\section{Introduction}

Numerous epidemiological observations, clinical mechanistic studies, and basic laboratory studies have suggested that the incidence of urinary symptoms increases with menopause and that hormione replacement therapy, or more speciffically, estrogen replacement therapy is associated with beneficial effects on the lower urinary tract in postmenopausal women [1, 2, 3]. Estrogen has a multifude of biological effects that may account for its apparent benefits on the urinary tract (which remain to be proved in randomized clinical trials) including favorable effects on smooth muscle of both bladder and urethral vesculature [1,2]. However, there are considerable contradictory data published in the literature on the specific effects of estrogen administration on bladder contractility $[1,4]$

Steroid hormones are recognized as producing their major long-term effects on cell structure and function via intracellular receptors acting on the expression of genes. There are currently new reports of studies that have concentrated on the genomic or morphological manifestations of steroids on receptor expression, transmitter synthesis and morphology [5, 6]. However, there is Increasing evidence that steroids also affect the surface of cells and alter ion permeability, as well as release of neuronal hormones and neurotransmitters. For example, estrogen has been shown to immediately alter the tone of vascular and other smooth muscle, probably, through steroild receptors located in the cell membrane which are not inhibited by classic estrogen receptor antagonist [7]. Other steroids, such as adrenal steroids and naturally produced and synthetic analogs of steroids, also show membrane effects. Whereas there is no doubt that the distinction between genomic and non-genomic mechanisms has considerable validity, it does not go far enough in addressing the variety of mechanisms that steroid hormones use to produce their effects on cells.

The purpose of the present study was to examine the acute effects of 17 - $\beta$-estradiol on castrated male and female bladder contractile function, as well as to determine whether estrogen receptors are necessary for mediation of the effect of estradiol on muscle contractility. 


\section{Materials and Methods}

\section{Tissue preparation}

Experiments were performed on adult female and castrated male pig urinary bladders obtained from the slaughterhouse approximately 30 minutes after slaughter. Each group of experiments was performed in six male and six female pig bladders. Strips of $2 \times 2 \mathrm{~cm}$ were taken, dissected from the dorsal side of the bladder dome and transported to the laboratory in oxygenated Krebs solution $\left(\mathrm{NaCl}, 118 \mathrm{mmol} / ; ; \mathrm{KCl}, 4.7 \mathrm{mmol} / ; ; \mathrm{NaHCO}_{3}, 25 \mathrm{mmol} / \mathrm{l} ; \mathrm{KH}_{2} \mathrm{PO}_{4}, 1.2 \mathrm{mmol} / \mathrm{CaCl}, 1.8 \mathrm{mmol} / ;\right.$ $\mathrm{MgSO}_{4,} 1.2 \mathrm{mmol} / \mathrm{l} ;$ glucose $11 \mathrm{mmol} / 1 ; \mathrm{pH} 7.4$; aerated with $\left.95 \% \mathrm{O} 2 / 5 \% \mathrm{CO} 2\right)$. The mucosa and the submucosal fat layer were removed using a binocular microscope, and strips of a comparable size. $0.3 \mathrm{~mm}$ diameter and length between 1 and $2 \mathrm{~mm}$, were excised. To facilitate diffusion the thin layer covering the muscle fiber was opened and for the greater part removed. Care was taken that the muscle fibers were running longitudinally.

\section{Organ bath}

Each strip was positioned horizontally in our custom-made organ bath, which contained a volume of 0,23ml, (IDEE, University Maastricht) between two tweezers of which one was attached to a KG4 force transducer connected to the BAM4C amplifier (Scientific instruments(B) Heidelberg). Another tweezer was connected to a translation stage that was regulated by a controller (translation stage M111, 1DG; Mercury Controller C860. Physic Instrumente(B)). An electrical field was generated between two platinum electrodes by a HM8130 Function Generator from Hameg(i) Instruments. Flow in the organ bath was regulated with separate in and outflow syringe pumps (Vickers Medical(1), IP4). Temperature was kept at $37^{\circ} \mathrm{C}$ using infrared radiation from a halogen lamp (Philips@; $12 \mathrm{~V}, 20 \mathrm{~W}, 6^{\circ}$ ) and controlled using a $200 \mu \mathrm{m}$ diameter thermocouple (Omega( ChAl/005).

\section{Experimental protocol}


The muscle strips were placed in the organ bath and incubated in Krebs. We determined $L_{0}$ at $37^{\circ} \mathrm{C}$; this is the length at which maximum isometric force is developed. The strips were sitimulated at the length at which maximum isometric force was developed. The strips were stimulated in a

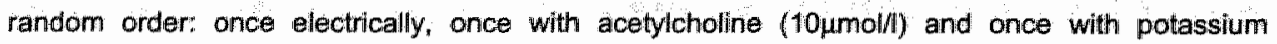
(100mmol/h). Electrical Field-stimulation (EFS) was given for 10 seconds with alternating amplitude of 7.5 Volt, a pulse duration of $5 \mathrm{~ms}$ and a frequency of 100 Hertz. When a muscle strip developed less than $100 \mu \mathrm{N}$ force it was excluded from further measurements. Between each stimulation there was an interval of 10 minutes. To examine concentration-dependent effects on muscle contractility, each strip was exposed to $17-\beta$-estradiol in 3 different concentrations $(1,10$ and $30 \mu$ mol/I). After twenty minutes of incubation with a concentration of the agent the strips were stimulated again in a random order with electrical field, acetylcholine and potassium. After washing out the hormone for twenty minutes a last EFS and pharmacological stimulation was applied before the next concentration of estradiol was applied to the organ bath. The control group with six muscle strips underwent the same stimulation protocol with DMSO in order to see whether it induced muscle relaxation.

The involvement of estrogen receptors in the effects of $17-\beta$-estradiol were assessed by incubating six castrated male and six female strips with the selective estrogen receptor antagonist ICI 182.780 (at the same concentrations of estradiol) for 45 minutes before the 3 different concentrations of 17 beta-estradiol were added to the organ bath. $1 \mathrm{Cl} 182.780$ is a type of receptor antagonist that is specific to intracellular estragen receptor beta.

\section{Compounds}

Acetylcholine thydrochloride (Achi), Potassium chloride (KCl) and 17-beta estradiol were obtained from Sigma Chemical Co. (St. Louis, MO). Estrogen receptor antagonist ( $\mathrm{Cl}$ 182.780) was purchased from Tocris Cookson Inc. (Elliswille, MO). All solutions were freshly prepared. Estradiol$17-\beta$ and $\mathrm{ICl} 182.780$ were dissolved in dimethylsulfoxide (DMSO) and diluted in Krebs and others were dissolved and diluted in Krebs. The final concentration of DMSO in bathing solution was less than $0.03 \%$ 


\section{Data analysis}

All isometric contractions were sampled at a rate of $100 \mathrm{~Hz}$ with a Pentium(133 $13 \mathrm{~Hz}$ type (AD conversion DAS 800) computer and stored for further analysis. Phase plots, which represent the first derivative of force as a function of the force itself, were calculated. Normally these phase plots of isometric smooth muscle contractions can be characterized by a straight line where $F$ is the measured force, $F_{i s o}$ is the maximum extrapolated isometric force, $t$ is time , and $C$ (see formula) is the negative reciprocal of the time constant for isometric force development. The time constant is an indicator of the rate limiting process in the excitation-contraction coupling and tells when $66 \%$ of the maximum force saturation level is reached [8]. The smaller the value of $\mathrm{C}$ the faster the rate of force development.

$F=F_{i s o}\left[1-e^{-(v C)}\right]$

$\mathrm{C}$ represents the limiting rate constant in the excitation-contraction coupling process.

Artifacts due to movement of fluid could be excluded from further analysis because they were recognized as irregular spikes. The value of EF-stimulation at Lo was seen as the optimal stimulation and therefore as reference for Fiso and time constant. This is maximum force development without treatment with estradiol. When the strips were incubated with estradiol we calculated the percentage of reduction of initial farce development. These percentages were averaged for all six-muscle strips from each group. Changes in rate of force development compared to the baseline measurements were determined. All calculations were processed in Matlab(12.1.

\section{Statistical evaluation}

Data are expressed as means \pm standard error of the mean, when appropriate. Differences of maximal force and time constant between pre and post-treatment were evaluated with SPSS 8.0 for Windows using Student's paired t-test. The level of significance chosen was $95 \%(p<0.05)$.

It was not necessary to normalize the values of maximal force and time constant of the strips because care was taken that the strips were very similar in order to reduce variability. 


\section{Results}

Characteristics of contractions of isolated detrusor strips induced by electrical and pharmacological stimuli in Krebs solution

The maximal force of contractions induced by EFS and Ach was higher than those induced by $\mathrm{KCl}$ unider normal conditions in female as well as male bladder smooth muscle. However, these results were not statistically significant $(p>0.05)$. The values of maximal force of contractions induced by EFS, Ach and $\mathrm{KCl}$ are described in the table.

\section{Effects of vehicle control}

The vehicle control for estradiol and estrogen receptor antagonist, DMSO $(0,03 \%)$, had no effect on the muscle contractility (results have not been shown).

\section{Effects of 17 - $\beta$-estradiol on muscle contractifity}

Estradiol-17- $\beta$ at a dose of $30 \mu$ molil elicited a reversible lower amplitude of contractions induced by EFS, Ach and $\mathrm{KCl}$ in female as well as in castrated male pig bladder smooth muscle strips (Figures $1,2$ and 3$)(\rho<0.05)$. In contractions induced by $\mathrm{KCl}$ a reduction was seen to $10 \%$ of the maximal force in female bladders and $11 \%$ in male bladders after incubation with estradiol ( $30 \mu$ moln). Contractions induced by EFS reduced to $53 \%$ and $40 \%$ after estradiol has been added to the organ bath, in female (figure 4y and male bladders, respectively. Incubation of the strips with estradiol reduced the maximal force of contractions induced by Ach to $38 \%$ and $34 \%$ in female and male bladder strips, respectively. The decrease of the maximal contractile response of bladder strips after KCl induced contractions was more than after EFS and Ach induced contractions $(p=0.03)$. The data above show that the relaxation was similar in female and male pig bladders.

There was not any statistically significant difference shown in the rate of force development among contractions induced by EFS, Ach and $\mathrm{KCl}$ in female and castrated male strips that were pretreated with estradiol in comparaslon with contractions induced in normal conditions (Krebs solution) ( $p>$ $0.05)$ 


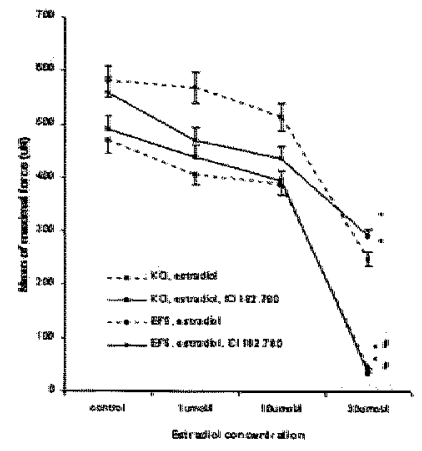

Fig. 1

Effects of preincubation of detrusor strips from the female pig with different concentrations of 17 - $\beta$-estradiel with and without pretreatment with estrogen receptor antagonist on the Maximal Force of contractions induced by EFS and $\mathrm{KCl}(100 \mathrm{mmol} / \mathrm{m})$. The values are means \pm SEM from 6 animals in each group. " $p$ less than 0.05 vs control group. \# $p$ less than 0.05 vs EFS responses at $30 \mu$ molly of estradiol.

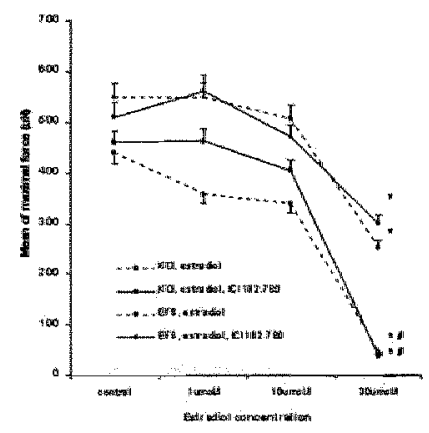

\section{Fig. 2}

Effecis of proincubation of delrusor strips from the castrated male pig with different concentrations of 17- $\beta$-estiradiol with and without pretreatment with estrogem receptor antagonist on the Maximal Force devolopment contractions induced by EFS and $\mathrm{KCl}(100 \mathrm{mmol} / \mathrm{l})$. The values are means \pm SEM trom 6 animats in each group. " $p$ less than 0.05 ws control group. W plass than 0.05 vs EFS responses at 30 jumollf of estradiol. 


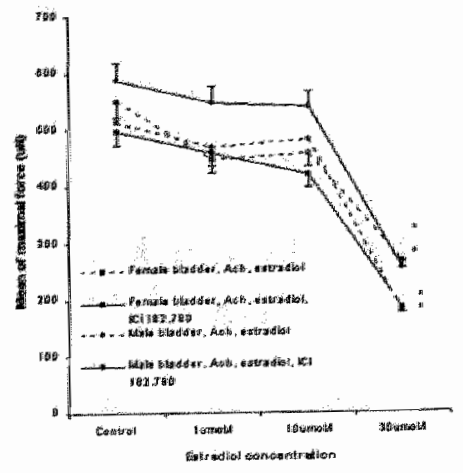

Fig. 3

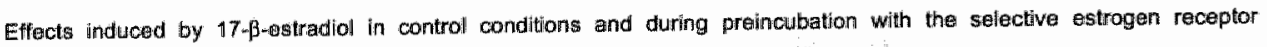
antaganist ICI 182.780 on Maximal Force of contractions induced by Ach (10 10molil). Values ane mean \pm SEM from 6 bladder strips in each group. "p value lass thian $0.05 \mathrm{v}$ contral.
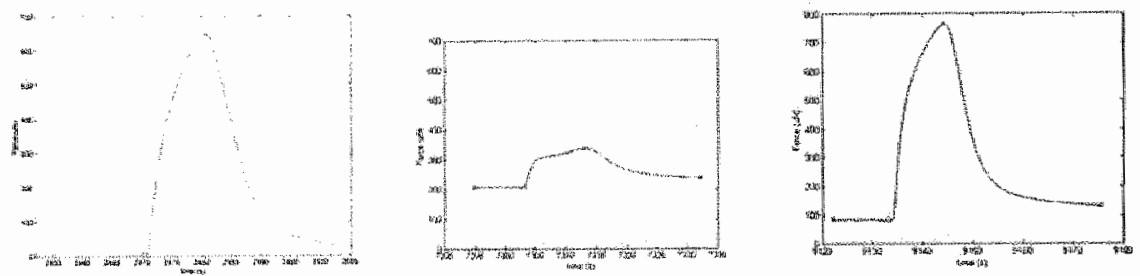

Fig. 4

Maximal force of a muscie contraction induced by EFs $(100 \mathrm{~Hz})$ in a female bladder. a.muscle contraction induced in normal conditlons (krebs solution); b.muscle contraction induced after 20 mimultes of incubation of the muscle strip with $17-\beta$ (a) contraction obtained after ramowal of estrogen from the bathing solution.

\section{Effects of the estrogen receptor antagonist}

As summarized in the figures 1,2 and 3 , the preceding incubation with the estrogen receptor antagonist $1 \mathrm{Cl} 182.780$ did not modify the inhibitory effects of $17-\beta$-estradiol at $30 \mu$ mol/ on muscle contractility after contractions induced by electrical field and pharmacological stimuli $(p>0.05)$. 


\section{Table}

Values of Maximal Force of contractions induced by Electrical Field Stimulation ( $100 \mathrm{~Hz})$, Acetylcholine (10/umol/l) and Potassium $(100 \mathrm{mmol} / \mathrm{l})$ in isolated smooth muscle strips from castrated male and female pig bladders in Krebs solution (without any treatment). The values are described in micro Newton $(\mu \mathrm{N})$.

\begin{tabular}{lll}
\hline & \multicolumn{1}{c}{ Maximal Force of contractions $(\mu \mathrm{N})$} \\
\cline { 2 - 3 } & Mean in 6 female pigs & Mean in 6 male pigs \\
\hline Electrical Field Stimulation & $579.7(498.1-602.1)$ & $550.6(478.0-588.8)$ \\
Acetylcholine hydrochloride & $550.8(512.7-613.4)$ & $514.3(458.4-568.4)$ \\
Potassium chloride & $470.3(415.5-498.6)$ & $439.8(412.3-487.4)$ \\
\hline
\end{tabular}

\section{Discussion}

Since its discovery and recognition as a "femalle" sex hormone, estradiol has been studied for its effects on the female reproductive tissues as well as its actions in the urinary system, and most recently for its specific effect on bladder function. Results from the present study indicate that $17-\beta-$ estradial at high concentrations causes inhibition of contraction in adult female and castrated male pig bladder. The observation that estradiol can act on female and male smooth muscle is in general agreement with previous studies [7].

The majority of estradiol effects are mediated by estradiol receptors that act as ligand-activated transcription factors $[9,10]$. Estradiol binding to specific receptors causes translocation of the receptor-hormone complex from the cytosol to the nucleus where the estradiol-receptor complex 
binds in a highly specific manner to the estradiol-response element of a promoter region of specific genes that results in an altered pattern of gene expression. Two types of intracellular estrogen receptors (ER), ER-alfa and ER-beta have been described in the literature [10]. Measurement of MRNA for ER-alfa and ER-beta reveal distributions in the body that differ quite markedly from each other, with high expression of ER-beta in the lower urinary tract of both male and female rats [11]. These effects of estradiol are delayed in onset and prolonged in duration, and are called "genomic" effects. However, estradiol can also have effects that can be rapid in onset and short in duration, they are called "non-genomic" effects [12].

Several lines of evidence argue against the possibility that smooth muscle relaxation induced by estradial is mediated by genomic mechanisms involving the nuclear estrogen receptors: the concentrations of 17 - $\beta$-estradiol required to evoke smooth muscle lower amplitude of contraction are several orders of magnitude higher than those required for genomic actions [13]; the rapid onset of action of 17- $\beta$-estradiol is inconsistent with the timecourse of a response requiring gene transcription and the selective nuclear estrogen receptor antagonist did not suppress vascular smooth muscle relaxation by estradiol [14]. The relatively rapid changes in muscle contractility abserved in the present study and the observation that the pure estrogen receptor antagonist ICI 182.780 did not inhibit the relaxant effects of 17-beta-estradiol in smooth muscle, are clearly not compatible with the classic genomic mechanism for the action of $17-\beta$-estradiol, which involves translocation of receptors to the nucleus and protein synthesis [15]. Furthermore, micromolar concentrations of $17-\beta$-estradiol were necessary to induce lower contractions of pig detrusor and those concentrations are clearly higher than physiological serum levels of the estrogen (around $100 \mathrm{pg} / \mathrm{ml}$, that $1 \mathrm{~s}_{\mathrm{n}}$ in the nanomolar range). However, White et al [16] suggested that protein (steroid hormone binding globulin)-bound hormone could act in vivo as a free fraction due to a rapid dissociation of bound steroid hormanes. Under our conditions, the bathing solution did not contain steroid binding protein, thus higher concentrations of free hormone would be necessary to mimic in wiwo physiological conditions. These data "taken together, support the hypothesis that estrogen may affect bladder smooth muscle contractility through a rapid non-genomic mechanism. However, the physiological importance of this acute inhibition by estradiol on bladder contraction is not clear. 
A change in intracellular free $\mathrm{Ca}^{2+}$ concentration $\left[\mathrm{Ca}^{2+}\right]_{1}$ is a crucial signal for diverse cellular functions. Previous research has shown that callium release from intracellular stores by an agonists and by inositol 1,4,5-trisphosphate (IP3) does not appear to be modulated by acule administration of estradiol in vascular smooth muscle [17]. Therefore, it was suggested that the ovarian steroid hormone relaxes smooth muscle predominantly by inhibiting the entry of $\left[\mathrm{Ca}^{2+}\right]_{i}$ into the cells [18]. In a previous study from our laboratory we have demonstrated that an active IP3 pathway was necessary for development of a contraction with a fast rate of force development. Thus, the specific inhibition of this pathway by Xestospongin $C$ induced a much slower contraction in pig urinary bladder smooth muscle (unpublished data). In this present study, the rate of force development of contractions was slower than rates during specific IP3 stimullation and not affected by estradiol preincubation. This result is consistent with the conclusion that estradiol does not appear to modulate the IP3 pathway and also that the mechanisms of estradiol induced-inhibition of muscle contractility do not affect the duration of bursts of intracellular calcium concentration per se. Ogata et al [19] suggested that estrogen acts on the cell membrane receptors rather than on cytosolic receptors because its action appeared to be very quick and current was restored rapidly after removal of estrogen from the bathing solution. In our experiments, the inhibitory action of estradiol on EFS, Ach and KCl-induced contractions was abserved after 20 minutes of incubation of the muscle strips with the hormone, and this inhibition could easily be removed by washout. It is possible that these plasma membrane receptors are also involved in $\left[\mathrm{Ca}^{2+}{ }_{1}\right.$ regulation by estrogens and mediate some of the effects on muscle contractility observed in the present study.

Herrera et al [15] have shown that different types of potassium channels are present in the guineapig detrusor, whose modulation offers a potential mechanism for affecting bladder contractility and

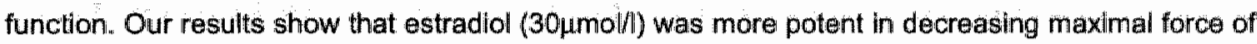
contractions induced by $\mathrm{KCl}$ compared to contractions evoked by electrical field-stimulation and Acetylcholine. Thus, these findings suggest that estradlol has a stronger inhibitory effect on the depolarisation of the muscle cell membrane than on the muscarinic receptor.

In conclusion, we speculate that under our conditions estrogen may act through a non-genomic pathway, mast likely via cell membrane receptors which are not inhibited by $1 \mathrm{Cl} 182.780$. 
Furthermore, the possitule role of $K(*)$ channel deactivation in the inhibition of contraction induced by $17-\beta$-estradiol in pig bladder provides a new approach to further research into the treatment of detrusor overactivity.

\section{Acknowledgment}

We would like to thank Dr. Kelly Hoenjet for his technical assistance.

\section{References}

01.Aikawa K, Suglno $T$, Matsumoto $S$, Chichester $P$, Whitbeck $C$ and Levin RM. The effect of ovarlectomy and estradiol on rabbit bladder smooth muscle contraction and morphology. $J$ Urol $2003,170: 634-637$.

02.Suguita $M$, Giraia $M J_{3}$ Simoes $M J$ sartori $M G$, Baracat ED and Rodrigues de Lima GR. A morphologic and morphometric study of the vesical mucosa and urethra of castrated female rats following estrogen and/or progestogen replacement. Clin Exp Obstet Gynecol 2000, 27:176-178.

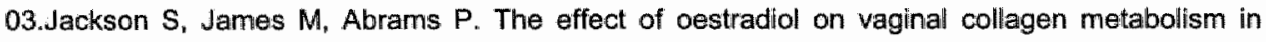
postmenopausal women with genuine stress incontinence. BJOG 2002, 109:339-344.

04. Dlep N. Constantinou CE. Age dependent response to exogenous estragen on micturition, contractility and cholinergic receptors of the rat bladder. Life Sci 1999, 64(23): PL 279-89.

05.Sanchez-Ortiz $R_{4}$ Wang $Z$, Menon $C$, DiSanto ME, Wein A and Chacko S. Estrogen modulates the expression of myosin heavy chain in detrusor smooth muscle. Am J Physiol Cell Physiol 2000, 280: $\mathrm{C} 433-\mathrm{C} 440$.

06. Erulkar SD. Rendt $\rfloor,$ Norl RD and Ger B. The influence of 17-beta-oestradiol on K+ currents in smooth muscle cells isolated from immature rat uterus. Proc. R. Soc. London 1994, 256:59-65. 
07. Salom JB, Burguete MC, Perez-Asensio FJ, Centeno JM, Torregrosa G and Alborch E. Acute relaxant effects of 17 -beta-estradiol through non-genomic mechanisms in rabbit carotid artery. Steroids 2002, 67:339-346.

08.Van Koeveringe GA and Van Mastrigt R: Excitatory pathways in smooth muscle investigated by phase-plot analysis of isometric force development. Am J of Physiol 1991, 26:138-44, 1991.

09.Greene GL, Gilna P, Waterfield M, Baker A, Hort $Y$ and Shine J. Sequence and expression of human estrogen receptor complementary DNA. Science 1986, 231:1150-1154.

10.Mendelsohn ME and Karas RH. Estrogen and the blood vessel wall. Curr Opin Cardiol 1994, 9:619-626.

11. Makela $S_{\sharp}$ Strauss $L_{\sharp}$ Kuiper $G$, Valve $E$, Salmi $S$, Santti $R$ and Gustafsson JA. Differential expression of estrogen receptors alpha and beta in adult rat accessory sex glands and lower urinary tract. Mol Cell Endocrinol 2000, 170(1-2):219-29.

12. Lee S.J and McEwen BS. Neurotrophic and neuroprotective actions of estrogens and their therapeutic implications. Ann. Rev. Pharmacol. Toxicall 2001, 41:569-591.

13. McEwen BS. Non-genomic and genomic effects of steroids on neural activity. Trends Pharmacol Scl. 1991, 12:141-147.

14. Freay $A D$, Curtis $S W_{y}$ Korach $K S$, Rubanyi GM. Mechanism of vascular smooth muscle relaxation by estrogen in depolarized rat and mouse aorta. Circulation Research 1997, 81(2): 2428.

15. Herrera GM. Heppner TJ and Nelson MT. Regulation of urinary bladder smooth muscle contractions by ryanodine receptors and BK and SK channels. Am $\Perp$ Physiol Regul Integr Comp Physiol 2000, 279:60-68.

16. White RW, Darkow DJ, Faivo Lang JL. Estrogen relaxes coronary arteries by opening Bkca channels through a cGMP-dependent mechanism. Circ Res 1995, 77:936-942.

17.Kitazawa T, Hamada E, Kitazawa K, Gaznabi AK. Non-genomic of 17 beta-oestradiol-induced Inhibition of contraction in mammalian vascular smooth muscle. J Physiol 1997, 1:499 (Pt2):497511. 
18, Jiang $C_{1}$, Sarrel $P M$, Pode-Wisson $P A_{8}$ Collins $P$. Acute effect of 17B-estradial on rabbit coronary artery contractile responses to endothelin-1. Am J Physiol, 1992, 263:H271-H275.

19.0gata $R$, Inoue $Y$, Nakano $H$, lto $Y$, Kitamura $K$. Oestradiol relaxes the rabbit basilar artery by Inhibition of voltage-dependent Ca channels through GTP-binding protein. B J Pharmacology 1996, 117,351-359. 


\section{Chapter IV}

Flavonoid galangin prevents smooth muscle fatigue of pig urinary bladder

Miriam Dambros, Rik de Jongh, Gommert van Koeveringe, Aalt Bast, Chantal GM Heljnen, Philip van Kerrebroeck.

J Pharm Pharmacol 57(5):617-622, 2005. 
Flavonoid galangin prevents smooth muscle fatigue of pig urinary bladder

\begin{abstract}
There is increasing evidence that the generation of free radicals plays a role in the development of blaidder dysfunction. Flavonoids are a group of polyphenolic compounds and have recentiy gained tremendous interest, due to their broad pharmacological activity. To the best of our knowledge, this is the first time, the protective effects of the flavonoid galangin on the progressive decrease of bladder smooth muscle contractile responses, during Repetitive Field Stimulation -RFS (a model for muscular fatigue), are demonstrated. Pig detrusor strips were mounted for tension recording in argan baths and were subjected to RFS for $90 \mathrm{~min}$ at $32 \mathrm{~Hz}$ for 15 seconds every 5 minutes. After that, all strips were washed 4 times with fresh buffer and were allowed a period of $90 \mathrm{~min}$ for recovery. Ninety minutes of repetitive stimulation caused a progressive decrease in maximal contractile response to electrical field stimulation (EFS) and to muscarinic agonist-induced contractions $\left(34 \%\right.$ and $46 \%$ decrease, respectively). Galangin $\left(10^{-7} \mathrm{M}\right)$ awoided the decrease in contractille smooth muscle response of strips to EFS during RFS, as compared to untreated tissues. The antioxidant activity of galangin was assessed by measuring its capability to inhibit the lipid peroxidation, induced by iron and ascorbate in rat liver microsomes $\left(\mathrm{IC}_{50}\right.$ was $\left.1.7 \pm 0.12 \times 10^{-6} \mathrm{M}\right)$. If the data are confirmed ily-vivo, exogenously administered gallangin might form a new avenue in the prevention and/or treatment of bladder dysfunction.
\end{abstract}

\title{
Introduction
}

Overactivity of the bladder adversely affects the quality of life in a significant proportion of the elderly population. Besides this, the cost of the treatment of bladder dysfunction exceeds a billion dollars each year in the world (Debruyne \& Heesakkers 2004). 
Concerning the basic mechanisms of bladder overactivity, there is increasing evidence that the generation of free radicals plays a role in the development of this pathology. Results of a previous study showed that RFS of smooth muscle strips isolated from the urinary bladder could be used as a model for muscular fatigue (Ohnishi et al 1998). This model has demonstrated to produce exhaustion of symaptic stores of acetylcholine and direct neuronal damage leading to increased lipid peroxidation and impaired smooth muscle contractility in the ischemic and hypoxic media as well as in the normal physiological media (Ohnishi et al 1998). In that study, the extent of contractile impairment correlated with the level of lipid peroxidation, suggesting the involvement of oxidative stress in bladder smooth muscle dysfunction. Furthermore, recent studies have introduced the concept that reactive oxygen species may function as a major factor in the progressive deterioration of bladder contractility induced by benign prostatic hyperplasia (partial outlet obstruction in animals) (Masick et al 2001).

Bladder dysfunction is frequently treated phanmacologically, but the side effects associated with the commonly used agents can be uncomfortable and significantly influence patient compllance. During the last few years, research has stimulated the development of new therapeutic approaches for the overactive bladder. It is important to focus on the development of pharmacological agents that can suppress the symptoms without altering normal voiding function.

Flavonoids comprise a large group of naturally existing polyphenolic compounds widely distributed throughout the plant kingdom. These natural products possess a wide spectrum of physiological and pharmacological effects such as inhibitory effects on both intestinal and thoracic aorta smooth muscle contraction (Ajay et at 2003; Gharzouli \& Holzer 2004) " but they are not equally physiologically active, because of differences in chemical and physical properties (van Acker at al 1996). The pharmacological effect can be explained by their inhibition of certain enzymes and their antioxidant activity. Despite the large amount of data available on the various effects of flavonolds, little is known about this effect of flavonoids on bladder smooth muscle.

Galangin, a member of the flavonol class of flavonoids, is present in high concentrations in honey and Alpinia officinarum and has been demonstrated to possess several biological propertles such as an anti-mutagenic (Wall et al 1988) and radical scavenging actions (Imamura et al 2000). More 
recently, its inhibitory effect on rat bladder contractility has been investigated (Capasso \& Tavares 2002):

The present study was conducted to investigate the efficacy of galangin to counteract the detrusor damage caused by the smoath muscle of the urinary bladder being exposed to repetitive fiell stimulation.

\section{Material and Methods}

\section{Tissue preparation}

Experiments were performed on pig urinary bladders obtained from the slaughterhouse approximately 30 minutes after slaughter. Strips of $2 \times 2 \mathrm{~cm}$ were dissected from the dorsal side of the bladder dome and transported to the laboratory in oxygenated Krebs solution (mM: $\mathrm{NaCl} 118$, $\mathrm{KCl} 5.6, \mathrm{NaHCO}_{3} 25, \mathrm{NaH}_{2} \mathrm{PO}_{4} 1.3, \mathrm{CaCl} 2.5, \mathrm{MgSO}_{4} 1.2$ glucose 6.1, $\mathrm{pH} 7.4$, aerated with $95 \% \mathrm{O}_{2}$ / $5^{\%} \mathrm{CO}_{2}$ ). Between 1 and 2 strips were taken from each bladder. The mucosa and the submucosal fat layer were removed using a binocular microscope, and strips of $1 \mathrm{~mm}$ diameter and length between 3 and $5 \mathrm{~mm}$ were excised. To facilitate diffusion the thin layer covering the muscle fibre was opened and for the greater part removed. Care was taken that the muscle fibres were running longitudinally.

Each strip was mounted in a separate $20-\mathrm{ml}$ organ bath containing Krebs-buffer solution which was gassed continuoulsly with $5 \% \mathrm{CO}_{2}-95 \% \mathrm{O}_{2 i}$ at $37^{\circ} \mathrm{C}$. An initial tension of $20 \mathrm{mN}$ was placed on each strip. Measurements were started after an equilibration period of $60 \mathrm{~min}$ with 4 intermediate changes of buffer solution.

In order to decide which frequency of stimulation had to be used to optimally stimulate nerves, a frequency-response curve $(5 \mathrm{~s}$ train pulses, $1 \mathrm{~ms}$ duration, $7.5 \mathrm{~V}$ voltage and $0.25-32 \mathrm{~Hz}$ frequency) was determined. The maximum contraction was observed at $32 \mathrm{~Hz}$. Accordingly, a frequency of $32 \mathrm{HZ}$ was chosen during the entire experimental procedure. When the tissue was preincubated with $10^{-6} \mathrm{M}$ tetradatoxin for $10 \mathrm{~min}$, the responses to $0.25-8 \mathrm{~Hz}$ stimuli were totally 
abolished and the responses to 16 and $32 \mathrm{~Hz}$ were inhibited by $93 \%$ and $83 \%$, respectively, which demonstrated their predominant neurogenic origin.

Contractions were measured isometrically using mechanoelectrical transducers connected to the BAM4C amplifier (Scientific instruments, Heidelberg). The electrical field was generated between two platinum electrodes connected to the HM8130 Function Generator from Hameg(i) Instruments.

\section{Effects of galangin on detrusor muscle tone under normal conditions}

After 60-min equilibration period, detrusor strips were electrically stimulated at $32 \mathrm{~Hz}$ and submitted to a methacholine concentration response curve-MCRC $\left(10^{-8}-10^{-5} \mathrm{M}\right)$, after which the strips were washed for up to $30 \mathrm{~min}$. Then, galangin, at different concentrations, was added to the perfusing Krebs solution for a period of $180 \mathrm{~min}$ to reproduce the same time period of both repetitive stimulation and recovery period. Its effect on the muscle contractility was observed after 90 min and $180 \mathrm{~min}$.

\section{Effect of repetitive field stimulation on detrusor contractility}

After the equillibration period, detrusor strips were stimulated at $32 \mathrm{~Hz}$ (single stimulus) and submitted to a MCRC. Then, eight strips were submitted to RFS for 90min ( $5 \mathrm{~s}$ train pulses, $1 \mathrm{~ms}$ duration, $7.5 \mathrm{~V}, 32 \mathrm{~Hz}$, applied for $15 \mathrm{~s}$ every $5 \mathrm{~min}$ ). At the end of the period of repetitive stimulation, responses to EFS at $32 \mathrm{~Hz}$ (single stimulus) and methacholine were rëassessed. After that, all strips were washed 4 times with fresh buffer and the strips were submitted to 90 min of recovery period (non-repetitive stimulation). Again, at the end of this period, the strips were submitted to EFS (single stimulus) and methacholine-induced contraction in order to detect the effect of the recovery period on muscle contractility.

Effect of galangin on detrusor contractility under repettive field stimulation condition 
After the equilibration time and an electrical and agonist stimuli have been applied, detrusor strips were subjected to $90 \mathrm{~min}$ of RFS followed by $90 \mathrm{~min}$ of recovery period. During this $180 \mathrm{~min}$ period, galangin, at different concentration, was added to the perfusion medium during the whole experiment. At the end of the repetitive stimulation period and the recovery period, muscle response of the strips was tested by the application of a single electrical stimulus at $32 \mathrm{~Hz}$ and methacholine $\left(10^{-6}-10^{-5} \mathrm{M}\right)$.

\section{Lipid peroxidation}

The present experimental model was developed to detect the antioxidant activity of galangin by measuring the inhibition of iron/ascorbate induced lipid peroxidation.

Liver microsomes were prepared from male Wistar rats, 200-250g(van Acker of al 1996). The Animal Protection Committee of our University approved the protocol. All animal experiments complied with British Home Office Regulations and associated guidelines in the European Communities Council Directive of 24 November $1986(86 / 609 / E C C)$.

Liver microsome pellet was heated at $100^{\circ} \mathrm{C}$ for $90 \mathrm{sec}$. to remove all enzymatic factors just before resuspending it on ice-cold Tris buffer.

Stock solution of galangin was freshly prepared in oxygen-free DMSO and water (1:1) just before use.

All compounds were added in ice, after which the incubates were transferred to a water bath $\left(37^{\circ} \mathrm{C}\right)$, where 50 $\mathrm{MM}$ ascorbate was added. The reaction was started by adding $10^{-5} \mathrm{M}$ freshly prepared $\mathrm{FeSO}_{4}$. Lipid peroxidation was assayed by measuring thiobarbituric acld (TBA)-reactive material in "oxygen free" pure water. The reaction in an aliquot of the incubation mixture was stopped by mixing with ice cold TBA-tichichoroacetic acid (TCA)-HCl-butylhydroxytoluene (BHT) solution. After heating $\left(15 \mathrm{~min}, 80^{\circ} \mathrm{C}\right)$ and centrifugation ( $5 \mathrm{~min}$ ) the absorbance at 535 versus $600 \mathrm{~nm}$ was determined.

The $\mathrm{IC}_{50}$ of galangin was determined by measuring the percent lipid peroxidation inhibition of several concentration and interpolating the $50 \%$ inhibition point on a straight line fitted through the concentrations which resulted in 20 to $80 \%$ inhibition. 


\section{Compounds}

Galangin and methacholine chlloride were obtained from Sigma Chemical Co (Netherlands) and FeSO4 was obtained from Merck (Netherlands). Galangin was dissolved in dimethylsulfoxide (the final concentration of DMSO in bathing solution was less than $0.05 \%)$. All solutions were freshly prepared. All other chemicals were of the highest grade of purity availlable.

\section{Data analysis}

Concentration-response data on methachalline were evaluated by sigmoild curve fitting and -log $E C_{50}$ values $\left(\mathrm{pD}_{2}\right)$ and maximum effect $\left(\mathrm{E}_{\max }\right)$ were calculated from individual values by non-linear regression analysis by using GraphPad Prism. Differences between mean values were statistically analysed.

The effect of repetitive stimulation on contractions induced by EFS at $32 \mathrm{~Hz}$, and the response following the recovery period are presented as the mean (I SEM) percentage of the control response (response prior to repetitive stimulation).

All isometric contractions induced by EFS were sampled with a computer and stored for further analysis. Phase plots, which represent the first derivative of force as a function of the force itself. were callculated. Normally a straight line can characterize these phase plots of isometric smooth muscle contractions where $F$ is the measured force, $F_{190}$ is the maximum extrapolated isometric force, $t$ is time, and $\mathrm{C}$ (see formula) is the negative reciprocal of the time constant for isometric force development. The time constant is an indicator of the rate limiting process in the excitationcontraction coupling and tells when $66 \%$ of the maximum force saturation level is reached (van Koeveringe \& van Mastrigt 1991). The smaller the value of $C$ the faster the rate of force development.

$F=F_{\text {isa }}\left[1-e^{4(t) C)}\right]$

C represents the limiting rate constant in the excitation-cantraction coupling process.

Artefacts due to movement of fluid could be excluded firom further analysis because they were recognized as irregular spikes. The value of EFS before repetitive stimulation was used as 
reference for time constant. Changes in time constant compared to the baseline measurements were determined. All calculations were processed in Matlab@12.1.

\section{Statistical evaluation}

Data are expressed as means \pm standard error of the mean, when appropriate. Statistical analyses were carried out using one-way analysis of variance followed by Dunnett's test. A probability value of $P<0.05$ was regarded as significant. All analyses were performed using GraphPad Prism software.

\section{Results}

\section{Effects of vehicle control}

The vehicle for galangin, dimethylsulfoxide (DMSO) $(0.05 \%)$, had no protective effect on the muscle contractility after repelitive stimulation (results are not shown). The effect of DMSO on imuscle contractility after repetitive stimulation was determined because it is known that solvents such as DMSO possess good radical scavenging activities themselves (van Acker et al 1996).

Incubation in normal physiological and galangin containing medium without repetitive stimulation Preliminary experiments without repetitive stimulation in which isolated strips were incubated either in normal Krebs solution or in galiangin solution $\left(10^{-8} \mathrm{M}, 5 \times 10^{-8} \mathrm{M}\right.$ and $\left.10^{-7} \mathrm{M}\right)$ showed no degradation of the contractile responses to EFS $(P>0.05)$ and MCRC after a 3-hour incubation period $(P>$ 0.05) (data are not shown).

Effects of $90 \mathrm{~min}$ of repetitive stimulation followed by $90 \mathrm{~min}$ of recovery on bladder tissue strip contraction in response to EFS and MCRC in normal physiological medium

Repetitive stimulation for $90 \mathrm{~min}$ in the presence of normal Krebs solution reduced significantly bladder strip contractions in response to EFS (Fig. 1) and methacholine 
(Fig. 2) (34\% and $46 \%$, respectively). Furthermore, the repetitive stimulation resulted in a significant increase in the time constant (i.e. a slower developing contraction) of contractions induced by EFS (Fig. 3). Following the 90min of recovery, the contractile responses to EFS, MCRC as well as the time constant showed no additional differences $(P>0.05)$.

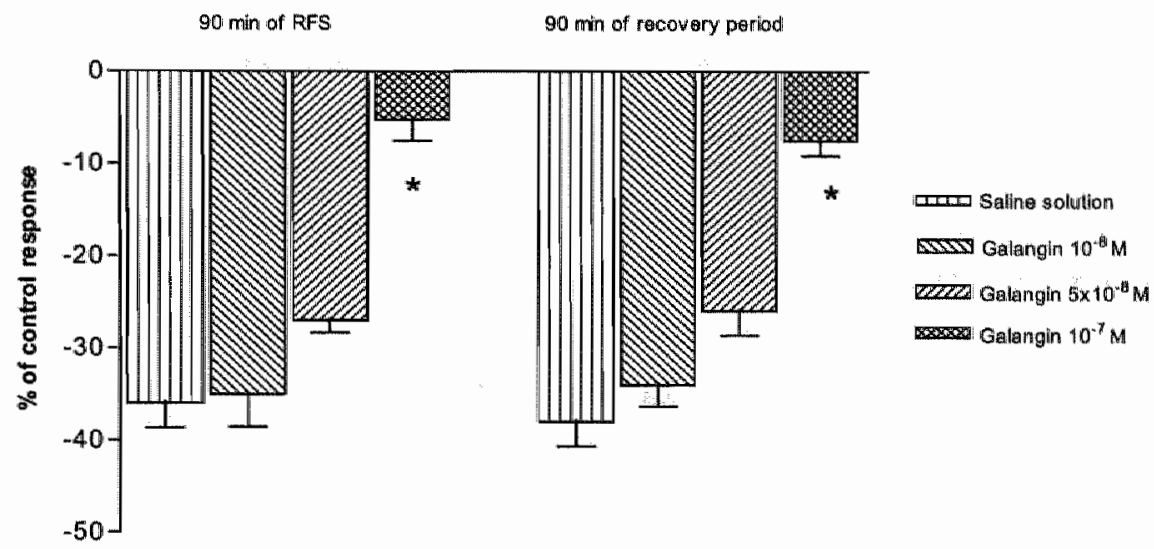

Figure 1: Electrical field stimulation-induced contractile responses of plg detrusor strips subjected to $90 \mathrm{~min}$ of repetitive field stimulated-induced smooth muscle fatigue and subsequent $90 \mathrm{~min}$ of recovery period. Experiments carried out in the absence or presence of galangin in different concentrations. The values are represented as percentages of the initial measured force values before RFS and expressed as mean \pm S.E.M. Significant differences from the controll group are indicated. " $P<0.05$. 


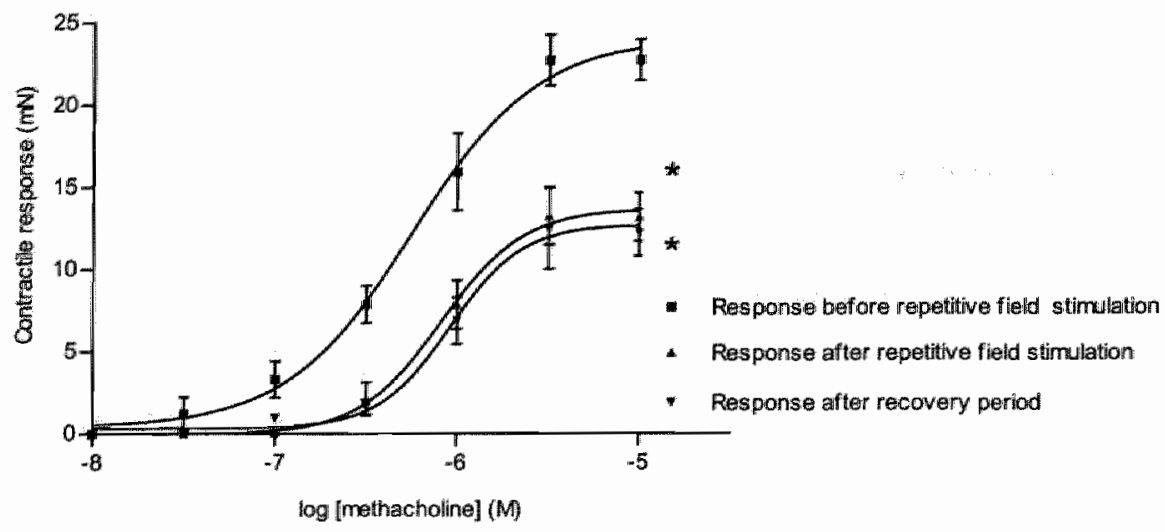

Figure 2: Effect of repetitive stimulation on the contractile response to methacholine in nomal physiological medium. Each point is the mean \pm SEM for $6-8$ individual preparations. The $\mathrm{pD}_{2} \pm$ SEM values of contraction induced before RFS, after $90 \mathrm{~min}$ of repeltive stimulation and after $90 \mathrm{~min}$ of period of recovery was $6.25(0.06)$ " $6.08(0.03)$ and $6.0(0.04)$, nespectively $(P<0.05$ versus contraction induced before RFS). The maximal effect (mN) was $23.81(0.11), 13.42(0.03)$ and $13.23(0.009)$ before RFS, after repetitive stimulation and after a periad of recovery, respectively. " $P<0.05$ compared contractions after RFS and recovery period to the initial response before RFS. 


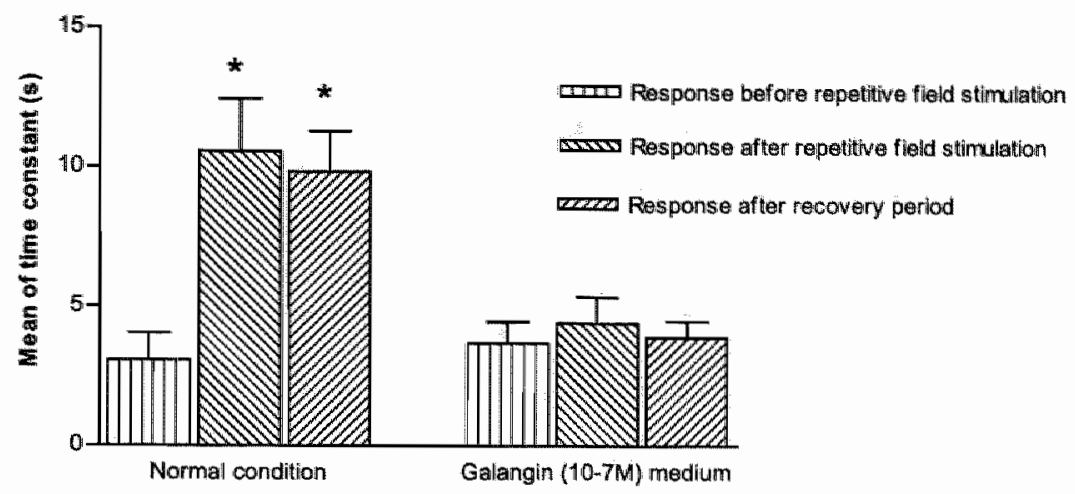

Figure 3: Effect of 90min of repetitive stumulation followed by $90 \mathrm{~min}$ of recovery peiriod on the thime constant of contractions induced by EFS $(32 \mathrm{~Hz})$ in different media. Each bar is the mean \pm SEM for 6 - 8 strips. * Significantly higher than the response before RFS $(P<0.05)$.

Effects of 90 min of repetitive stimulation followed by 90 min of recovery on bladdler strip contractions in response to EFS and MCRC in galangin medium

The responses of detrusor muscle strips to EFS in the galangin-treated groups are shown in Fig. 1. Galangin at $10^{-7} \mathrm{M}$ concentration avoided signiflcantly the RFS-induced muscle fatigue (Fig. 4), reaching $94.80 \pm 3.25 \%$, as compared to $64 \pm 2.65 \%$ of control (RFS in saline medium) $(P<0.05)$. At $10^{-6} \mathrm{M}$ and $5 \times 10^{-8} \mathrm{M}$, they did not exert any significant protective effect on muscle contractility $(65.00 \pm 3.56 \%$ and $73.00 \pm 1.34 \%$, respectively) as compared to control (RFS in saline medium) (P $<0.05)$

The responses of detrusor to methacholine in the gallangin media $\left(10^{-8}, 5 \times 10^{-8}\right.$ and $\left.10^{-7} \mathrm{M}\right)$ are shown in Fig. 5. Following the period of recovery, the contractility of isolated strips and the time constant were not statistically different from the responses obtained immedlately before the recovery in all groups $(P<0.05)$. 
A.

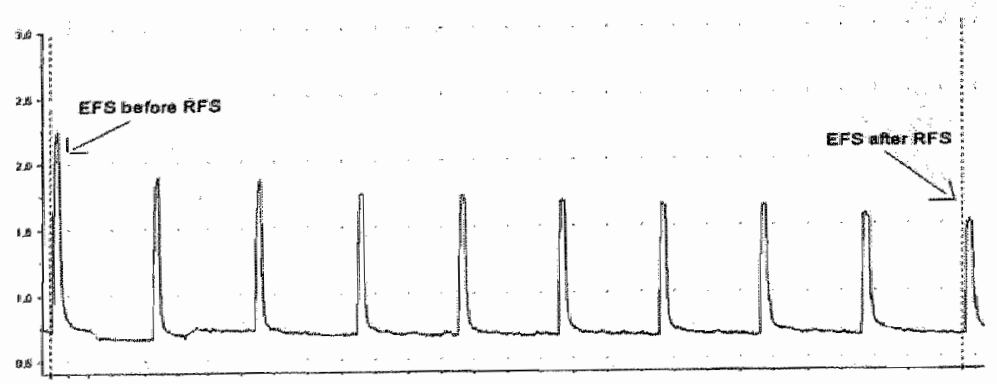

B.

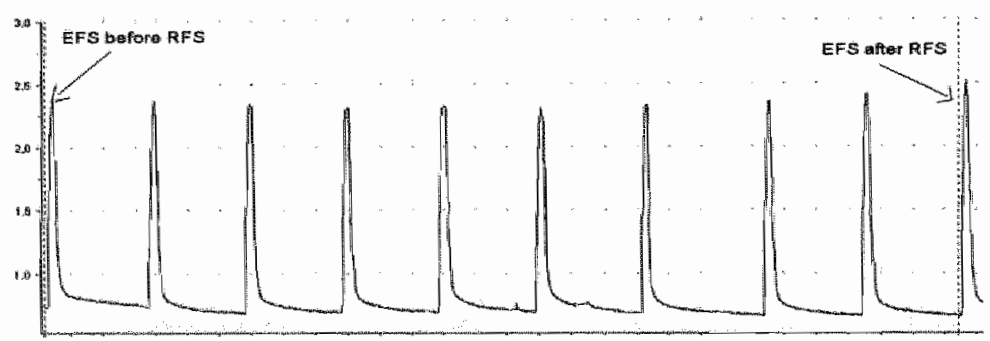

Flgure 4: A typical trace showing the effects of 90 min of repetitive fieid stimulation - RFS on detrusor contractility induced by electrical field stimulation - EFS. A. Saline medium the figure shows a control contraction (before RFS), the last 45 min of RFS and a final contraction (after 90 min of RFS); B. Galangin $10^{-7}$ M medium - control contraction, the last 45 min of RFS and a muscle contraction after a period of RFS. 


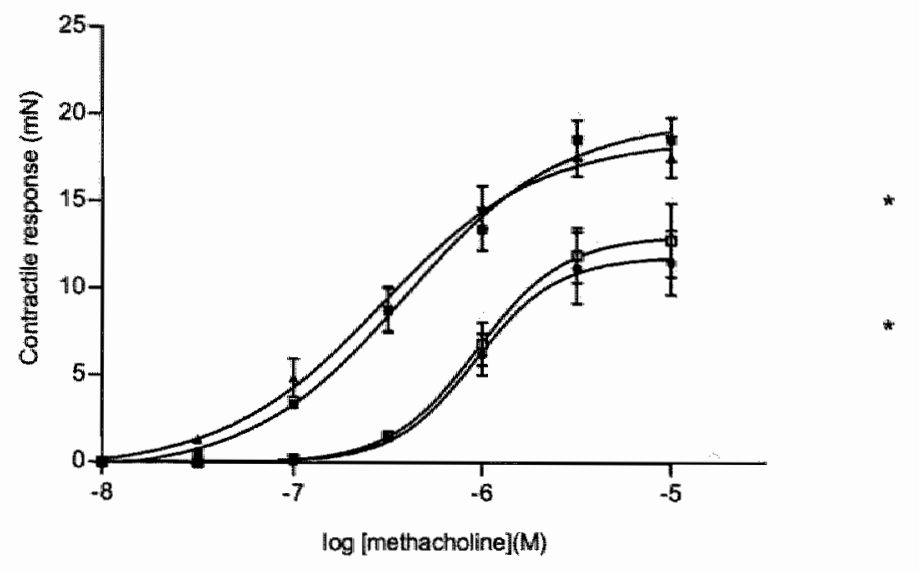

- Response before repetitive field stimulation

- Response after RFS in the presence of galangin $10^{\circ 7} \mathrm{M}$

- Response after RFS in the presence of galangin $10^{*} \mathrm{M}$

- Response after RFS in the presence of galangin $5 \times 10^{-8} \mathrm{M}$

Figure 5: Effect of repettitive stimulation on the contractle response to methacholine in galangin medium at different concentrations. Each point is the mean $\pm S E M$ for $6-8$ individual preparations. The $p D_{2} \pm S E M$ values of contraction induced before repetitive field stimulation - RFS was $6.40(0.07)$ and after $90 \mathrm{~min}$ of RFS in the presence of galangin at $10^{-7} \mathrm{M}, 5 \times 10^{-8} \mathrm{M}$ and $10^{-18} \mathrm{M}$ was $6.53(0.07), 6.03(0.02)$ and $6.02(0.01)_{1}$ respectively. * Significantly lower than the response before FFS $(P<0.05)$.

\section{Antioxidant acthity of galangin}

Galangin exhibited remarkable antiperoxidant activity with a $1 \mathrm{C}_{50}$ value of $1.7+0.12 \times 10^{-6} \mathrm{M}(\mathrm{Fig} .6)$ 


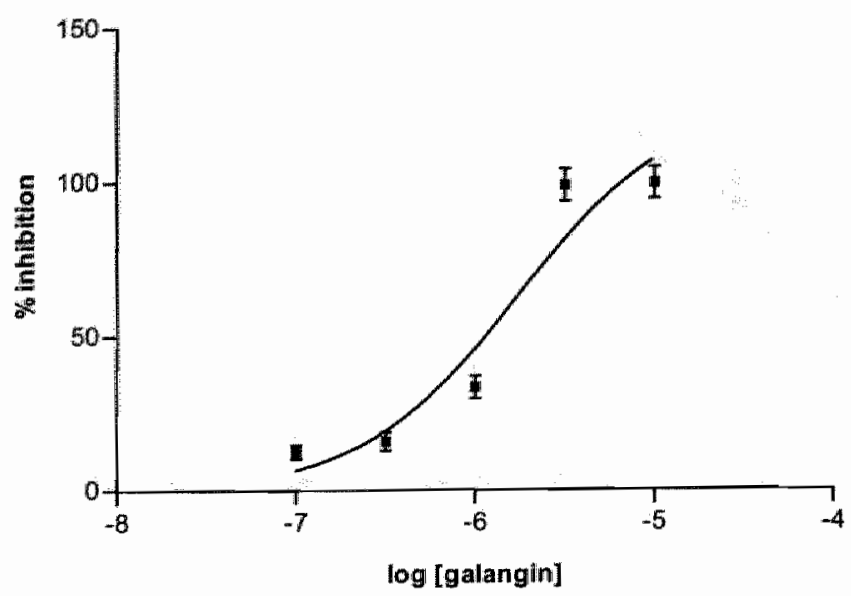

Figure 6: Dosemesponse curve for inhibition of $\mathrm{Fe}^{2+} /$ ascorbate induced lipid peroxidation of galangin.

\section{Discussion}

There is increasing evidence that flavonoids have beneficial effects and therefore can be used for treatment and prevention of specific diseases related to reactive oxygen species damage (Tokalov et al 2004). Although many of these effects have been linked to their potent antioxidant activity, other mechanisms of action may contribute such as vaso-dilatation and Inhibition of the activities of various ATPases (So ot al 1997). In view of their many reported bilological actions, we studied the effects of the flavonoid galangin on pig detrusor contractility after a period of repetitive stimulation. The possible role of oxidative stress in the pathophysiology of bladder dysfunction has not been clarified. Recent studies suggested that the urinary bladder might undergo cyclicall ischemia reperfusion during overdistension or increased pressures due to outlet obstruction, which in turn may lead to oxidative stress and the injury by free radicals (Zhao et al 1997). Results of previous studies showed that repetitive field stimulation of smooth muscie strips isolated from the urinary bladder can lead to exhaustion of the synaptic stores of acetylcholine and to direct neuronal 
damage that does not reverse upon cessation of the repetitive stimulation (Ohnishi al al 1998). These studies demonstrated that repetitive stimulation caused in a significant increase in the accumulation of malondialdehyde (MDA) within the smooth muscle membrane components of the bladder strips, and that both the MDA concentration and level of contractile dysfunction are directly related to the calcium concentration, i.e. high calcium enhances both the content of MDA in the tissue and the level of contractile dysfunction, whereas low calcium reduced bath parameters (Levin et al 1998). Two recent studies demonstrated that dangerously elevated levels of cytosolic $\mathrm{Ca}^{2+}$ concentration, or $\mathrm{Ca}^{2+}$ overload, and iron-overload occur during ischemia-reperfusion in cardiac myocytes (Oudit et al 2003; Eigel et al 2004). These studies indicated that the permeation of these ions occur likely through the L-type voltage-dependent $\mathrm{Ca}^{2+}$ channel as well as rapid reactivation of $\mathrm{Na}^{+} / \mathrm{Ca}^{2+}$ exchanger. Therefore, it can be suggested that radical scavengers capable of limiting the $\mathrm{Ca}^{2+}$ influx into the cells might be used as effective drugs for the prevention of tissue damage by ischemia-reperfusion injury.

The current study is consistent with other studies and has shown that repetitive stimulation in the presence of a normal physiological solution results in a decrease of the contractille responses of the bladder smooth muscle to both EFS and a muscarinic agonist (Ohnishi of al 1998). Additionally, we showed that a period of repetitive stimulation resulted in a much slower contraction development induced by EFS, which was demonstrated by the significantly higher time-constant (the time constant was $3.08+0.98$ sec before RFS and $10.55+1.98$ sec after RFS). In a previous study from our laboratory we have demonstrated that an active IP3 pathway was necessary for development of a contraction with a fast rate of force development in pig urinary bladder smooth muscle (unpubl. data). In the present study, the force development of contractions was affected after 90 min of RFS. We hypothesize that RFS decreases bladder smooth muscle contractility by affecting, at least partially, the IP3 pathway. We have also demonstrated that galangin at $10^{-7} \mathrm{M}$ concentration is capable of avoiding the decrease of smooth muscle contraction amplitude and the rate of force development after a period of repetitive stimulation. Recent studies have documented that galangin in a higher concentration range, in a concentration-dependent manner, reduced the contraction amplitudes evoked by electrical stimulation of the rat bladder (Capasso \& Tavares 2002). To the 
best of our knowledge, this is the first time, the protective effects of galangin in a lower concentration on bladder smooth muscle contractility have been demonstrated.

Flavonoids are a group of polyphenolic compounds with a broad pharmacological activity spectrum ubiquitously found in fruits and vegetables. Many authors have attempted to eluciclate the structureactivity relationships (SARs) of this antioxidant activity (Cotelle et al 1992; Heijnen et al 2002). However, this is hampered by the fact that antioxidant activity can be explained by several factors, of which lipophilicity, iron chelation and scavenging of free radicals are the most important. Furthermore, as flavonoids are known to be good transition metal chelators, most lipid peroxidation inhibition assays measure a combination of transition metal (usually tron) chelation and radical scavenging.

Some flavonoids have a biphasic effect on the contractile responses, with a potentiation at lower concentration $\left(10^{-6} \mathrm{M}\right)$ and a relaxant effect at higher concentrations $\left(10^{-5} \mathrm{M}\right)$ (Herrera at a/ 1996). At low concentrations (sub- $\mu M$ ) the protective effect of galangin predominates, while at higher concentrations $\left(>10^{-5} \mathrm{M}\right)$ its effect on smooth muscle relaxation prevails (Capasso \& Tavares 2002). Likely this effect can be explained, at least partially, by its structure.

The mechanism(s) by which galangin protects the detrusor muscle contractility from repetitive field stimulation injury is only a matter of speculation. It might be suggested that, for example, galangin can act through L-type calcium channels (Capasso \& Tavares 2002) and avoid the elevated levels of cytosolic $\mathrm{Ca}^{2+}$ concentration that can occur during RFS (Levin et al 1998). Clearly, further elucidation of the mechanism of galangin is crucial for development of new approaches for the treatment of patients with bladder dysfunction. 


\section{Conclusion}

This study demonstrated that galangin exerted a protective effect on bladder smooth muscle contractility. Although there is no proof that our results are reproducible in functional or dysfunctional human bladders, on the basis of our experiments, we suggest that, if the data are confirmed in-vivo, exogenously administered galangin might have a possible role in treating bladlder dysfunction.

\section{Acknowledgements}

Supported in part by grants from the European Community, Joint co-operation in REBEC (Project Number QLG5-CT-2001-00822) and the WAMU foundlation Maastricht.

\section{References}

Ajay, M., Gilani, A.H., Mustafa, M.R. (2003) Effects of flavonoids on vascular smooth muscle of the isolated rat thoracic aorta. Life Sciences 74:603-612.

Capasso, R. Tavares, I. (2002) Effect of the flavonoid galangin on urinary bladder rat contractility in-vitro. I Pharm Pharmacol 54:1147-1150.

Cotelle, N., Bernier, J.L., Hénichart, P.J., Catteau, J.P., Gaydou, E. and Wallet, J.C. (1992) Scavenger and antioxidant properties of ten synthetic flavones. Free Radical Biol. Med. 13:211-219.

Debruyne, F.M., Heesakkers, J.P. (2004) Clinical and socioeconomic relevance of overactive bladder. Urology $63: 42-44$.

Eigel, B.N., Gursahani, H., Hadley, R.W. (2004) ROS are required for rapid reactivation of $\mathrm{Na}+/ \mathrm{Ca} 2+$ exchanger in hypoxic reoxygenated guinea pig ventricular myocytes. Am. J. Physiol. 286:H955-963.

Gharzouli, K., Holzer, P. (2004) Inhibition of Guinea Pig intestinal peristalsis by the flavonoids quercetin, naringenin, apigenin and genistein. Pharmacology 70:5-19. 
Heijnen, C.G.M., Haenen, G.R.M.M., Oostveen, R.M., Stalpers, E.M. \& Bast, A. (2002) Protection of Flavonoids against lipid peroxidation: the structure activity relationship revisited. Free Radic. Res. 36: $575-581$.

Herrera, M.D., Zarzuello, A. Jimenez, J., Marhuenda, E., Duarte, J. (1996) Effects of flavonoids on rat aortic smooth muscle contractility: structure-actitivy relationships. Gen. Pharmacol. 27:273-277.

IImamura, Y. Migita, T., Uriu, Y., Otagiri, M., Okawara, T. (2000) Inhibitory effects of flavonoids on rabbit heart carbonyl reductase. J. Biochem. 127: 653-658.

Levin, R.M., Leggett, R., Whitbeck, C., Horan, P. (1998) Effect of calcium and calcium chelators on the response of the bladder to in vitro ischemia. Br. J. Urol. 82:882-887.

Masick, J.M., Levin, R.M., Hass, M.A. (2001) The effect of partial outlet obstruction on prostaglandin generation in the rabbit urinary bladder. Prostaglandins Other Lipid. Medlat. 66:211-219

Ohnishi, N."Liu, S.P., Horan, P., Levin, R. (1998) Effect of repetitive stimulation on the contractile response of rabbit urinary bladder subjected to in vitro hypoxia or in vitro ischemia followed by reoxygenation. Pharmacology 57:139-147.

Oudit, G.Y., Sun, H., Trivieri, M.G., Koch, S.E., Dawood, F., Ackerley, C.y Yazdanpanah, M., Wilson, G.d, Schwartz, A., Liu, P.P., Backx, P.H. (2003) L-type Ca2* channels provide a major pattway for iron entry into cardiomyocytes in iron-overload cardiomyopathy. Nat. Med. 9: 11871194.

So, F.V., Guthrie, N. Chambers, A.F., Carroll, K.K. (1997) Inhibition of proliferation of estrogen receptor-posilive MCF-7 human breast cancer cells by flavonoids in the presence and absence of excess estrogen. Cancer Lelt. 112:127-133.

Tokalov, S.V Kind, B., Wollenweber, R., Gutzeit, H.O. (2004) Biological effects of epicuticular flavonolds from Primula denticulata on inuman leukemia cells. J. Agric. Food. Chem. 52: 239-245.

van Acker, S., van Den Berg, D.J., Tromp, M., Griffioen, D.H., van Bennekom, W.P., van der Vijgh, W.J., Bast, A. (1996) Structural aspects of antioxidant activity of flavonoids. Free Radic. Biol. Med. 20: $331-342$. 
van Koeveringe, G.A., van Mastrigt, R. (1991) Excitatory pathways in smooth muscle investigated by phase-plot analysis of isometric force development. Am. J. Physiol. 26:R138-144.

Wall, M.E., Wani, M.C., Manikumar, G., Abraham, P., Taylor, H., Hughes, T.J., Warner, J" McGivney, R. (1988) Pllant antimutagenic agents. 2. Flavonoids. J. Nat. Prod. 51:1084-1091.

Zhao, Y., Levin, S.S., Wein, A.J., Levin, R. (1997) Correlation of ischemia/reperfusion or partial outlet obstruction-induced spectrin proteolysis by calpain with contractile dysfunction in rabbit bladder. Urology 49:293-300. 


\section{Chapter V}

Galangin protects pig detrusor nerves from repetitive field stimulation and anoxia-glucopenia injuries

Miriam Dambros, Rik de Jongh, Gommert van Koeveringe, Aalt Bast, Philip van Kerrebroeck

Urology 66(6):1327-31, 2005 


\section{Galangin protects pig detrusor nerves from repetitive fleld stimulation and anoxia- glucopenia injuries}

\section{Abstract}

Background: There is increasing evidence that the generation of free radicals and ischaemia/reperfusion play a role in the development of bladder dysfunction. The goal of this paper was to test the capability of the flavonoid galangin to protect pig urinary bladder from damage due to a period of repetitive field stimulation as well as a period of anoxia/glucopenia and reperfusion. Materials and methods: Smooth muscle strips of the pig bladder were mounted for tension recording in small organ baths and the strips submitted either 1.5 hours of repetitive field stimulation (RFS) at $32 \mathrm{~Hz}$ for 15 seconds every 5 minutes or under anoxia-glucopenia and reperfusion conditions. Galangin, at different concentration, was added to the reperfusion Krebs to check the effect of this flavonoid compared to untreated strips in the same conditions. A group of experiments was performed to examine tts possible underlying mechanisms. Results: One and half hours of RFS caused a progressive decrease in maximal contractile response to EFS ( $34 \%$ decrease). Galangin $\left(10^{-7} M\right)$ partially prevented the progressive decrease in contractile response. This effect was significantly reduced when verapamil was added to the solution. Galangin improved significantly the response of strips to electrical field stimulation submitted to a period of anoxia/glucopenia and reperfusion conditions, as compared to untreated tissues. Conclusion: Galangin has a protective effect on bladder contractility by an action that at least in part, depends on L-type calcium channels. Furthermore, galangin protects detrusor nerves against the anoxia-glucopenic and reperfusion damage. 


\section{Introduction}

Overactivity of the bladder adversely affects a significant proportion of the elderly population.

Concerning the basic mechanisms of bladder overactivity, there is increasing evidence that the generation of free radicals plays a role in the development of this pathology. Results of a previous study showed that repetitive fleld stimulation of smooth muscle strips isolated from urinary bladder could be used as a model for muscular fatigue (1). This model has been shown to produce exhaustion of synaptic stores of acetylcholine and direct neuronal damage leading to increased lipid peroxidation and impaired smooth muscle contractility in the ischemic and hypoxic media as well as In the normal physiological media (1). In that study, the extent of contractile impairment correlated with the level of lipid peroxidation, suggesting the involvement of oxidative stress in bladder smooth muscle dysfunction. Furthermore, periodic bladder ischaemia during obstructed micturition has been suggested to result in the partial denervation of the detrusor smooth muscle, through ischaemic and reperfusion injury to the post-ganglionic parasympathetic neurones within the bladder wall (2).

Galangin, a member of the flawonol class of flavonoids, is present in high concentrations in honey and Alpinia officinarum and has been demonstrated to possess several biological actions such as an anti-mutagenic (3) and radical scavenging activities (4). More recently, its inhibitory effect on rat bladder contractillty has been investigated (5).

The present study was conducted to investigate the effect of galangin on the contractile responses of Isolated pig bladder strips measured after a period of repetitive fleld stimulation and to examine the possible underlying mechanisms. Furthermore, we examined the efficacy of gallangin to counteract the damage suffered by neurones in urinary bladder strips exposed to anoxia/glucopenia and reperfusion. 


\section{Material and Methods}

\section{Tissue preparation}

Experiments were performed on pig urinary bladders obtained from the slaughterhouse approximately 30 minutes after slaughter. Strips of $2 \times 2 \mathrm{~cm}$ were dissected from the dorsal side of the bladder dome and transported to the laboratory in oxygenated Krebs solution (mM: $\mathrm{NaCl} 118$, $\mathrm{KCl}$ 5.6, $\mathrm{NaHCO}_{3} 25, \mathrm{NaH}_{2} \mathrm{PO}_{4} 1.3, \mathrm{CaCl} 2.5, \mathrm{MgSO}_{4} 1.2$, glucose 6.1, $\mathrm{pH} 7.4$ ). Between 1 and 2 strips were taken from each bladder. The mucosa and the submucosal fat layer were removed using a binocular microscope, and strips of $1 \mathrm{~mm}$ diameter and length between 3 and $5 \mathrm{~mm}$ were excised. To facilitate diffusion the thin layer covering the muscle fibre was opened and for the greater part removed. Care was taken that the muscle fibres were running longitudinally.

Each strip was mounted in a separate 20 -ml organ bath containing Krebs-buffer solution which was gassed continuously with $5 \% \mathrm{CO}_{2}-95 \% \mathrm{O}_{2}$, at $37^{\circ} \mathrm{C}$. An initial tension of $20 \mathrm{mN}$ was placed an each strip and the measurements were started after an equilibration period of $60 \mathrm{~min}$.

In order to decide which frequency of stimulation had to be used to optimally stimulate nerves $\mathrm{i}_{i}$ a frequency-response curve (5 s train pulses, $1 \mathrm{~ms}$ duration; $7.5 \mathrm{~V}$ voltage and $0.25-32 \mathrm{~Hz}$ frequency) was determined. The maximum contraction was observed at $32 \mathrm{~Hz}$. Accordingly; a frequency of $32 \mathrm{~Hz}$ was chosen during the entire experimental procedure. Tetrodotoxin $10^{-16} \mathrm{M}$ inhibited the response to $32 \mathrm{~Hz}$ by $83 \%$. Atropine at $10^{-6} \mathrm{M}$ only inhibited the response by $13 \%$. These results indicate the contractions were predominately neurogenic and due to the release of other kind of neurotransmitters different from acetylcholine from bladder ineurones at $32 \mathrm{~Hz}$.

Contractions were measured isometrically using mechanoelectrical transducers connected to the BAM4C amplifier (Scientific instruments, Heidelberg). The electrical field was generated between two platinum electrodes connected to the HM8130 Function Generator from Hameg@ Instruments. 
Under normal conditions, the Krebs solution was bubbled with $5 \% \mathrm{CO}_{2}-95 \% \mathrm{O}_{2}$, while under schaemic-like conditions, glucose was replaced isosmotically with $\mathrm{NaCl}$, the solution was gassed with $95 \% \mathrm{~N}_{2}, 5 \% \mathrm{CO}_{2}$. Oxygen tension in the organ baths was measured using a fine platinum oxygen electrode, previously calibrated in solutions of known oxygen tension. During the anoxia phase the oxygen tension in the solution of the organ bath dropped to $6.1 \pm 1 \mathrm{mmHg}$.

\section{Effect of galangin on detrusor contractility under normal conditions}

After 60-min equilibration period, detrusor strips were electrically stimulated at $32 \mathrm{~Hz}$, after which the strips were washed for up to $30 \mathrm{~min}$. Then, galangin at $10^{-6} \mathrm{M}, 5 \times 10^{-8} \mathrm{M}$ and $10^{-7} \mathrm{M}$ was added to the perfusing Krebs solution for a period of 90 and 210 min to reproduce the same time period of both repetitive stimulation and anoxia/glucopenia and reperfusion.

Effect of repetitive field stimulation on detrusor contractility

After the equilibration period, detrusor strips were stimulated at $32 \mathrm{~Hz}$ (single stimulus). Then, eight strlps were submitted to RFS for $90 \mathrm{~min}(5 \mathrm{~s}$ train pulses, $1 \mathrm{~ms}$ duration, $7.5 \mathrm{~V}, 32 \mathrm{~Hz}$; applied for $15 \mathrm{~s}$ every $5 \mathrm{~min}$ ). At the end of the period of repetitive stimulation, responses to EFS at $32 \mathrm{~Hz}$ (single stimuluis) were re-assessed in order to detect the effect of RFS on muscle contractility.

\section{Effect of galangin on detrusor contractility under repetitive field stimulation conditions}

After the equilibration time, detrusor strips were subjected to 90min of RFS. During this period, galangin at different concentration $\left(10^{-8} \mathrm{M}, 5 \times 10^{-8} \mathrm{M}\right.$ and $\left.10^{-7} \mathrm{M}\right)$ was added to the perfusion medium during the whole experiment. At the end of the repetitive stimulation period, muscle response of the strips was tested by the application of a single electrical stimulus. 
Effect of RFS in bladder strips in galangin medium after the administration in the bath of capsazepine, propranolol, phentolamine or verapami.

The effect of galangin at $10^{-7} \mathrm{M}$ (in this dose galangin had the strongest effect on muscle contractility) on responses to a single stimulus at $32 \mathrm{~Hz}$ was also evaluated after the administration in the bath (contact time of $30 \mathrm{~min}$ ) of propranolol $\left(10^{-6} \mathrm{M}\right)$ (to block beta-adrenergic receptors): capsazepine $\left(10^{-5} \mathrm{M}\right.$ ) (to block vaniloid receptors): phentolamine $\left(10^{-6} \mathrm{M}\right)$ (to block alfa-adrenergic receptors) and verapamil $\left(10^{-7} \mathrm{M}\right)$ (to block L-type calcium channels). Strips were equilibrated in these buffers for 30 minutes then a single electrical sfimulation was performed to check the effectiveness of the compounds. Then, galangin was added in those groups and, after 30 min of incubation and the response to EFS (single stimulus) has been checked, RFS was applled for 90 min. At the end of the period of repetitive stimulation, respanses to EFS (single stimulus) were reassessed to detect the effect of RFS on muscle contractility. The concentrations of the blockers were selected on the basis of previous work (6).

\section{Effect of ischaemia- and reperfusion-like conditions}

After the equilibration period, the tissue was subjected to electrical field stimulation every $15 \mathrm{~min}$ until the response was reproducible. Then "detrusor strips were subjected to 60 min of anoxia/glucopenia followed by $150 \mathrm{~min}$ of reperfuston. During this 210 -min period, intrinsic merves were stimulated electrically at $60 \mathrm{~min}$ and $210 \mathrm{~min}$. The response of the strips to electrical field stimulation was expressed as a percentagle of the initial response in Krebs solution, taken to be $100 \%$. Galangin, at different concentration, was added to the perfunsion medium during the ischaemic conditions and the first 30 min of reperfusion as it is supposed that the major damage to the tissue develops not only during ischaemia, but also when the oxygen reaches the tissue again. 


\section{Compounds}

Galangin, phenylephrine hydrochloride, propranolol hydrochloride, verapamil hydrochloride, tetrodotoxin, atropine and capsazepine were obtained from Sigma Chemical Co. All solutions were freshly prepared. Calangin as well as capsazepine were dissolved in dimethylsulfoxide (DMSO) and diluted in Krebs and others were dissolved and diluted in Krebs. The final concentration of DMSO in bathing solution was less than $0.05 \%$ and had no protective effect on the muscle contractility.

\section{Statistical evaluation}

Data are expressed as means \pm standard error of the mean, when appropriate. Statistical analyses were carried out using Student's t-test and one-way analysis of variance followed by Dunnett's test. A probability value of $p<0.05$ was regarded as significant. All analyses were performed using GraphPad Prism software.

\section{Results}

Effect of galangin on detrusar contractility under normal conditions

Preliminary experiments without repetitive stimulation in which isolated strips were incubated either in normal Krebs solution or in galangin solution showed no degradation of the contractile responses to EFS after a 3-hour incubation period (data are not shown). 
Effect of repetitive field stimulation on detrusor contractility

Repetitive stimulation for $1,5 \mathrm{~h}$ in the presence of normal Krebs solution reduced the amplitude of bladder strip contractions in response to EFS ( $E_{\text {priaxintilal }} 21.32 \pm 1.10 \mathrm{mN}_{\mathrm{i}} E_{\text {niaxaftierRFs }} 16.20 \pm$ $1.45 \mathrm{mN}$ ) (figure 1).

Effect of galanginon detrusor contractility under repetitive field stimulation conditions

The responses of detrusor muscle strips to EFS in the galangin-treated groups are shown in Fig. 1. Galangin at $10^{-7} \mathrm{M}$ concentration partially prevented significantly the RFS-induced muscle fatlgue, reaching $94.80 \pm 3.25 \%$, as compared to $64 \pm 2.65 \%$ of controll (RFS in saline medium) $(p<0.05)$. At $10^{-8} \mathrm{M}$ and $5 \times 10^{-8} \mathrm{M}$, they did not exert any significant protective effect on muscle contractility $(65.00 \pm 3.56 \%$ and $73.00 \pm 1.34 \%$, respectively) as compared to control (RFS in saline medium) ( $p$ $<0.05)$. 
Figure 1: Effect of $1.5 \mathrm{~h}$ repettive stimulation on the contractile responses to EFS ( $32 \mathrm{~Hz}$ ) in different media. Each bar represents the average normalized percentages for 6 - 8 strips. * Significantly lower than the initial maximal response $(\rho<0.05)$

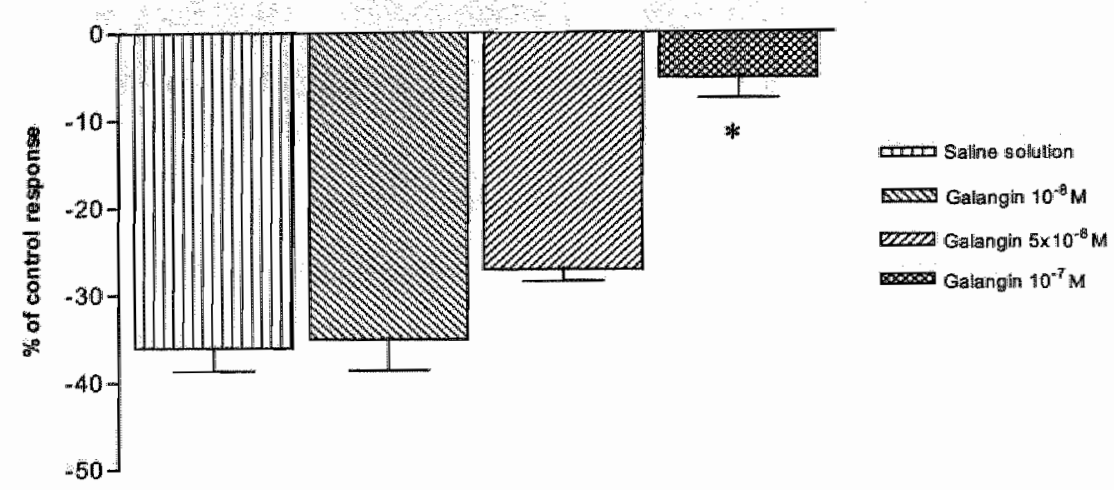

Effect of RFS in bladder strips in galangin medium after the administration in the bath of capsazepine, propranolol, phentolamine or verapamil.

The effect of galangin in the EFS-induced contractions after repetitive stimulation was unaffected by a combination with propranolol, capsazepine and phentolamine (table 1). However, the effects of galangin were partially abolished when verapamil was added to the organ bath ( $E_{\text {maxwerapamil }} 20.13 \pm$

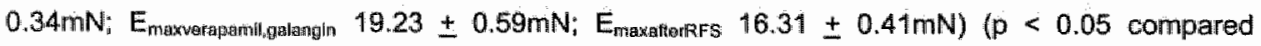
$E_{\text {maxwerapanili, galengin }}$ to $E_{\text {maxixafterlRFs }}$ 


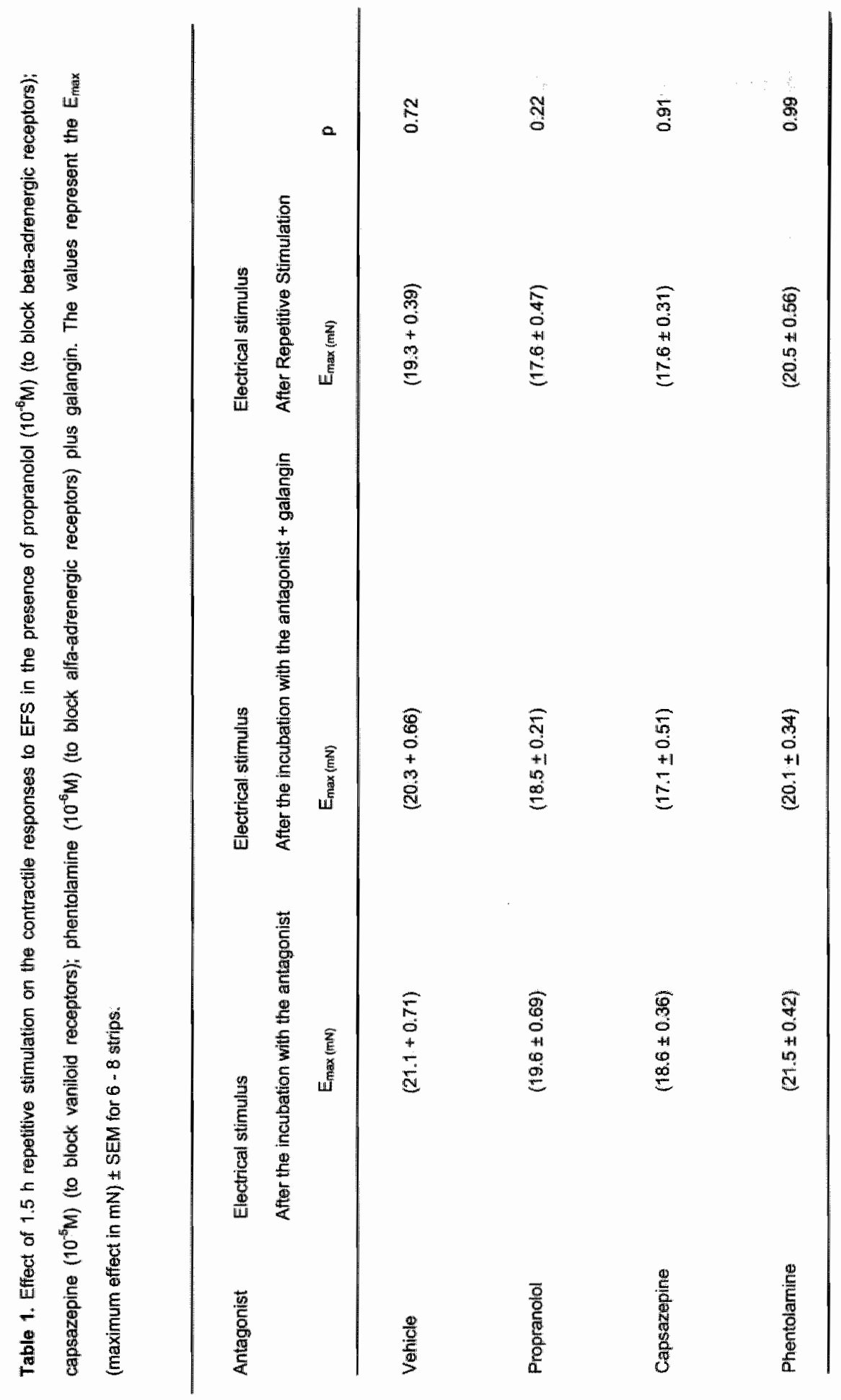


Effect of ischaemia- and reperfusion-like conditions

The response to electrical field stimulation declined in the combined absence of oxygen and substrate, reaching $25 \%$ of the initial response whithin an hour, in Krebs solution medium. After reintroduction of normal conditions, the recovery of the response to electrical field stimulation was poor, reaching a maximum of about $26 \%$ of the initial response in $2 \mathrm{~h}$ (figure 2 ) .

Galangin at $10^{7} \mathrm{M}$ concentration Improved significantly the electrical field stimulation-induced contractile response both in anoxia/glucopenia and in reperfusion phase, reaching $33 \% \pm 3.02 \%$ at $60 \mathrm{~min}$ and $64 \% \pm 4.1 \%$ at $210 \mathrm{~min}\left(\mathrm{p}<0.05\right.$ compared to non-treated group). At $10^{-8}$ and $5 \times 10^{-8} \mathrm{M}$ there was not any significanily effect compared to non-treated group.

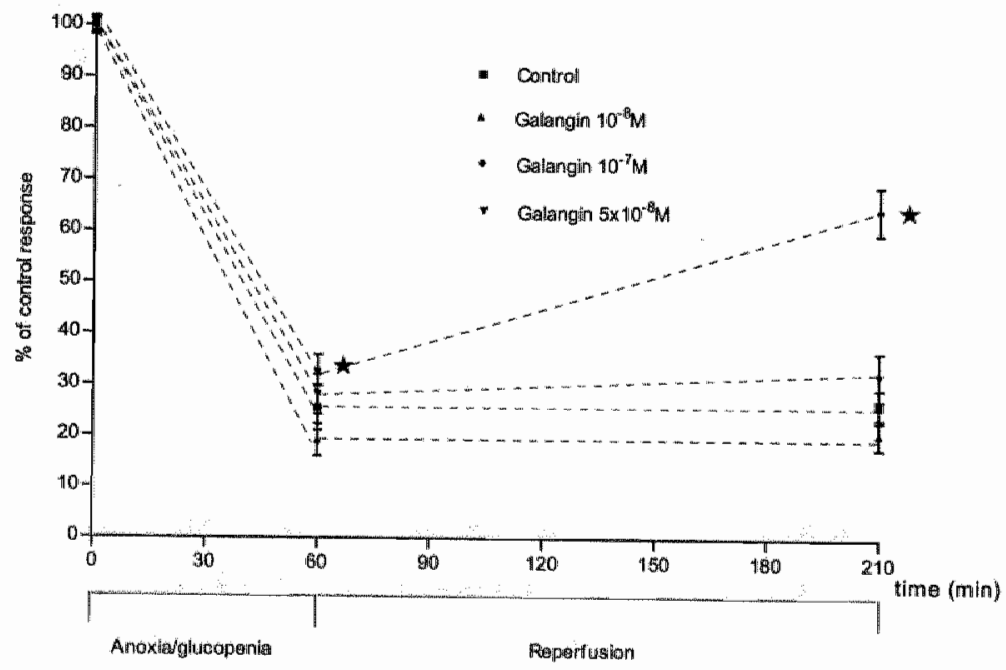

\section{Discussion}

There is increasing evidence that flavonoids have beneficial effects and therefore can be used for treatment and prevention of specific diseases related to reactive oxygen species damage $(7)$. In 
view of their many repiorted biological actions, we studied the effects of the flawonoid galangin on pig detrusor contractility after a period of repetitive stimulation.

The possible role of oxidative stress in the pathophysiology of bladder dysfunction has not been clarified. Recent studies suggested that the urinary bladder might undergo cyolical ischemia reperfusion during overdistension or increased pressures due to outlet obstruction, which in turn may lead to oxidative stress and the injury by free radical (8). Results of previous studies showed that repetitive field stimulation of smooth muscle strips isolated from the urinary bladder can lead to exhaust ion of the synaptic stores of acetylcholline and to direct neuronal damage that does not reverse upon cessation of the repetitive stimulation (1). These studies demonstrated that repetitive stimulation caused in a significant increase in the accumulation of malondialdehyde (MDA) within the smooth muscle membrane components of the bladdler strips, and that both the MDA concentration and level of contractile dysfunction are directly related to the calcium concentration (9). Two recent studies demonstrated that dangerously elevated levels of cytosolic $\mathrm{Ca}^{2+}$ concentration, or $\mathrm{Ca}^{2+}$ overload, and iron-overload occur during ischemla-repenfusion in cardiac myocytes $(10,11)$. These studies indicated that the permeation of these ions occur likely through the $\mathrm{L}$-type voltage-dependent $\mathrm{Ca}^{2+}$ channel as well as rapid reactivation of $\mathrm{Na}^{*} / \mathrm{Ca}^{2+}$ exchanger. Therefore, it can be suggested that radical scavengers capable of limiting the $\mathrm{Ca}^{2 *}$ influx into the cells might be used as an effective drugs for the prevention of tissue damage by ischemiareperfusion injury.

The current study is consistent with other studies and has shown that repetitive stimulation in the presence of a normal physiological solution results in a decrease of the contractile responses of the bladder smooth muscle to EFS (1). We have also demonstrated that, at low concentration, galangin is capable of avoiding the decrease of smooth muscle contraction after a period of repetitive stimulation. Furthermore, galangin at $10^{-7} \mathrm{M}$ concentration protected effectively urinary bladder strips undergoing anoxila/glucopenia-reperfusion damage. The mechanism(s) by which galangin protects the detrusor muscle nerves from repetitive field stimulation and anoxla/glucopenia and reperfusion injuries is only a matter of speculation. Based on our study it is possible to exclude the involvement of adrenergic receptors, as propranolol and phentolamine did not modify the effect of galangin. Also 
vanilloid receptors were proven to be not inwolved, as the vanilloid receptor antagonist capsazepine did not influence galangin-induced protective effect on bladder contractile response. However, the fact that the effect of galangin was blocked when tested after verapamil, a L-type calcium channels blocker, suggests that the role of this flavonoid could involve L-type calcium channels. Moreover, we have previously demonstrated that galangin exhibits significant antiperoxidant activity ( $\left(\mathrm{C}_{50}\right.$ value of $\left.1.7+0.12 \times 10^{-6} \mathrm{M}\right)(12)$. We can hypothesize that its antioxidlant activity is important for the neuroprotection afforded on pig detrusor strips subjected to anoxia/glucopenia and reperfusion.

In conclusion ${ }$ galangin is a natural flavonoid exerting protective effects on bladder contractility. Although it remains to be elucidated, outlined in the present investigation, we suggest that the antioxidant compound, galangin, acts on L-type calcium channels and might have a possible role in treating bladder dysfunction.

\section{References}

1. Ohnishi N, Liu SP, Horan P, et al: Effect of repetitive stimulation on the contractile response of rabbit urinary biladder subjected to in vitro hypoxia or in vitro ischemia followed by reoxygenation. Pharmacology 57:139-147, 1998.

2. Brading AF: Alternations in the physiological properties of urinary bladdler smooth muscle by bladder emptying against an obstruction. J Urol 184:51-8, 1997.

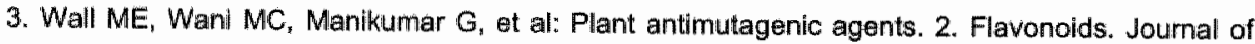
Naturail Praducts 51(6):1084-1091, 1988.

4. Imamura $Y$, Migita $T$, Uriu $Y$, et al:: Inhibitory effects of flavonoids on rabbit heart carbonyl reductase. Journal of Biochemistry 127(4): 653-658, 2000 .

5. Capasso $R$, and Tavares I: Effect of the flawonoid galangin on urinary bladder rat contractility invitro. Joumal of Pharmacy and Pharmacology 54:1147-1150, 2002.

6. Capasso R, Borrelli F, Capasso F, et al: Inhibitory effect of the antidepressant ST. John's wort (Hypericum perforatum) on rat bladder contractility in vitro. Urology 64(1):168-172, 2004. 
7. Tokalov SV, Kind B, Wollenweber R, et al: Biological effects of epicuticular flavonoids from Primula denticulata on human leukemia cells. J Agric Food Chem 52(2): 239-245, 2004.

8. Zhao Y, Levin SS , Wein AJ, et al: Correlation of ischemia/reperfusion or partial outlet obstructioninduced spectrin proteolysis by calpain with contractile dysfunction in rabbit bladder. Urology 49:293-300, 1997.

9. Levin RM, Leggett $R$, Whitbeck $C$, et al: Effect of calcium and calcium chelators on the response of the bladder to in vitro ischemia. Br J Urol 82:882-887, 1998,

10. Oudit GY, Sun $H$, Trivieri $M G$, et al: L-type Ca2+ channels provide a major pathway for iron entry into cardiomyocytes in iron-overload cardiomyopathy. Nature Medicine 9(9): 1187-1194, 2003. 11. Eigel $B N$, Gursahani $H$. Hadley RW: ROS are required for rapid reactivation of Na+/Ca2+ exchanger in hypoxic reoxygenated guinea pig ventricular myocytes. Am J Physiol 286:H955-H963, 2004.

12. van Acker S, van Den Berg DJ, Tromp M, ef al: Structural aspects of antioxidant activity of flawonoids. Free Radical Biology \& Medicine 20(3): 331-342, 1996. 


\section{Chapter VI}

Multiple-signaling pathways are involved in the inhibitory effects of galangin on urinary bladder contractility

Miriam Dambros, Rik de Jongh, Gommert van Koeveringe, Marjanka van Deutekom, Jo G de Mey, Philip van Kerrebroeck.

Neurourol Urodyn 24(4):369-73, 2005 


\section{Multiple-signaling pathways are Involved in the inhibitory effects of galangin on urinary bladder contractility}

\section{Abstract}

Purpose: Flavonoids comprise a large group of natural polyphenolic compounds, which possess a wide spectrum of physiological and pharmacological effects. Recently, the flavonoid galangin was found to modulate smooth muscle contractility. The aim of the present study was to investigate the mechanism of actions of galangin on pig bladder smooth muscle and to characterize its potential as an alternative inhibitor of bladder smooth muscle contraction.

Materials and Methods: Strips of pig detrusor muscle were mounted in separate 6-ml organ baths containing Krebs solution. The contractile response to carbachol $\left(10^{-8}-10^{-4} \mathrm{M}\right)$, potassium $\left(2 \times 10^{-2}-\right.$ $\left.10^{-8} \mathrm{M}\right)$ and electrical field stimulation - EFS $(2-32 \mathrm{~Hz})$ were determined before and after the addition of galangin $\left(3 \times 10^{-5} \mathrm{M}\right)$. The contractile responses to carbachol in calclum-free Krebs' solution plus EGTA and L-type channel blocker were determined in the absence and presence of the flavonoid. Furthermore, the effect of galangin was also evaluated after the administration in the bath of a number of antagonists/inhibitors including a combination of propranoliol, phentolamine, capsazepine and verapamil. Student's $t$ - test and one factor ANOVA were used to determine the statistical significance of the effects.

Results: Galangin inhibited the maximal contractile response to carbachol and potassium by $57.41 \%(p<0.01)$ and $33.52 \%(p<0.05)$, respectively. The maximum force of the carbachol-evoked contractions, in calcium-free solution after incubation with galangin was $32 \%$ of the maximum initial force $\left(E_{\max \text { tnitial. }}: 5.8387 \pm 0.72 \mathrm{mN} E_{\max \text { Galangin: }}: 1.9157 \pm 0.30 \mathrm{mN}, p<0.01\right)$. The maximal contractile responses to EFS at $2,4,8,16$ and $32 \mathrm{~Hz}$ were reduced, compared to control, by $91.61 \%(\mathrm{p}<0.01)$, $79.46 \%(p<0.01), 70.54 \%(p<0.01), 61.10 \%(p<0.01)$ and $9.8 \%(p>0.05)$, respectively. The inhibitory effect of galangin was unaffected by a combination of propranolol, phentolamine and capsazepine 
$(p>0,05)$. However, when verapamil was added to the medium, the inhibitory effects of galangin were partially blocked.

Conclusion: Galangin, at high concentrations, exerts an inhibitory effect on pig bladder smooth muscie contractility through the inhibition of calcium influx and the modulation of intracellular calcium movement. Furthermore, we have demonstrated that the inhibitory effect of galangin involver, at least in part, L-type calcium channels pathways.

\section{Introduction}

Flavonoids represent a wide group of polyphenolic compounds with different structural, chemical and pharmacological properties. These natural products possess a wide spectrum of physiological and pharmacological effects such as inhibitory effects on both intestinal and arterial smooth muscle [Gharzouli $\mathrm{K}$ and Holzer $2004 ;$ Ajay, 2003]. They are not equally physiologically active "presumably because of differences in lipid solubility and in the presence of different substitutions on the carbon atoms of the basic skeleton [van Acker et al., 1996]. Their pharmacological effects can be explained by their inhibition of certain enzymes and their antioxidant activity. Despite the large amount of data available on the various effects of flavonoids, little is known about the effect of flavonoids on bladder smooth muscle.

Galangin, a member of the flavonol class of the flawonoids, is present in high concentrations in honey, allphia officinarum and in propolis, which is a resinous material made by bees [Park at al., 1995]. As most flavonoids, galangin has several biological effects and affects the behaviour of many cell systems [Di Carlo et al., 1999; Rezende et al., 2004]. Besides its anti-oxidant, antimutagenic and anti-tumor effects, galangin has also relaxation effects on the contractility of smooth muscle cells in a concentration-dependent manner [Rezende et al., 2004; Capasso and Tavares 2002]. A recent study demonstrated that galangin inhibited the contractile response of rat detrusor muscle to electrical field stimulation without modifying the contractions produced by exogenous acetylcholine. The response to electrical stimulation was almost completely abolished by 
fetrodotoxin, which blocks presynaptic activation and neurotransmitter release. From this the authors concluded that the mode of action of galangin on detrusor smooth muscle contraction was due to a presynaptic mechanism [Capasso and Tavares, 2002]. The present study was undertaken to further examine the actions of galangin on the contractile responses of isolated bladder strips and to test the hypothesis that an effect on calcium mobilization in smooth muscle cells is involved.

\section{Material and Methods}

Tissue preparation

Experiments were performed on plg urinary bladders obtained from the slaughterhouse approximately 30 minutes after siaughter. Strips of $2 \times 2 \mathrm{~cm}$ were taken from the dorsal side of the bladder dome and transported to the laboratory in oxygenated Krebs solution $\left(\mathrm{NaCl} 118 \mathrm{mM}_{\mathrm{i}} \mathrm{KCCl}\right.$ $5.6 \mathrm{mM} ; \mathrm{NaHCO}_{3} 25 \mathrm{mM} ; \mathrm{KH}_{2} \mathrm{PO}_{4} 1.2 \mathrm{mM}_{*} \mathrm{CaCl} 2.5 \mathrm{mM} ; \mathrm{MgSO}_{4} 1.2 \mathrm{mM}$; glucose $6.1 \mathrm{mM} ; \mathrm{pH} 7.4 ;$ aerated with $95 \% \mathrm{O}_{2} / 5 \% \mathrm{CO}_{2}$ ). The mucosal layer and connective tissue were removed using a binocular microscope, and strips with a width of $0.5 \mathrm{~mm}$ and a length between 5 and $7 \mathrm{~mm}$ were excised. To facilitate diffusion the thin layer covering the muscle fibre was opened and for the greater part removed. Care was taken that the muscle fibres were running longituidinally.

Each strip was mounted in a separate 6-ml organ bath containing Krebs-buffer solution which was gassed continuously with $5 \% \quad \mathrm{CO}_{2}-95 \% \mathrm{O}_{2}$, at $37^{\circ} \mathrm{C}$. Contractions were measured using an isometric force transducer (Kistler Morce DSC 6, Seattle, WA) and stored digitally. Measurements were started after an equilibration period of $60 \mathrm{~min}$ with 4 intermediate changes of buffer solution. An initial tension of $20 \mathrm{mN}$ was placed on each strip.

\section{Compounds}

Galangin, carbachol, potassium chloride, phenylephrine hydrochloride, atropine sulphate, propranolal hydrochloride, werapamil hydrochloride, capsazepine and tetrodotoxin (TTX) were 
obtained from Sigma Chemical Co. (Netherlands). All solutions were freshly prepared. Galangin as well as capsazepine were prepared by first dissolving the solid in dimethylsulfoxide (DMSO) and diluted in Krebs. Nifedipine was dissolved in ethanol and then diluted in Krebs. The other agents were dissolved and diluted in Krebs. The final cancentration of DMSO in the bathing solution was less than $0.05 \%$. Carbachol was made up in $\mathrm{Krebs}^{7}$ solution and in calcium free solution. The $\mathrm{Ca}^{2+}$. free medium was made without $\mathrm{CaCl}_{2}$ and with addition of ethylene glycol-bis (8-aminoethyl ether)$N_{s} N_{s} N$ N $N$-tetraacetic acid (EGTA) at $10^{-15} \mathrm{M}$.

\section{Experimental protocoll}

Effect of galangin on electrical fleld-evoked responses

After a 1-hour equilibration period, the strips were subjected to electrical field stimulation (EFS) at 2, $4,8,16$ and $32 \mathrm{~Hz}$ stimulation in the absent and presence of galangin $3 \times 10^{-5} \mathrm{M}$ (incubation time of $30 \mathrm{~min})$. The electrical field was generated between two platinum electrodes connected to the HM8130 Function Generator from Hameg(e) instruments $(85 \mathrm{~mA}, 2 \mathrm{msec}$ pulse width, applled for $10 \mathrm{~s})$.

In a preliminary study, galangin $\left(10^{-7}-10^{-4} \mathrm{M}\right)$ decreased the amplitude of the EFS $\left[1 \mathrm{C}_{50} 0^{-4} 4.1 \times 10^{-6} \mathrm{M}\right.$ $\left.\left(1.9 \times 10^{-6}-8.9 \times 10^{-6} \mathrm{M}\right)\right]_{-}$-evoked contractions in a concentration-dependent manner. Based on this concentration response curve to galangin we have chosen the concentration of $3 \times 10^{-5} \mathrm{M}$ to be used in further experiments.

The effects of tetrodotoxin (to ellminate neurogenic contractions) $10^{-6} \mathrm{M}$ (contact time 10 minutes) and atropine (to determine the purinergic component of nerve stimulation) $10^{-6} \mathrm{M}$ (contact time 10min) on EFS-induced contractions were evaluated. 
Effect of galangin on potassium-evoked responses

To determine the effect of galangin on contractile response to potassium, a control contractle response curve was obtained to potassium $\left(2 \times 10^{2}-10^{-1} \mathrm{M}\right)$ and then repeated after the strips were exposed to galangin $\left(3 \times 10^{-5} \mathrm{M}\right)$ Krebs' solution for 30 min.

Effect of galangin and nifedipine on carbachol-evoked responses in normal calcium solution and calcium-free Krebs' medium.

A cumulative concentration response curve to carbachol in normal Krebs' solution $\left(10^{-8}-10^{-4} \mathrm{M}\right)$ ) was determined. Responses were then repeated in the presence of galangin $3 \times 10^{-5} \mathrm{M}$.

To determine the effect of galangin on intracellular calcium release, carbachol $10^{-5} \mathrm{M}$-evoked contractile responses were determined in calcium-free Krebs' solution. Control contractile responses to carbachol were obtained in normal Kreb's solution and then in $\mathrm{Ca}^{2+}$-free Krebs" solution. After the contractile response to be determined in $\mathrm{Ca}^{2+}$-free medium, the bladder strips were reincubated in normal Krelbs' solution for $20 \mathrm{~min}$ in order to refill the intracellular calcium stores. Then, the strips were incubated with elther nifedipine $10^{-8} \mathrm{M}$ alone or with nifedipine plus gallangin for $30 \mathrm{~min}$ before being stimulated again with carbachol in calclum-free medium.

Effects of EFS-induced contractions in bladder strips in galangin medium after the administration in the bath of capsazepine, propranolol, phentolamine and verapamil.

The effect of galangin at $3 \times 10^{-5} \mathrm{M}$ on responses to electrical stimulation $(16 \mathrm{~Hz}, 2 \mathrm{~ms}, 85 \mathrm{~mA})$ was also evaluated after the administration in the bath (contact time of $30 \mathrm{~min}$ ) of propranolol $\left(10^{-6} \mathrm{M}\right)$ (to

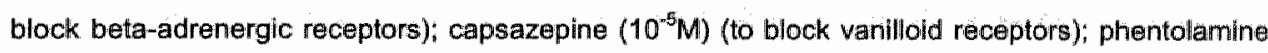
$\left(10^{-6} \mathrm{M}\right)$ (to block alfa-adrenergic receptors) and werapamil $\left(10^{-7} \mathrm{M}\right)($ to block L-type calcium channels). Strips were equilibrated in these buffers for 30 minutes then ellectrical stimulation was performed to check the effectiveness of the compounds. The incubation medium was changed and 
galangin was added in those groups (contact time of 30 min) then contraction was induced by electrical field stimulation. The concentrations of the blockers were selected on the basis of previous work (9).

\section{Statistical evaluation}

Concentration-response data of carbachal and potassium chloride were evaluated by sigmoid curve fitting and $-\log \mathrm{EC}_{50}$ values $\left(\mathrm{pD}_{2}\right)$ and the maximal effect $\left(\mathrm{E}_{\max }\right)$ were calculated from individual values by non-linear regression analysis using GraphPad Prism. Differences between mean values were statistically analysed using Student's t-test and one-way analysis of variance followed by Dunnett's test. A probability value of $p<0,05$ was regarded as significant. All analyses were performed using GraphPad Prism software.

\section{Results}

Effects of vehicle control

The vehicles control for galangin and capsazepine, DMSO (0.05\%) and for nifedipine, ethanol $(0.2 \%)$, had no effect on the muscle contractility (data not shown).

\section{Effect of galangin on EFS-ovoked responses}

When stimulated with EFS the detrusar strips contracted with a maximal force, at $2,4,8,16$ and $32 \mathrm{~Hz}$, of $1.31 \pm 0.55,5.34 \pm 1.87,9.16 \pm 2.32,17.91 \pm 4.89$ and $32.28 \pm 5.85 \mathrm{mN}$, respectively. Incubation with galangin reduced the maximal contractile response to EFS at $2,4,8,16$ and $32 \mathrm{~Hz}$ compared to control to $9.16 \% \pm 0.0(p<0.01), 20.56 \% \pm 0.0(p<0.01), 29.47 \% \pm 1.0(p<0.01)$. $38.86 \% \pm 1.6(p<0.01), 90.79 \% \pm 2.9(p>0.05)$, respectively. 
Electrical stimulation of the pig bladder strips gave a contractile response that was totally abolished by tetrodotoxin $\left(10^{-6} \mathrm{M}\right)$ at 2,4 and $8 \mathrm{~Hz}$ and partially abolished at 16 and $32 \mathrm{~Hz}$ (by $90 \%$ ). When atropine $\left(10^{-6} \mathrm{M}\right)$ was added to the nedium, the contractions induced by EFS were totally abolished at 2,4 and $8 \mathrm{~Hz}$ and partially affected at 16 and $32 \mathrm{~Hz}$ (the contractions decreased to 39.1 and $87 \%$, respectively). These results indicate the contractions were predominately neurogenic and due to the release of acetylcholine at $2,4,8$ and $16 \mathrm{~Hz}$ and due to the release of purines from bladder neurones at $32 \mathrm{~Hz}$ (Fig. 1).

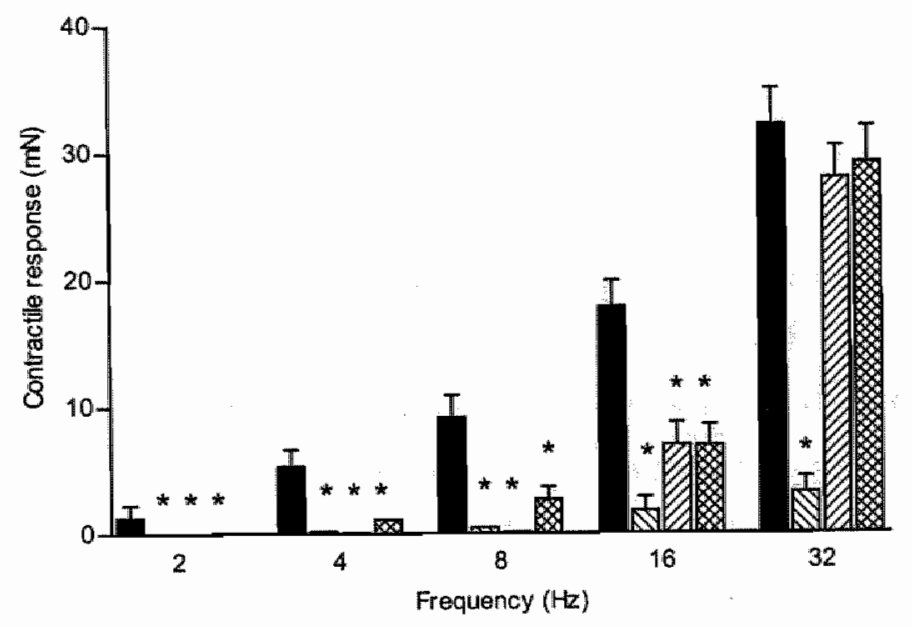

EFS EFS, tetrodotox in 2000 EFS, atropine EFs, galangin

Figure 1. Effect of galangin $\left(3 \times 10^{-5} \mathrm{M}\right)$ on the contractile response of pig detrusor muscle to electrical field stimulation at $2,4,8,16$ and $32 \mathrm{~Hz}$. Each bar is the meen \pm SEM (in mN) of 6-8 bladder strips. " $p<0.05$ versus controll response. 
In the presence of galangin $\left(30 \times 10^{-5} \mathrm{M}\right)$ the maximal contractile response to carbachol was reduced by $57.41 \%$ ( $\left.E_{\text {maxintial }} 21.48 \pm 1.23 E_{\text {max gallangin: }} 9.147 \pm 0.41 \mathrm{mN}\right)$. The $\mathrm{pD}_{2}$ values of control contraction and in the presence of galangin were $6.35 \pm 0.05$ and $5.83 \pm 0.06$, respectively $(p<0,05)$

Effect of galangin and nifedipine on carbachol-induced contractions in calcium-free medium.

The contractile response to cabachol in calcium-free Krebs' solution was inhilited by $72.86 \% \pm$ 2.12 ( $p<0.001)$ compared to control response in normal Krebs' solution. A lower concentration of nifedipine $\left(10^{-8} \mathrm{M}\right)$ was used to reduce the possibility of non-specific effects, and a shorter incubation period was used to minimize loss of calcium from intracellular stores. The addition of nifedipine to calcium-free solution had no additional inhibitory effect on the contractile response to carbachol, indicating that the residual contraction was due to mobilization of calcium from intracellular stores. When gallangin was added together with nifedipine, the contractile response to carbachol was reduced to $32.76 \% \pm 1.8$ of the control response (contraction induced by carbachol in calcium-free solution) $(p<0,001)$ (Fig. 2) 


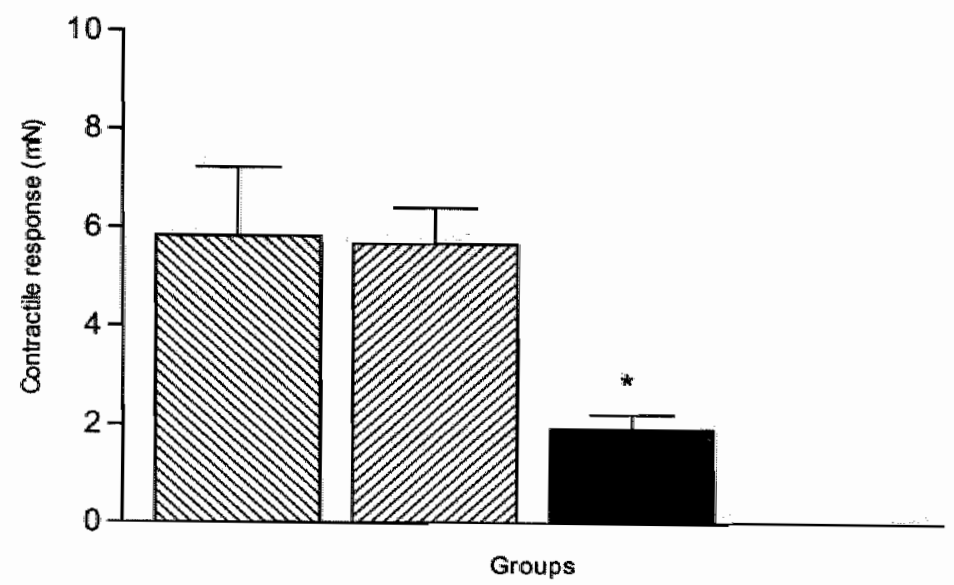

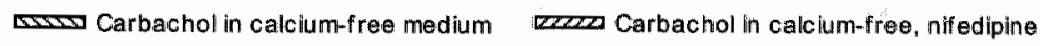

Carbachol in calcium-free, nifedipine, gatang in

Figure 2. Inhibitory effect of galangin $\left(3 \times 10^{-5} \mathrm{M}\right)$ on carbachol $\left(10^{-5} \mathrm{M}\right)$-evoked contractions in calcium free solution plus EGTA and nifedipine $\left(10^{-8} \mathrm{M}\right)$ in the pig urinary bladder. These results are expressed as mean maximum force $\pm S E M\left(\right.$ in $m N$ ) of $6-8$ strips. ${ }^{*} \mathrm{p}<0.05$ versus carbachal in $\mathrm{Ca}^{2+}$ free solution.

Effect of galangin on potassium-evoked responses

The addition of galangin to the medium reduced the contractile response to potassium significantly. The maximal contractile response was inhibited by $33.52 \%\left(E_{\text {riaxintilial: }}: 26.16 \pm 2.09 \mathrm{mN} \mathbb{E}_{\text {max galangln: }}\right.$ : $17.39 \pm 0.34 \mathrm{mN})(p<0.05)$. The $\mathrm{pD}_{2}$ values of control contraction and in the presence of galangin were $1.68 \pm 0.18$ and $1.49 \pm 0.01$, respectively $(p>0.05)$ 
Effects of galangin on bladder strip contraction in response to EFS $(16 \mathrm{~Hz})$ in galangin medium after the administration in the bath of capsazepine, phentolamine, propranolol and verapami.

Bladder contractions induced by EFS were nat significantly modified by capsazepine, phentolamine and propranolol $(p>0.3)$. Contractions induced by EFS were partially affected by verapamil (contractile response decreased to $79 \% \pm 2.1$ ). Inhibitory effects of galangin on the EFS-evolked contractions were unaffected by a combination of propranolol, capsazepine and phentolamine but significantly reduced by verapamil (Fig. 3 ).

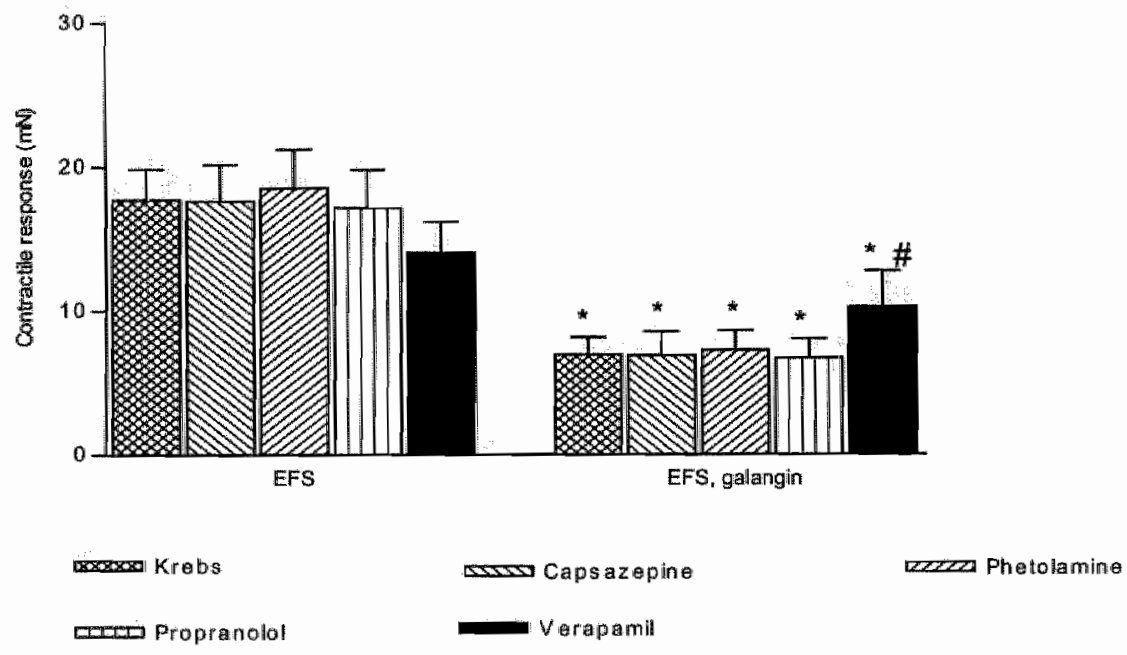

Figure 3. Electrical field stimulation (16)Hz)-induced contractions in isolated pig bladder; effect of galangin $\left(3 \times 40^{-4} \mathrm{M}\right)$ in Krebs'solution and in presence of vanilloid receptor antagonist capsazepine $\left(10^{-5} \mathrm{M}\right)$, betaadrenergic nerves blocker propranolol $\left(10^{-6} \mathrm{M}\right)$, alfa-adrenergic nerves blocker phentolamine $\left(10^{-6} \mathrm{M}\right)$ and L-type calcium channel blocker verapamil $\left(10^{-7} \mathrm{M}\right)$. Each bar represents imean of 6-8 strips. Vertical lines show SEM. " $P<0.01$ versus corresponding control, \# $p<0.05$ versus EFS plus galangin in Krebs' medium. 


\section{Discussion}

Flavonolids are a large heterogenic group of benzo-\%pyron derivates, which are abundantly present in our diet, e.g. in fruits and vegetables. Positive health effects of these compounds have been described in several diseases, such as pulmonary and cardiovascular diseases as well as cancer [Hertog et al., 1993].

Some flavonoids induce a bimodal effect on vascular tissuie, with a potentiation of the muscle contraction at concentrations lower than $1 \mu \mathrm{mol} / \mathrm{h}$, while at higher concentrations $(>1 \mu$ mol$/)$ their effect on smooth muscle relaxation prevails [Fusi et al., 2003]. It should be noted that high doses of flavonoids are used as food supplements and can reach micromolar concentrations in human blood. In addition, clinical trials are planned in which flavonoids are injected intravenously, thus reaching even higher concentrations in the blood.

The pharmacological analysis of drug effects on smooth muscle contractility is complicated by the multiplicity of sites at which drugs can interfere with the neural and muscular effector systems of contractility. Recently, a study suggested that the inhibition of the detrusor smoath muscle contraction due to a pre-synaptic site by the flavonoid galangin was the primary mode of action of this compound in the detrusor muscle of the rat [Capasso and Tavares, 2002]. However, studies have demonstrated that flavonoids induce smooth muscle relaxation by inhibiting of extraceillular $\mathrm{Ca}^{2 *}$ influx [Yu-Wen et al., 2003] as well as inhibition of $\mathrm{Ca} 2+$ release from intracellular store [Li et al., 2004]. Based on that and in the knowledge that the most important pathway to elicit a contraction of urinary bladder smooth muscle is via muscarinic receptors and an elevation of intracellular $\mathrm{Ca}^{2+}$ concentrations, which can irvolve both mobilization from intracellular stores and influx from the extracellular space [Andersson, 1993], we hypothesised that galangin had effects on calcium mobilization during detrusor contraction.

The overall aim of this in vitro study was to examine the influence of galangin on pig smooth muscle bladder contractility. Moreover, we tried to define the site of the flavonoid action with pharmacological agents known to interfere with certain transmission relays in the detrusor pathways of contractility. 
We have demonstrated that galangin has an inhibitory action on the contractile response of pig detrusor muscle strips to EFS. Galangin preferentially inthibited the contractille responses elicited by EFS at $2,4,8$ and $16 \mathrm{~Hz}$, which are mediated by the release of acetylcholine. However, the effect of galangin on smooth muscle was not specific for EFS, the compound also inhibited the contractions induced by exogenous carbachol and potassium.

Potassium induces detrusor muscle contraction by opening L-type $\mathrm{Ca} 2+$ channels in the sarcolemma [Laptifpour et al., 1992]. The inhibition of potassium-simulated contractile responses by galangin suggested that galangin has an inhibitory effect on excitation-coupling mechanisms and may inhibit calcium influx through volltage-sensitive calcium channels. However, the inhibition by galangin of the contractions induced by electrical stimuli and carbachol was greater than the inhibition of the peak contractile responses to membrane depolarising potassium that is dependent solely on extracellular calcium entry, suggesting that galangin was active on additional mechanisms independent of sarcolemmal calcium entry.

The most important pathway to ellicit a contraction of urinary bladder smooth muscle is via muscarinic -receptors [Anderssoin, 1993]. The contractile response to the exogenous agonist carbachol has been attributed predominantly if not exclusively to $\mathrm{M}_{3}$ receptors in pigs [Yamanishi et al., 2000]. Additionally, $\mathrm{M}_{3}$ receptor stimulation typically results in elevation of intracellular $\mathrm{Ca}^{2+}$ concentrations, which can involve both mobilization from intracellular stores and inffux from the extracellular space. The greater susceptibility of carbachol-stimulated contractile response to galangin compared to membrane depolarising potassium suggests that there might be an inhibitory action of galangin on intracellular calcium release, in addition to an inhibition of extracellular calcium entry. The effect of the nominally $\mathrm{Ca}^{2 *}$-free external solution on carbachol-induced contractions are a good way to characterize the source of $\mathrm{Ca}^{2+4}$ release involved in the responses to carbachal [Sugita et al., 1998]. Thus, we added nifedipline to remove the calcium entry component and those responses were not inhibited further by this calcium entry blocker, indicating that the residual contractile activity in these experiments was due to mobilization of intracellular calcium stores. Together, the data are suggestive of actions of galangin to inhibit both calcium entry and release of internal calcium stores. 
In order to further characterise the mode of action of galangin we performed a series of experiments with antagonists or inhibitors of a number of receptors and ion channels that are known to be involved in bladder contractility. Our findings enable us to exclude a number of factors as potential contributory mechanisms involved in the effects of galangin. In particular, we can exclude the involvement of adrenergic receptors, as propranolol and phentolamine did not modify the effect of gallangin. We can also exclude the involvement of vanilloid receptors, as the vanilloid receptor antagonist capsazepine did not influence galangin-induced inhibitory effect on bladder contractile response. The fact that the effect of galangin was partially eliminated when tested during treatment with verapamil, a L-type calcium channel blocker, suggests that the role of this flavonoid could involve those channels. However " werapamil did not completely counteract the effect of the flavonoid, thus, it suggests the involvement of a L-type calcium channel independent pathway.

In summary, the current experiments have shown that galangin inhibits pig bladder contractillty. which probably resulted from an action on $\mathrm{Ca}^{2+}$ mobilization from intracellular stores as well as influx of calcium.

At the present, there is no proof that our results are reproducible in functional or dysfunctional human bladders. Further study is needed to investigate the potential of galangin to be used to inhibited detrusor overactivity in vivo.

\section{References}

Ajay M, Gilani AH, Mustafa MR. 2003. Effects of flavonoids on vascular smooth muscle of the isolated rat thoracic aorta. Life Sciences 74:603-612.

Andersson KE. 1993. Pharmacology of lower urinary tract smooth muscles and penile erectile tissues. Pharmacol Rev 45:253-308.

Capasso $R$ and Tavares I. 2002. Effect of the flavonold galangin on urinary bladder rat contractllity in-vitro. JPP 54:1147-1150.

Di Carlo G, Mascolo N, Izzo AA et al. 1999. Minireview, Flavonoids: old and new aspects of a class of naturall therapeutic drugs. Life Sci $65: 337-53$. 
Gharzoull $K$ and Holzer P. 2004. Inhibition of Guinea Pig intestinal peristalsis by the flavonoids quercetin, naringenin, apigenin and genistein. Pharmacology 70:5-14.

Hertog MGL, Feskens EJM, Hollinan PCH et al. 1993. Dietary antioxidant flavonoids and risk of coronary theart disease: the Zutphen elderly study. Lancet 342:1007-1011.

Fusl F, Saponara $S$, Frosini $M$ et al: 2003. L-type Ca2+ channels activation and contraction elicited by myricetin on vascular smooth muscles. Naunyn-Schmiedeberg's Arch Pharmacol 368: 470478 .

Laptifpour $J_{i}$ Yoshida $M$, Weiss RM. 1992. Evidence for the presence of regional differences in the calcium antagonist receptors in lower urinary tract smooth muscle. Naunyn Schmiedebergas Arch Pharmacol 345:679-87.

Li HF, Wang LD, QU SY. 2004. Phytoestrogen genistein decreases contractile response of aortic artery in vitro and arterial blood pressure in vivo. Acta Pharmacol Sin 25:313-8.

Park YK, Koo MH, Sato HH at al. 1995. Survey of some components of propolis, which were collected by Aplis mellifera in Brazil. Arch boil Technol 38: 1253-9.

Rezende BA, Cortes SP, Lemos VS. 2004. Mechanisms involved in the vasodilator effect of the flavanol floranol in rat smoll mesenteric arteries. Planta Med 70: 456-7.

Sugita M, Tokutomi $N$, Takutomi $Y$ et al. 1998. The properties of caffeine- and carbachol-induced intracellular $\mathrm{Ca}^{2 *}$ release in mouse bladder smooth muscle cells. Eur J Pharmacol 348:61-70.

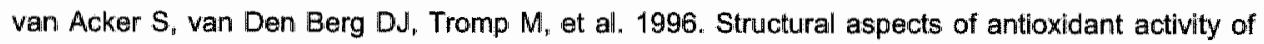
flavonoids. Free Radical Biology \& Medicine 20: 331-342.

Yamanishi $T$, Chapple $C R_{\text {, }}$ Yasuda $K$ et al. 2000. The role of M2-muscarinic receptors in mediating contraction of the pig urinary bladder in vitro. Br J Pharmacol 131:757-766.

Yu-Wen $C_{\text {. }}$ Ching Hao $L$, Chen-Chen $L$ et al. 2003. Alpha-naphthoflavone induces vasorelaxation through the induction of extracellular calcium influx and NO formation in endothelium. NaunynSchmiedeberg"s Arch Pharmacol 386: 377-385. 


\section{Chapter VII}

The inhibitory effect of the flavonoid galangin on urinary bladder smooth muscle contractility is mediated in part by modulation of $\mathrm{Ca}^{2+}$ release from intracellular stores

Miriam Dambros; Marjanka van Deutekom; Rik de Jongh; Gommert A van Koeveringe; Jo G, R. De Mey, Philip van Kerrebroeck.

Planta Med 71(10):962-964, 2005 
The inhibitory effect of the flavonoid galangin on urinary bladder smooth muscle contraictility is mediated in part by modulation of $\mathrm{Ca}^{2+}$ release from intracellular stores

\section{Abstract}

The present study was designed to examine the effect of the flawonoid galangin on the muscarinic receptor mediating a carbachol-induced contraction and to investigatte the effect of the flavonoid on $\mathrm{Ca}^{2+}$ release from intracellular stores in the urinary bladder of the pig.

Galangin $\left(10^{-7}-10^{-4} \mathrm{M}\right)$ produced a concentration-dependent inhibition of the contractile responses to Electrical Field Stimulation (EFS) and carbachol $10^{-5} \mathrm{M}$. Galangin $3 \times 10^{-5} \mathrm{M}$ reduced muscle contractions evaked by carbachal $10^{-5} \mathrm{M}$ in calcium containing solution as well as contractions evoked by carbachol and caffeine $2 \times 10^{-2} \mathrm{M}$ in $\mathrm{Ca}^{2+}$-free solutions significantly. The flavonoid had a stronger effect on maximal force of contractions induced by caffeine, compared to contractions induced by carbachol. These results suggest that gallangin has an important effect on the intracellular calcium mobilization, which might be attributed predominantly to its influence on ryanodine-receptors. 


\section{Introduction}

Galangin, a member of the flavonol class of the flavonoids, is present in high concentrations in honey, aliphia officinarum and in propolis, which is a resinous material made by bees [1]. As most flavonolds, galangin has several biological effects, by modulating the activity of enzymes and affecting the behavior of many cell systems [2 - 3]. Besides its anti-oxidant, anti-mulagenic and antifumor effects, gallangin additionally has relaxing effects on the contractilly of smooth muscle cells in a concentration-dependent manner $[3,4]$. The most important pathway to elicit a contraction of urinary bladder smooth muscle is via muscarinic receptors [5]. The contractile response to the exogenous agonist carbachol has been attributed predominantly if not exclusively to $\mathrm{M}_{3}$ receptors in plgs [6]. Additionally, $\mathrm{M}_{3}$ receptor stimulation typically results in elevation of intracellular $\mathrm{Ca}^{2+}$ concentrations, which can involve both mobilization from intracellular stores and influx from the extracellular space. For the intracellular stores, two molecularly distinct intracellular $\mathrm{Ca}^{2+}$ release mechanisms have been identified in smooth muscle; an inositol trisphosphate $\left(\mathrm{PP}_{3}\right)$ and a $\mathrm{Cia}^{2+}$ and ryanodine sensitive, $\mathrm{Ca}^{2+}$ induced $\mathrm{Ca}^{2+}$ release (RyR-CICR) process [7]. Activation of the cholinergic pathway induces the activation and release of a G-protein, which stimulates the production of $\mathrm{IP}_{3}$, in turn relleasing $\mathrm{Ca}^{2+}$ from the sarcoplasmic reticulum [8]. It is well known that free radical scavengers, capable of limiting the $\mathrm{Ca}^{2+}$ influx into cells as well as $\mathrm{Ca}^{2+}$ release from intracellular stores, might serve as effective drugs in preventing tissue damage from ischerniaIreperfiusion injury [9]. Recently, a study demonstrated that galangin Inhibited the contractile response of rat detrusor muscle to EFS without modifying the contractions produced by exogenous acetylcholine. The response to electrical stimulation was almost completely abolished by tetrodotoxin. From this, the authors concluded that the mode of action of galangin on rat detrusor smooth muscle contraction was due to a presynaptic effect [4]. Based an the above paints, the present study was primarily designed to investigate the effects of galangin on muscarinic responses as well as on calcium mobilization from intracellular stores. To determine whether galangin modulates intracellular calcium stores we analyzed the muscle responses to caffeine and carbachol 
in calcium-free medium, which respectively stimulate, mainlly, ryanodine-sensitive and $\mathbb{P}_{3}$ dependent mechanisms [10].

\section{Material and methods}

Experimental protocol: Strips (1 $\mathrm{mm}$ in diameter, $6-7 \mathrm{~mm}$ in length) were prepared from the bladder dome of pig urinary bladders obtained from a local slaughterhouse approximately 30 minutes after slaughter. They were individually mounted in a separate $6-\mathrm{ml}$ organ baths containing Krebs solution $\left(\mathrm{NaCl}, 118 \mathrm{mM} ; \mathrm{CaCl}_{2}, 2.5 \mathrm{mM} ; \mathrm{KCl}, 4.7 \mathrm{mM} ; \mathrm{NaHCO}_{3}, 25 \mathrm{mM}_{;} \mathrm{KH}_{2} \mathrm{PO}_{4}, 1.2 \mathrm{mM}\right.$; glucose $6.1 \mathrm{mM}^{\prime} \mathrm{pH} 7.4$ ), which was gassed continuously with $95 \% \mathrm{O}_{2}-5 \% \mathrm{CO}_{2}$, at $37{ }^{\circ} \mathrm{C}$. Contractions were measured using an isometric force transducer (Kistler Morce DSC 6, Seattle, WA) and stored digitally.

After 60 min of equilibration at a resting tension of $20 \mathrm{mN}$ the strips were repeatedly contracted by EFS. After stable control contractions evoked by EFS had been recorded, the responses produced by EFS $(16 \mathrm{~Hz}, 2 \mathrm{~ms}, 7 \mathrm{~V})$ or carbachol $10^{-5} \mathrm{M}$ were observed in the presence of increasing cumulative concentrations of galangin $\left(10^{-7}-10^{-4} \mathrm{M}\right)$. The contact time for each concentration of galangin was $30 \mathrm{~min}$. In a preliminary experiment the effect of tetrodotoxin $10^{-6} \mathrm{M}$, contact time 10 min, on EFS-induced contractions was evaluated.

To determine the effect of galangin on the ryanodine-pathway, the amplitudes of caffeine $2 \times 10^{-2} \mathrm{M}-$ ewoked contractile responses were determined. Briefly, control contractile responses to caffeine were obtained in normal Kreb's solution and then in $\mathrm{Ca}^{2 *}$-free Kreb's solution. After the contractile response in the $\mathrm{Ca}^{2+}$-free solution, the bladder strips were reincubated in normal Kreb's solution for $20 \mathrm{~min}$ in order to refill the intracellular calcium stores. The normal Kreb's solution was then switched to calcium-free medium and the strips were incubated with either nifedipine $10^{-8} \mathrm{M}$ alone or with nifedipine plus galangin $3 \times 10^{-5} \mathrm{M}$ for $30 \mathrm{~min}$ before being stimulated with caffeine again. This concentration of the flavonoid was chosen based on our previous experiment in which we demonstrated that galangin at $3 \times 10^{-5} \mathrm{M}$ inhibited approximately $60 \%$ of the maximal amplitude of contractions induced by carbachol in pig bladder. 
The effect of the flavonoid on the contractile response of the detrusor muscle to carbacholl $10^{-5} \mathrm{M}$; in a calcium free solution, was determined in the presence of galangin. For these experiments, the same experimental protocol, described above, was repeated with carbachol instead of caffeine.

Statistical analysis: Data are expressed as means \pm standard error of the mean, when appropriate. Non-linear regression analyses for all concentration response curves were performed. Statistical analyses were carried out using a one-way analysis of variance followed by Tukey's test. A probability value of $p<0.05$ was regarded as significant. All curve-fitting and statistical calculations were performed with Prism program (version 4.0, GraphPad Software Inc, San Diego, Ca).

Drugs: All solutions were freshly prepared. Final concentration of galangin was prepared by first dissolving the solid in DMSO (the concentration of DMSO in bathing solution was less than $0.05 \%$ ). Nifedipine was dissolved in ethanol and then diluted in Kreb's solution. Caffeine and carbachol were made up in Kreb's solution and in calcium-free solution. The $\mathrm{Ca}^{2+}$-free medium was being made without $\mathrm{CaCl}_{2}$ and with addition of ethylene glycol-bis (8-aminoethyl ether)- $N_{3} N_{n} N, N$-tetraacetic acid (EGTA) $10^{-5} \mathrm{M}$. All compounds were purchased from Sigma-Aldrich Company Ltda., Germany).

\section{Results and Discussion}

Galangin $\left(10^{-7}-10^{-4} \mathrm{M}\right)$ decreased the amplitude of the EFS $\left[1 \mathrm{C}_{50}: 4.1 \times 10^{-6}\left(1.9 \times 10^{-18}-8.9 \times 10^{-6}\right)\right]$ and carbachol $10^{-5} \mathrm{M}\left[1 \mathrm{C}_{50}: 3.5 \times 10^{-6}\left(1.5 \times 10^{-7}-7.7 \times 10^{-5}\right)\right]$-evoked contractions in a concentrationdependent imanner (Fig. 1). In a preliminary experiment we observed that contractions induced by EFS were abolished by tetrodotoxin $\left(10^{-6} \mathrm{M}, \rho<0.001\right)$, indicating that they result from the stimulation of nerve fibers. Taken together, these results indicate that galangin has a post-synaptic site of action as well as a direct muscarinic effect in pig bladder. 
The maximum contractile responses to caffeine- and carbachol-, in the presence of a $\mathrm{Ca}^{2+}$-free solution were reduced compared to the response in a nomal Krebs solution. This was only statistically significant in the case of carbachol $(p<0.001)$. One interpretation of these observations is that contractions induced by caffeine at $2 \times 10^{-2} \mathrm{M}$ are almost entirely dependent on intracellular $\mathrm{Ca}^{2+}$ release. On the other hand, contractions induced by carbachol at $10^{-5} \mathrm{M}_{\text {, }}$ are not exclusively dependent on the intracellular stores [11].

Fig. 2 shows the maximum force $\left( \pm\right.$ SEM) during carbachol $10^{-5} \mathrm{M}$-evoked contractions, in a Ca ${ }^{2+}$. free solution, and the inhibiting effect of galangin $3 \times 10^{-5} \mathrm{M}$ on these contractions ( $E_{\text {max intal: }} 6.84 \pm$ $0.72 \mathrm{mN} E_{\text {rmax galangin: }} 1.42 \pm 0.30 \mathrm{mN}, p<0.05$ ). The higher susceptibility of carbachol-stimulated contractile response in calcium free solution to galangin, at the same concentration, compared to the same stimull in calcium containing solution $(p<0.05)$ suggests that there might be an inhibitory action of this flavonoid on the release of intracellular calcium from the sarcoplasmic reticulum or an alteration of its availability to the contractile machinery within the cell, in addition to an inhibition of extra cellular calcium entry. Galangin inhibited the contraction amplitude during caffeine stimulation

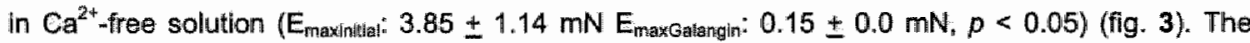
maximum force of the carbachol and caffeine-evoked contractions after incubation with galangin was $20.64 \%$ and $3.81 \%$ of the maximum initial force, respectively: This may suggest that galangin affects, mainly, the ryanodine-receptors, as the caffeine-evoked contraction was more potently reduced by the flavonoid than the carbachol-evoked contractions.

The effects of the nominally $\mathrm{Ca}^{2 *}$-free solution and of the L-type $\mathrm{Ca}^{2+}$ channel blocker, nifedipine, on both caffeine-induced and carbachol-induced contractions were also tested to characterize the source of $\mathrm{Ca}^{2+4}$ rellease involved in the responses to caffeine and carbachol [10]. Nifedipine $10^{-8} \mathrm{M}$ did not reduce contractile responses to caffeine or carbachol in $\mathrm{Ca}^{2+}$-free solution indicating that the residual contractile activity in these experiments was due to mobilization of calcium from the intraceillular stores.

In summary, the data of this study indicate that galangin inhibits contractions of the pig bladder at least partly by inhibition of calcium release from internal calcium stores, possibly by modulation of the $\mathrm{Ca}^{2+}$-induced $\mathrm{Ca}^{2 *}$ release (ClCR). However, effects on the contractile machinery itself cannot 
be ruled out. These data open a new avenue for research on the treatment with galangin of in vivo bladdler overactivity.

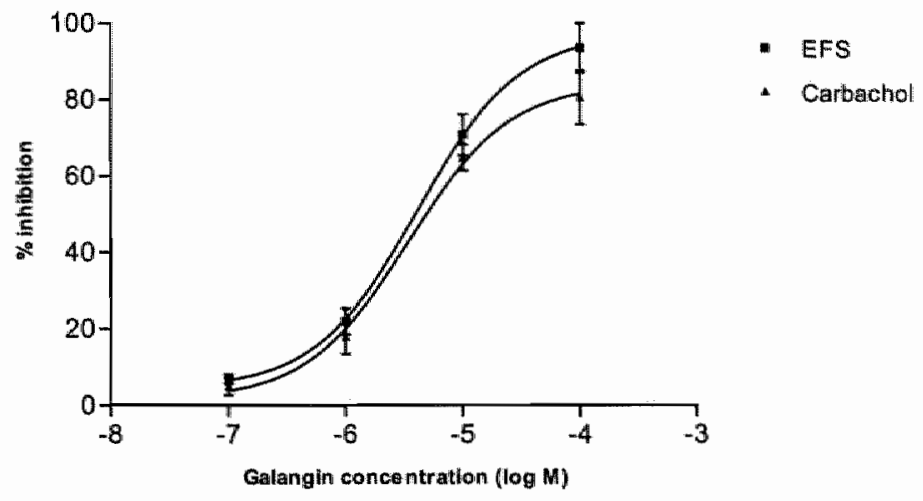

Fig. 1. Effect of galangin $\left(3 \times 10^{-5}\right)$ on the contractile response produced by EFS $(16 \mathrm{~Hz}, 2 \mathrm{~ms}, 7 \mathrm{~V})$ or carbachol $\left(10^{-5}\right) \mathrm{M}$ in the pig urinary bladder. Each point represents the mean of 6-7 experiments. Bars show SEM. " $p<0.05$ vs control.

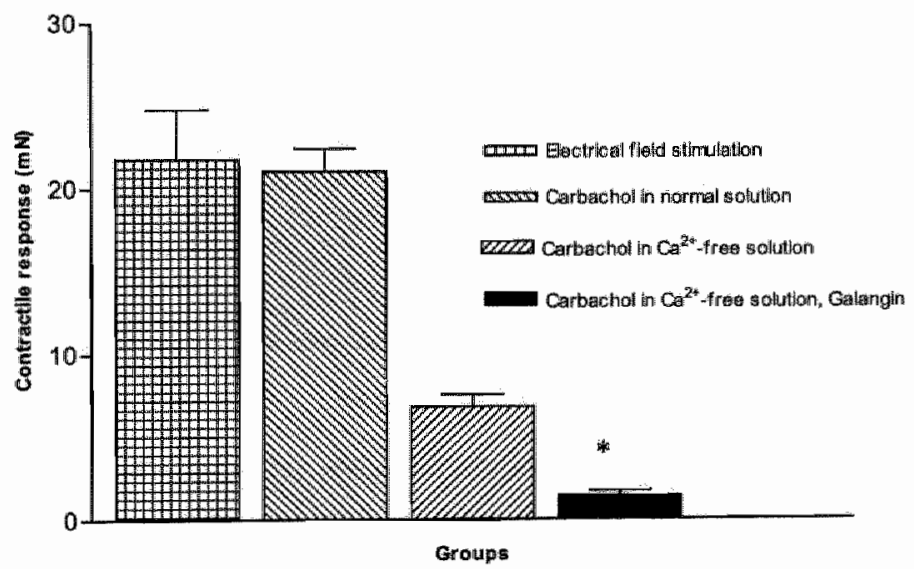


Fig. 2. Inhibitory effects of galangin $\left(3 \times 10^{-5}\right)$ on carbachol $\left(10^{-5}\right)$-evoked contractions in the pig urinary bladder. These results are expressed as mean maximum force \pm SEM (in mN) of 6-8 strips. $p<0.05$ versus carbachol in $\mathrm{Ca}^{2+}$ free solution.

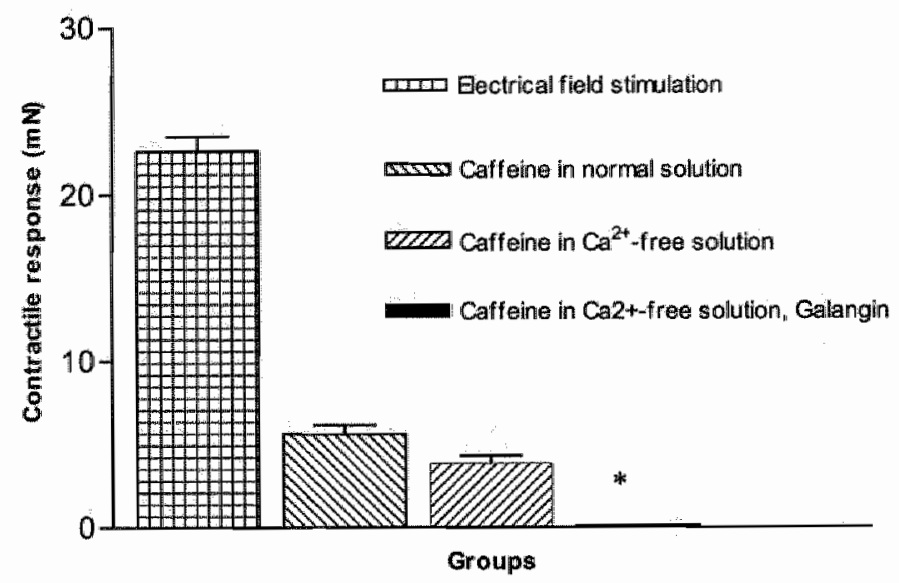

Fig. 3. Inhibitory effects of galangin $\left(3 \times 10^{-5}\right)$ on caffeine $\left(2 \times 10^{-2}\right)$-evoked contractions in the pig urinary bladder. These results are expressed as mean maximum force + SEM (in $\mathrm{mN}$ ) of 6-8 strips. $" p<0.05$ versus caffeine in $\mathrm{Ca}^{2+}$ free solution.

\section{References}

${ }^{t}$ Park $\mathrm{YK}$, Koo $\mathrm{MH}$, Sato HH, Contado لlL. Survey of some components of propolis, which were collected by Apis mellifera in Brazil. Arch boll Technol 1995; 38: 1253-59.

${ }^{2}$ Di Carlo G, Mascolo N, Izzo AA, Capasso F. Minireview. Flavonoids: old and new aspects of a class of natural therapeutic drugs. Liffe Sci 1999; 65(4): 337-53. 
${ }^{3}$ Rezende BA, Cortes SP, Lemos VS. Mechanisms involved in the vasodilator effect of the flavanol floranol in rat small mesenteric arteries. Planta Med $2004 ; 70: 456-57$.

${ }^{4}$ Capasso $R$, Tavares IA. Effect of the flavonoid galangin on urinary bladder rat contractility invitro. J Pharm Pharmacol 2002; 54: 1147-50.

${ }^{5}$ Andersson KE. Pharmacology of lower urinary tract smooth muscles and penile erectile tissues. Pharmacol Rev 1993; 45:253-08.

${ }^{6}$ Yamanishi T, Chapple $\mathrm{CR}_{n}$ Yasuda $\mathrm{K}$ and Chess-Williams $\mathrm{R}$. The role of $\mathrm{M}_{2}$-muscarinic receptors in mediating contraction of the pig urinary bladder in vitro. $\mathrm{Br} \mathrm{J}$ Pharmacol $2000 ; 131: 757$. 66.

${ }^{7}$ Somlyo AP and Somlyo AV. Signal transduction and regulation in smooth muscle. Nature $1994 ; 372: 231-36$.

Eglen RM, Reddy $H$, Watson $N$, Challiss RAJ. Muscarinic acetylcholine receptor sutypes in smooth muscle. Trends Pharmacol Scl 1994; 15:114-19.

${ }^{9}$ Sparagli GP, Valoti M, Gorelli B, Fusi F, Palmi M, Mantovani P. Calcium antagonist and anti peroxidant properties of some hindered phenols. Br J Pharmacol 1993; 110:369-77.

${ }^{10}$ Sugita $M$, Tokutomi $N$, Tokutomi $Y$, Terasaki $H$, Nishi $K$. The properties of caffeine- and carbachol-induced intracellular $\mathrm{Ca}^{2+}$ release in mouse bladder smooth muscle cells. Eur J Pharmacol 1998; 348:61-70.

${ }^{11}$ Maters JG, Neal DE, Gillesple Jl. The contribution of intracellular $\mathrm{Ca}^{2+}$-release to contraction in human bladder smooth muscle. Br J Pharmacol 1999; 127(4): 996-02. 
Chapter VIII

General discussion and Future perspectives 


\section{General Discussion}

This thesis is a compilation of work that addresses some original contributions to the understanding of the pathophysiology and treatment of overactive bladder. Because this pathology is not a homogeneous entity, but a clinical syndrome occurring due to a heterogeneous group of alterations with a wide variety of etiologies, in studying the overactive bladder syndrome one is severely limited by the experimental approach that is selected.

In the first part of this thesis, an outline on the innervation, physlology, pharmacology and pathophysiology of the bladder is given. Chapter 1 gives an overview regarding the overactive bladder syndrome. Some background information is given on two classes of drugs that have relaxant effects on the bladder smooth muscle contractility: estrogens and flavonoids. The presence of estrogen receptors has been demonstrated in the human lower urinary tract (Blakeman et al. 2000). The postmenopausal period is associated with a high incidence of symptoms from the lower urinary tract (losif and Bekassy, 1984). This supports the widespread practice of giving estrogen replacement treatment to postmenopausal women with lower urinary tract dysfunction. Increased collagen deposits between the smooth muscle cells of the detrusor and urethra might affect the functional properties of the lower urinary tract. The collagen content of the detrusor muscle has been found to be significantly increased in females after the age of 50 when compared to younger females and to males at same age in a postmortem study (Susset et al., 1978). However, the results from animal experiments on the influence of ovarian hormones on extra cellular components of the urinary bladder have been contradictory (Eika et al., 1990; Persoon et al., 1996).

Flawonoids are components of fruit and vegetables that may be beneficial to the prevention of diseases such as cancer and cardiovascular diseases. Recently, the study of the effects of the flavonoid galangin on bladder muscle contractilty was described for the first time in the literature (Capasso and Tavares, 2002). That study demonstrated that galangin inhibited the cantractile response of rat detrusor muscle to electrical field stimulation without modifying the contractions produced by exogenous acetylcholine. Thus, based on those resuits the authors suggested that galangin might be candidate for the treatment of the overactive bladder. 
In Chapter 2 , the effects of 17 - $\beta$-estradiol on collagen and elastic fibers in the bladder wall were investigated. Collagen and elastic fibers, which form the major components of the connective tissue, are present throughout the urinary bladder wall and are important determinators of bladder compliance. Previous studies have focused mainly on the structural and quantitative alterations of the extracellular matrix fibers of the muscle layer related to conditions like aging and hormonal status. Experiments performed on animals to investigate the effect of owarian hormones on bladder structure obtained contradictory results regarding the effect of estrogen on connective tissue. We carried out a quantitative morphometric analysis of rat bladders to investigate the possible effects of ovariectomy and successive estrogen replacement therapy on the structure of the bladder wall. We found that ovariectomy as well as ovariectomy followed by estradiol treatment had no effect on bladider volume. A comparison of the stereological findings showed no significant difference in the absolute wolume and volumetric density of the collagen fibers. Analysis of the elastic system showed that there were no significant differences in the absolute volume and volumetric density of the groups. Long-term estrogen deprivation did not have a significant influence on the extracellular matrix of the bladder. Ovariectomy and successive estrogen supplementation did not affect the collagen and elastic fiber concentration in the bladder wall of rats. We can therefore conclude that there was no relationship found between estrogen serum levels and bladder extracellular matrix in rats.

In Chapter 3, we showed the effect of 17- $\beta$-estradiol on bladder smooth muscles contractility and the Involvement of specific estrogen receptor stimulation in this effect. Estradiol at a high concentration elicited a lower amplitude of contractions induced by electrical and pharmacological stimuli in pig bladder smooth muscle strips. The effects of 17 - $\beta$-estradiol were stronger in contractions induced by potassium chloride than those induced by other forms of stimulation. Preincubation with pure estrogen receptor antagonist had no effect on 17 - $\beta$-estradiol-induced Inhibition of muscle contractility. These observations suggest that $17-\beta$-estradiol induces lower amplitude of contraction in pig detrusor, which is not mediated by the classic estrogen receptor. Furthermore, we can conclude that estradiol has a stronger inhibilory effect on the depolarisation of muscle cell membrane compared to the muscarinic receptor-induced contraction. However, 
micromolar concentrations of 17 -p-estradiol were necessary to induce lower contractions of pig detrusor and those concentrations are clearly higher than physiological serum levels, thus, the physiologicall importance of this acute inhibition by estradiol on bladder contraction is not clear.

Chapter 4 focuses an the effect of a low sub-micromolar dose of the flavonoid galangin in avoiding the decrease of bladder smooth muscle contractile responses, after a period of fatigue and generation of free radicals by a repetitive field stimulation model. There is increasing evidence that the generation of free radicals plays a role in the development of bladder dysfinction. Studies demonstrated that bladder strips subjected to a period of oxidative stress contained an accumulation of malondialdehyde (MDA) within the smooth muscle membrane and that both the MDA concentration and level of contractile dysfunction are directly related to the extracellular calcium concentration (Levin et al., 1998). Thus, it can be hypothesised that radical scavengers capable of limiting the $\mathrm{Ca}^{2+}$ influx into the cells might be of use to effectively prevent tissue dermage due to injuries caused by an excess of free radicals. Flavonoids are a group of polyphenolic compounds and have recently gained tremendous interest, due to their broad pharmacological activity, mainly the antioxidant capacities. Galangin at $10^{-7} \mathrm{M}$ concentration was capable of avoiding the decrease of smooth muscle contraction amplitude and the rate of force development after repetitive stimulation. This study demonstrated that galangin exerted a protective effect on bladder smooth muscle contractility. We can suggest that galangin prevents the decrease of muscle contractility by its radical scavenging effect. Further experiments, involving the use of more specific methodology, are needed to confirm the role of this mechanism in detrusor overactivity. In Chapter 5. we demonstrated that this effect was significantly reduced when verapamil was added to the solution: Clinical and experimental data suggest that ischemic neuronal damage is partly induced by free radicals and or lipid peroxidation, during both ischemic and the subsequent reperfusion phase (Maxwell \& Lip, 1997). We investigated the role of galangin during an anoxia and reperfusion period and we showed that galangin improved significantly the response of strips to electrical field stimulation submitted to a period of anoxia and glucopenia and reperfusion conditions, as comparad to untreated tissues. Based on that, our conclusion was that glalangin has a protective effect on 
bladder smooth muscle damage induced by a period of anoxia and reperfusion by an action that at least in part, depends on L-type calcium channels.

Following this study, the inhibitory effect of galangin, on rat bladder contractility has been investigated. Chapter 6 explores the relaxation effects of a higher micromolar dose of the flavonoid galangin on bladder smooth muscle contractility. The contractile response to electrical and pharmacological stimull were determined before and after the addition of galangin. Moreover, the effect of galangin was also evaluated after the administration of antagonists or inhibitors in order to examine the possible underlying mechanisms and the involved excitation-contraction pathways. Galangin inhibited the maximal contractile response to carbachol, potassium and electrical stimuli. The inhibitory effect of galangin was unaffected by a combination of propranolol phentolamine and capsazepine. However, verapamil partially blocked the effect of galangin. In view of these results, we suggested the involvement of an L-type calcium channel independent pathway, which probably resulted from an action on $\mathrm{Ca}^{2+}$ mobilization from intracellular stores as well as influx of calcium. Finally, in Chapter 7 we showed that the flavonoid galangin had a stronger effect on maximal force of contractions induced by caffeine, compared to contractions induced by carbachol. These results suggest that galangin had an important effect on the intracellular calcium mobilization, which might be attributed predominantly to its influence on ryanodine-receptors.

Summarizing, chapters 2 and 3 have demonstrated that estradiol did not have any effect on bladder extracellular matrix. Furthermore, it was shown, in an in vitro study, that estradiol at high concentrations had an inhibitory effect on bladder smooth muscle contractile responses, that were not mediated by the classic estrogen receptor. Chapters $4,5,6$ and 7 have shown that galangin, in sub-micromolar concentrations; exerted a protective effect on bladider smooth muscle contractility. Furthermore, galangin, in micromolar concentrations inhibited pig bladder contractility, which probably resulted from an action on $\mathrm{Ca}^{2+}$ mobilization from intracellular stores as well as influx of calcium.

Further studies are needed to better determine the mechanisms by which estrogen and flavonoids affect bladder smooth muscle contractility and to clarify the links between hormonal deficiency. antioxidants and detrusor overactivity. 


\section{Future perspectives}

Our understanding of the molecular and cellular changes in the bladder during abnormal structural and functional changes that manifest themselves clinically as overactive bladder is still not well understood. The idlentification of a number of defined cellular factors and the recognition of the importance of cell-cell interactions have greatly expanded our understanding of the regulation of detrusor smooth muscle under physiological and pathological conditions.

During the last few years research has stimulated the development of new therapeutic approaches for overactive bladder as acting on CNS transmitter and modulator systems, urothelial signaling mechanisms, and afferent neves.

Despite the many potential targets, few drugs with modes of action other than antimuscarinlc have passed the proof of concept stage. A major problem has been to find drugs exhibiting "clinical uroselectivity". For the future, it is important to focus on the development of neuropharmacological agents that can suppress the unique components of abnormal bladder reflex mechanisms and, thereby, act selectively to decrease symptoms without altering normal volding function.

Beyond the horizon of short-term advancement, the development of a new paradigm in functional urology therapeutics can be predicted. What has already started is the evolution of unstoppable forces of change in medicine, including pharmacogenomics, gene therapy and tissue engineering. Possible gene therapy strategies for overactive bladder and urge incontinence may include suppressing bladder muscle activity or neural pathways that trigger the micturition reflex. An example of this type of gene therapy is Herpes simplex virus (HSV) vector mediated gene transfer to the bladder and bladder afferent nerves of preproenkephalin, a precursor of enkephalins that is

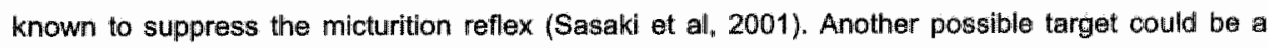
modulation of neurotrophic factors such as nerve growth factor (NGF) in bladder and bladder sensory pathways (Phelan et all, 2000). NGF has been recognized as a chemical mediator that induces an overactive bladder in various pathological conditions, thus, the therapy to suppress NGF expression could be a future potential candidate for treating urge-incontinence. Tissue enginearing. especially with stem cells, has the potential to rebuild the damaged bladder and urethral sphincter 
$\left(\right.$ Atala $_{1}$ 1999). Through purifying techniques, muscle derived stem cells than can differentiate into urinary tract smooth muscle and an improvement of the function of the bladder wall and urethral sphincter could become possible.

Further studies are needed to clarify the complex interplay among the various neurotransmitters and other substances derived from uroepithelium, detrusorr-muscle cells, and afferent fibers themselves, to understand the mechanisms by which these stimuli may adversely affect detruser muscle, and to determine more specific targets for the treatment of the overactive bladder. 


\section{Samenvatting}

De overactieve blaas is een klinisch syndroom en geen op zichzelf staande pathologische entiteit. Dit maakt dat verschillende experimentele benaderingen moeten worden gekozen om tot een beter begrip van dit probleem te komen.

In het eerste deel van dit proefschrift wordt de fysiologie, farmacologie, pathofysiologie en innervatie van de blaas besproken. Het werkingsmechanisme van oestrogenen em flavonoiden, twee klassen farmacologische stoffen met een relaxerend effect op glad spierweefsel van de blaas wordt toegelicht. Doordat het weefisel van de blaas een oestrogeen receptor bevat en bij postmenopausale vrouwen relatief vaak lagere urineweg symptomen voorkomen, is men helt effect: van oestrogenen op de blaasspier en op het bindweefsel van de blaas gaan bestuderen. Verschillende onderzoeken spreken elkaar tegen ten aanzien van een duidelijke relatie tussen lagere urineweg symptomen en oestrogeen niveaus. De invloed van flavonoiden op blaasfunctie is ook bestudeerd in dit proefschrift. Flavonolden vindt men vooral in fruit en groenten en zijn al een geruime periode onderzocht in relatie tot het voorkomen van kanker en hart en vaatzlekten. In een recente studie werd ook een effect van flavonoiden op de blaasspier van de rat beschreven. In dit proefschrift wordt in hoofdstuk 2 en 3 dieper ingegaan op het effect van oestradiol op het bindweefsel en het spierweefsel van de blaas. In hoofdstuk 2 wordt beschreven dat oestradiol geen invloed heeft op de hoeveelheid en de structuur van collageen vezels noch van elastische vezels in het bindweefsel van de blaas. Hoofdstuk 3 beschrijft dat oestradiol well invloed heeft op de samentrekkingskracht van het splerweefsel wan de blaas. Dit effect verloopt niet via de in de blaas aanwezige oestrogeen receptor maar waarschijnlijk via een ander nog niet opgehelderd mechanisme. Well zijn voor dit effect hoge niet-fysiologische concentraties nodig.

in hoofdstuk 4 en 5 werd het beschermende effect van galangine op de functie van de blaasspier bestudeerd. Hoofdstuk 4 beschrijt dat er in de blaas zeker door vaak samen te trekken, zuurstof radicaal productie is, een stof die schadelijk is voor de blaasfunctie. Doordat van galangine bekend is dat het deze zuurstofradicalen kan wegvangen, is het effect van deze stof bekeken op 
splerweefisel dat werd blootgesteld aan herhaalde elektrische stimulatie. Het bleek dat een kracht reductie na herhaalde stimulatie door een lage concentratie galangine kon worden voorkomen. In hoofdstuk 5 kon worden aangetoond dlat ook na ischemie en reperfusie in een lage concentratie galangine een betere samentrekkingskracht werd gezlen dan wanneer dit zonder galangine gebeurde. Dit effect van galangine kon grotendeets worden geremd wanneer ook een blokker van Litype Calcium kanalen in de vloelstof aanwezig was. Dit maakt het waarschijnlijk dat galangine voor haar effect deze kanalen nodig heeft. Hoofdstuk 6 beschrijft dat een hogere concentratie van galangine juist zorgt woor een vermindering van de samentrekkingskracht van thet blaasspierweefsel. Ook dit effect kon weer gedeeltelijk worden geremd door een blokker van de Ltype calcium kanalen. Hoofdstuk 7 laat vervolgens zien dat dit relaxerende effect van een hoge dosis galangine sterker is als een contractie werd gestimuleerd met caffeine (een stimulator van intracellulaire calcium mobilisatie) vergeleken met een contractie gestimuleerd met carbachol (een muscarine receptor stimulator). Dit laatste suggereert een belangrijk remmend effect van galangine op de mobilisatie van calcium uit de intracellulaire calcium woorraden.

Verder onderzoek is nodig om bovenstaande werkingsmechanismen van oestrogenen en flawonoiden nog verder te verhelderen, waarna deze stoffen of afgeleide stoffen hierwan zouden kumnen worden toegepast woor de behandeling van de overactieve blaas. 


\section{References}

Abdel-Latif AA. Cross-talk between cyclic nucleotides and phosphoinositides hydrolysis, protein kinases and contraction in smooth muscle. Exp Biol Med 226:153-163, 2001.

Abrams $P$, Cardozo $L$, Fall $M$ et al. The standardisation of terminology of lower urinary tract function: report from the Standardisation Sub-committe of the International Continence Society. Neurourol Urodyn 21: 167-78, 2002.

Ahlstrom $K_{,}$Sandahl $B$, Sjoberg $B$ et al. Effect of combined treat-ment with phenylpropanolamine and estriol, compared with estriol treatment alone, in postmenopausal women with stress urinary incontinence. Gynecoll Obstet Invest 30:37-43, 1990.

Aikawa $K$, Sugino T, Matsumoto $S$ et al. The effect of ovariectomy and estradiol on rabbit bladder smooth muscle contraction and morphology. J Urol 170:634-637, 2003.

Ajay M, Gilani AH, Mustafa MR. Effects of flavonoids on vascular smooth muscle of the isolated rat thoracic aorta. Lffe Sciences 74:603-612, 2003.

Andersson KE. Pharmacology of lower urinary tract smooth muscles and penile erectile tissues. Pharmacol Rev 45:253-308, 1993.

Atala A. Creation of bladder tissue in vitro and in vivo. A system for organ replacement. Adv Exp Med Bial 462:31, 1999.

Blakeman PJ, Hilton P, Bulmer JN. Destrogen and progesterone receptor expression in the female lower urinary tract, with reference to oestrogen status. BJU Int 86(1): 32-38, 2000.

Brading AF, Pessina F, Esposito L et al. Effects of metabolic stress and ilschaemia on the bladder. and the relationship with bladder overactivity. Scand UUrol Nephrol Suppl 215:84-91, 2004.

Brading AF. A myogenic basis for the overactive bladder. Urology 50:57-62, 1997.

Brading AF. Alternations in the physiological properties of urinary bladder smooth muscle by bladder emptying against an obstruction. J Urol 184:51-8, 1997.

Capasso R \& Mascola N. Inhibitory effect of the plant flavonold galangin on rat vas deferens in vitro. Live Scien 72:2993-3001, 2003. 
Capasso R \& Tavares I. Effect of the flavonoid galangin on urinary bladder rat contractility in-vitro. $J$ Pharm Pharmacol 54:1147-1150, 2002.

Capasso $R$, Borrelli $F$. Capasso $F$ et al. Inhibitory effect of the antidepressant ST. John's wort (Hypericum perforatum) on rat bladder contractility in vitro. Urology 64(1):168-172, 2004.

Cardozo $L_{\text {, }}$ Lose G, McClish D et al. A systematic review of the effects of estrogens for symptoms suggestive of overactive bladder. Acta Obstet Gynecol Scan 83:892-896, 2004.

Cardozo LD \& Kelleher CJ. Sex hormones, the menopause and urínary problems. Gynecol Endocrinol $9(1): 75-84,1995$.

Chan $\mathrm{ECH}$, Pannangpetch $\mathrm{P}$, Woodman $\mathrm{OL}$. Relaxation of flavones and flavonols in rat isolated thoracic aorta: mechanism of action and structure-activity relationships. I Cardiovasc Pharmacol $35: 326-333,2000$.

Cotelle N, Bermier JL, Hénichart P.J. Scavenger and antioxidant properties of ten synthetic flavones. Free Radical Biol Med 13:211-219, 1992,

Cruz-Orive L M \& Weibel ER. Recent stereological methods for cell biology: a brief survey. Am J Physiol 258: L148-56, 1990.

Debruyne FM \& Heesakkers JP. Clinical and socioeconomic relevance of overactive bladder. Urology 63:42-44, 2004.

Delesse M. Procédé mécanique pour déterminer la composition des roches. Ann Mines 13: 379-85, 1848.

Di Carlo G, Mascolo N, lzzo AA et al. Minirevlew. Flavonoids: old and new aspects of a class of natural therapeutic drugs. Liffe Sci $65: 337-53,1999$.

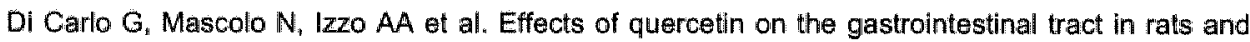
mice. Phytother Res 8:42-45, 1994 .

Diep N \& Constantinou CE. Age dependent response to exogenous estrogen on micturition. contractility and cholinerglc receptors of the rat bladder. Life Sci 64(23): PL279-89, 1999.

Duarte $\rfloor_{\|}$Perez-Vizcaino $F$, Utrilla $P$ et al. Vasodilatory effects of flavonoids in rat aortic smooth muscle. Structure-activity relationships. General Pharmacol 24: 857-862, 1993. 
Eglen RM, Reddy $\mathrm{H}$, Watson $\mathrm{N}$ et al. Muscarinic acetylcholine receptor sutypes in smooth muscle. Trends Pharmacol Sci 15:114-119, 1994.

Eligel BN, Gursahani $H$, Hadley RW. ROS are required for rapid reactivation of $\mathrm{Na}+\mathrm{Ca2}+$ exchanger in hypoxic reoxygenated guinea pig ventricular myocytes. Am J Physiol 286:H955-H963, 2004 .

Eika $B$, Salling $L N$, Christensen LL et al. Long-term observation of the detrusor smooth muscle in rats: its relationship to ovariectomy and estrogen treatment. Urol Res 18: 439-442, 1990.

Ekström J, losif CS, Malmberg L. Effects of long-term treatment with estrogen and progesterone on in vitro muscle responses of the female rabbit urinary bladder and urethra to autonomic drugs and nerve stimulation. J Urol 150: 1284-88, 1993.

Erulkar SD, Rendl J, Nori RD et al. The influence of 17-betia-cestradiol on K+ currents in smooth muscle cells isolated from immature rat uterus. Proc R Soc London 256:59-65, 1994.

Falconer $C$, Ekman-Ordeberg $G$, Blomgren $B$ et al. Paraurethral connective tissue in stressincontinent women after menopause. Acta Obstet Gynecol Scand 77(1): 95-100, 1998.

Fisser Ad, Waimsley K, Blaivas JG. Urodynamic classification of patients with symptoms of overactive bladder. J Ural 169: 529-34, 2003.

Fitzpatrick DF, Hirschfield SL, Coffey RG. Endothelium-dependent vasorelaxing activity of wine and other grape products. Ann J Physiol 265: H774-H778, 1993.

Fletcher TF \& Bradley WE. Neuroanatomy of the bladder-urethra. J Urol $119: 153-160,1978$.

Freay AD, Curtis SW, Korach KS et al. Mechanism of vascular smooth muscle relaxation by estrogen in depolarized rat and mouse aorta. Circulation Research 81(2): 242-8, 1997.

Fry $\mathrm{CH} \&$ Wu C. The cellular basis of bladder instability. BJU 81:1-8, 1998.

Fry $\mathrm{CH}$. Experimental models to study the physiology, pathophysiology, and pharmacology of the lower urinary tract. J Pharmacol Toxicol Meth 49:201-210, 2004.

Fusi $F$, Saponara $S$, Frosini $M$ et al. L-type $\mathrm{Ca} 2+$ channels activation and contraction ellicited by myricetin on vascular smooth muscles. Naunyn-Schmiedaberg's: Arch Pharmacol 368: 470-478, 2003. 
Galati G \& OBrien PJ. Potential toxicity of flavonoids and other dietary phenolics: significance for their chemopreventive and anticancer properties. Free Radical Biol \& Medic 37:287-303, 2004.

Galvez J, Crespo ME, Jimenez J et al. Antidiarrhoeic activity of quercetin in mice and rats. $J$ Pharm Pharmacol 45:157-159, 1993.

Gharzoull $K$ \& Holzer $P$. Inhibition of guinea pig intestinal peristalsis by the flavonoids quercetin, naringenin $n_{i}$ apigenin and genistein. Pharmacology $70: 5-14,2004$.

Glerum JJ \& van Mastrigt R. Mechanical properties of mamalian single smooth muscle cells: Evaluation of a modified technique for attachment of cells to the measurement apparatus. J Musc Resear Cell Motility 11:338-343, 1990.

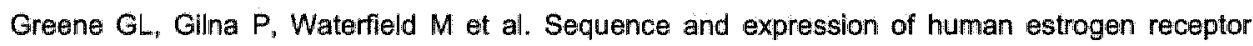
complementary DNA. Science 231:1150-1154, 1986.

Gulati OP. Nordman $H$, Aellig $A$ et al. Protective effects of $O-(\beta$-hydroxyethyl)-rutosides (HR) against adriamycin-induced toxicity in rats. Arch Int Pharmacodyn 273:323-334, 1985.

Haies DM, Gil d, Weibel ER. Morphometric study of rat lung cells. I. Numerical and dimensional characteristics of parenchymal cell population. Am Rev Respir Dis 123:533-541, 1981.

Hally A. A counting method for measuring the volumes of tissue components in microscopical sections. Quaterly J Microsc Sci 105: 503-517, 1964.

Hammad HM \& Abdalla SS. Pharmacological effects of selected flavonoids on rat isolated ileum: Structure-activity relationship. Gen Pharmacol 28:767-771, 1997.

Hassager $C_{n}$ Jensen LT, Podenphant $J$ et al. Collagen synthesis in postmenopausal women during therapy with anabolic sterald or female sex hormones. Metabolism 39(11): 1167-69, 1990.

Havsteen B. Flavonoids. A class of natural products of high pharmacological potency. Biochem Pharmacol 32:1141-1148, 1983.

Heijnen CGM, Haenen GRMM, Oostveen RM et al. Protection of flavonoids against llipid peroxidation: the structure activity relationship revisited. Free Rad Res 36:575-581, 2002.

Hendrix SL, Cochrane BB, Nygaard IE et al. Effects of estrogen with and without progestin on urinary incontinence. JAMA 293:935-948, 2005. 
Heo MY, Sohn SJ, AU WW. Anti-genotoxicity of galangin as a cancer chemopreventive agent candidate. Mutation Res 488:135-150, 2001.

Herrera $\mathrm{GM}_{\mathrm{v}}$ Heppner $\mathrm{T} \Downarrow$, Nelson MT. Regulation of urinary bladder smooth muscle contractions by ryanodine receptors and BK and SK channels. Am J Physiol Regul Integr Comp Physiol 279:60-68, 2000.

Herrera MD, Zarzuelo $A$, Jiménez $J$ et al. Effects of flavonoids on rat aortic smooth muscle contractility: structure-actitivy relationships. Gen Pharmacol 27:273-277, 1996.

Hertog MGL, Feskens EJM. Hoilman PCH et al. Dietary antioxidant flavonoids and risk of coronary heart disease: The Zutphen Elderly study. Lancet 342: 1007-1011, 1993.

Hughes $\mathrm{J}$, Kosterlitz HW, Leslie FM. Effect of morphine on adrenergic transmission in the mouse vas deferens. Assessment of agonist and antagonist potencies of narcotic analgesics. Brit J Pharmacol 53(3):371-81, 1975.

Imamura $Y$, Migita $T$, Uriu $Y$ et al. Inhibitory effects of flavonoids on rabbit heart carbonyl reductase. J Biochem Tokyo 127: 653-658, 2000.

losif CS \& Bekassy Z. Prevalence of genito-urinary symptoms in the late menopause. Acta Obstet Gynaecol Scand 63:257-260, 1984.

Jackson $S$, James $M$, Abrams $P$. The effect of oestradiol on vaginal collagen metabolism in postmenopausal women with genuine stress incontinence. BJOG 109:339-344, 2002.

Jackson S, Shepherd A, Brookes $S$ et al. The effect of oestrogen supplementation on postmenopausal urinary stress incontinence: a double-blind placebo-controlled triall. $\mathrm{Br} J$ Obstet Gynaecol 106:711-718, 1999.

Jacob MP. Badier-Commander $C_{n}$ Fontaine $V$ et al. Extracellular matrix remodeling in the vascular wall. Patholl Biol 49:326-332, 2001.

Jiang C, Sarrel PM, Poolle-Wilson PA et al. Acute effect of 17B-estradiol on rabbit coronary artery contractile iresponses to endothelin-1. Am J Physiol 263:H271-H275, 1992.

Kitazawa T, Hamada E, Kitazawa $K$ et al. Non-genomic of 17 beta-oestradiol-induced inhibition of contraction in mammalian vascular smooth muscle. J Physiol 1;499 (Pt2);497-511, 1997. 
Knekt $P$, Jarvinen $R$, Reunanen $A$ et al. Flavonoid intake and coronary mortality in Finland: a comparative study. Brit Med J 312:478-481, 1996.

Kuehnau J. The flavonoids. A class of semi-essential food components: their role in human nutrition. Word Rew Nutr Diet 24:117-191, 1976.

Kuru M. Nerwous control of micturition. Physiol Rev 45: 425-494, 1965.

Laptifpour $J_{*}$ Yoshida $M$; Weiss RM. Evidence for the presence of regional differences in the callcium antagonist receptors in lower urinary tract smooth muscle. Naunyn Schmiedebergas Arch Pharrnacol 345:679-87, 4992.

Lee SJ \& MCEwen BS. Neurotrophic and neuroprotective actions of estrogens and their therapeutic implications. Ann. Rev. Pharmacol. Toxicol 41:569-591, 2001.

Lewin RM, Legigett $R$, Whitbeck $C$ et al. Effect of calcium and calcium chelators on the response of the bladder to in vittro ischemia. $\mathrm{Br} \mathrm{J}$ Urol 82:882-887, 1998.

LU HF, Wang LD, Qu SY. Phytoestrogen genistein decreases contractile response of aortic artery in vitro and arterial blood pressure in vivo. Acta Pharmacol Sin 25:313-8, 2004.

Lincoln $\mathrm{J} \&$ Burnstock $\mathrm{G}$. Autonomic innervation of the urinary bladider and urethra. In :Maggi CA (ed) Nervous Control of the Urogenital System. London: Hanwood Academic 1993; 33-68.

Longhurst PA \& Uvellus B. Pharmacological techniques for the in vitro study of the urinary bladder. J Pharmacol Toxicol Meth 45:91-108, 2001.

Macander PJ. Flavonoids affect acetylcholine, prostaglandin $E_{2}$ and antigen-mediated smooth muscle contraction. Prog Clin Biol Res 213:489-492 „1986.

Maggi CA, Bevan $S$, Walpole CSJ et al. A comparation of capsazepine and ruthenium red as capsaicin antagonists in the rat isolated urinary bladder and vas deferens. Brit $\mathrm{J}$ Pharmacol $108(3): 801-5,1993$.

Makela S, Strauss L, Kuiper $\mathrm{G}$ at al. Differential expression of estrogen receptors alpha and beta in adult rat accessory sex glands and lower urinary tract. Mol Cell Endocrinol 164(1-2): 109-16, 2000. Masick JM, Lewin RM, Hass MA. The effect of partial outlet obstruction on prostaglandin generation in the rabbil urinary bladder. Prostaglandins Other Lipid Mediat 66:211-219, 2001. 
Maters JG, Neal DE, Gillespie J. The contribution of intracellular Ca ${ }^{2+}$-release to contraction in human bladder smooth muscle. Br J Pharmacol 127(4): 996-02, 1999.

Mathieu $\mathrm{O}$, Cruz-Orive LM, Hoppeler $\mathrm{H}$ et al: Measuring error and sampling variation in stereology: comparison of the efficiency of various methods for planar image analysis. $J$ Microsc $121: 75-88$, 1981.

Maxwell SR \& Lip GV. Reperfusion injury: a review of pathophysialogy, clinical manifestations and therapeutic options. Int J Cardiol 58:95-117, 1997.

McEwen BS. Non-genomic and genomic effects of steroids on neural activity. Trends Pharmacol Sci 12:141-147, 1991.

Mendelsohn ME \& Karas RH. Estrogen and the blood vessel wall. Curr Opin Cardiol 9:619-626, 1994.

Montes GS. Distribution of oxytalan, elaunin and elastic fibers in tissues. Ci Cult J Braz Assoc Adv Sci 44:224-233, 1992.

Mantes GS. Structural biology of the fibers of the collagienous and elastic systems. Cell Biol Inter 20(1): 15-27, 1996.

Myara I, Pico I, Vedie B et al: A method to screen for the antioxidant effect of compounds on lowdensity lipoprotein (LDL): illustration with flavonoids. J Pharmacol Toxicol Methods 30: 69-73, 1993. Ogata $R$, Inoue $Y$, Nakano $H$ et al. Oestradiol relaxes the rabbit basilar artery by intibition of voltage-dependent $\mathrm{Ca}$ channels through GTP-binding protein. B U Pharmacology 117:351-359, 1996.

Onnishi N, Liu SP, Horan $P$ et al. Effect of repetitive stimulation on the contractile response of rabbit urinary bladder subjected to in vitro hypoxia or in vitro ischemia followed by reoxygenation. Pharmacology 57:139-147, 1998.

Oudit GY, Sun H, Trivieri MG et al. L-type Ca2* channeis provide a major pathway for iron entry into cardiomyocytes in iron-overload cardiomyopathy Nature Medicine 9(9): 1187-1194, 2003.

Owens RG \& Karram MM. Comparative tolerability of drug therapies used to treat incontinence and enuresis. Drug Safety 19: 123-139, 1998. 
Palea $\mathbf{S} \&$ Angel I. The effect of ovariectomy on the contractile response of the rat isolated detrusor muscle and urethra. Life Sci 61(1): PL21-26, 1997.

Park YK, Koo MH, Sato HH et al. Survey of some components of propolis; which were collected by Apis mellifera in Brazil: Arch boil Technol 38: 1253-9, 1995.

Persson $K_{i}$ Svane D, Glawind B et al Effects of ovariectomy on mechanical properties and collagen content in rabbit lower urinary tract smooth muscle. Scand J Urol Nephrol 30(1):7-14, 1996.

Phelan MW, Yoshimura N, Goins WF et al. Nerve growth factor (NGF) gene therapy improwesrat diabetic cystopathy, but does not increase pain sensation. J Urol suppl 163:245, abstract 1089, 2000.

Pickering JG. Regulation of vascullar cell behaviour by collagen: form is function. Circ Res 88:458$459,2001$.

Resnick NM \& Yalla SV. Detrusor hyperactivity with impaired contractile function: an unrecognized but common cause of incontinente in elderly patients. JAMA 257: 3076-81, 1987.

Rezende BA, Cortes SP, Lemos VS. Mechanisms Involved in the vasadilator effect of the flavanol floranol in rat smoll mesenteric arteries. Planta Med 70: 456-7, 2004.

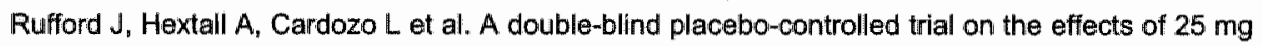
estradiol implants on the urge syndrome in post-menopausal women. Int Urogynecoll J Pelvic. Floor Dysfunct $14: 78-83,2003$.

Salom JB, Burguete MC, Perez-Asensio FJ et al. Acute relaxant effects of 17-beta-estradiol through non-genomic mechanisms in rabbit carotid artery. Steroids 67:339-346, 2002.

Sanchez-Ortiz R F, Wang $Z$, Menon $C$ et al. Estrogen modulates the expression of myosin heavy chain in detrusor smooth muscle. Am J Physiol 280(3): C433-40, 2001.

Sasaki K, Yoshimura $N_{0}$ Phelan MW et al. Nerve growth factor (NGF) gene therapy mediated by herpes simplex virus (HSV) vectors reverses bladder dysfunction and the decline in NGF expression in L6-S1 afferent neurons in diabetic rats. J Urol suppl 165:274, abstract 1125, 2001.

Scherle W. A simple method for volumetry of organs in quantitative stereology. Mikroskopie 26: 57 63. 1970. 
Silva ID, Gaspar J, Costa GG et al. Chemical features of flavonols affecting their genotoxicity. Potential implications in their use as therapeutical agents. Chem Biol Interact 124:29-51, 2000.

So FV, Guthrie N, Chambers AF et al. Inhibition of proliferation of estrogen receptor-positive MCF-7 human breast cancer cells by flavonoids in the presence and absence of excess estrogen. Cancer Lett 112:127-133, 1997.

Somlyo AP \& Somlyo AV. Signal transduction and regulation in smooth muscle. Nature $372 ; 231$. 236, 1994.

Sparagli GP, Valoti M, Gorelli B et al. Calcium antagonist and anti peroxidant properties of some hindered phenols. Br J Pharmacol 110:369-77, 1993.

Sterling AM, Ritter RC, Zinner NR. The physical basis of obstructive uropathy. In: Hinman F (ed). Benign prostatic hypertrophy. Springer-Verlag, New York, 1983 "p 433-442.

Sugita $M$, Tokutomi $N$, Tokutomi $Y$ et al. The properties of caffeine- and carbachol-induced intracellular $\mathrm{Ca}^{2+}$ release in mouse bladder smooth muscle cells. Eur J Pharmacol 348:61-70, 1998. Suguita M. Girao MJ. Simoes MJ et al. A morphologic and morphometric study of the vesical mucosa and urethra of castrated female rats following estrogen and/or progestogen replacement. Clin Exp Obstet Gynecol 27:176-178, 2000.

Susset JG \& Regnier $\mathrm{CH}$. Viscoelastic properties of bladder strips: standardization of a technique. Invest Ural 18(8):445-50, 1981 .

Susset JG, Servat-Viguier D, Lamy F et al. Collagen in 155 human bladders. Invest Urol $16(3)$ : 204-206, 1978.

Temml C, Halidinger G, Schmidbauer $\mathrm{J}$ et al. Urinary incontinence in both sexes: Prevalence rates and impact on quality of life and sexual life. Neurourol Urodyn 19:259-274, 2000.

Tokalov SV, Kind $B_{1}$ Wollenweber $R$ et al. Biological effects of epicuticular flawonoids from Primula denticulata on human leukemia cells. J Agric Food Chem 52(2): 239-245, 2004.

van Acker S, van Den Berg DJ., Tromp $M$ et al. Structural aspects of antioxidant activity of flavonoids. Free Rad Biol \& Med 20(3): 331-342, 1996.

van Koeveringe GA \& Van Mastrigt R. Excitatory pathways in smooth muscle investigated by phase-plot analysis of isometric force development. Am J of Physiol 1991, 26:138-44" 1991. 
Wall ME, Wani MC, Manikumar $G$ et al. Plant antimutagenic agents. 2. Flavonoids. Joumal of Natural Products 51(6):1084-1091, 1988.

Walle T. Absorption and metabolism of flavonoids. Free Rad Biol \& Med 36:829-836, 2004.

Weibel ER, Kistler GS, Scherie WF. Practical stereological methods for morphometric cytology. J Cell Biol 30: 23-38, 1966.

Wein $\mathrm{AJ}_{*}$ Levin $\mathrm{R} \mathrm{M}_{i}$ Barrett $\mathrm{DM}$. Voiding function. relevant anatomy, physiology, and pharmacology. In: Gillenwater JY, Grayhack JT, Howards SS, Duckett JD (eds). Adult and pediatric urology. Year Book Medical Publishers, Chicago, 1991, p 933-999.

White RW, Darkow DJ, Falvo Lang $\mathrm{JL}$. Estrogen relaxes coronary arteries by opening Bkca channels through a cGMP-dependent mechanism. Circ Res 77:936-942, 1995.

Wilson PD, Faragher B, Butler B et al. Treatment with oral piperazine oestrone sulphate for genuine stress incontinence in postmenopausal women. Br J Obstet Gynaecol 94:568-574, 1987.

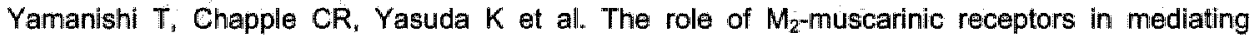
contraction of the pig urinary bladder in vitro. Br J Pharmacol 131:757-66, 2000.

Yu-Wen $C$, Ching-Hao L, Chen-Chen $L$ et al. Alpha-naphthoflawone induces vasorelaxation through the induction of extracellular calcium influx and NO formation in endothelium. NaunynSchmiedeberg's Arch Pharmacol 386: 377-385, 2003.

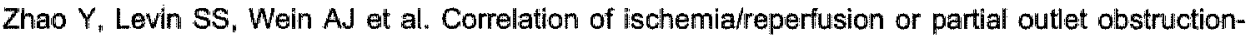
induced spectrin proteolysis by calpain with contractile dysfunction in rabbit bladder. Urology 49:293 300, 1997. 


\section{Acknowledgements}

This thesis received the contributions of many people. I would like to thank all those who helped me with this work.

Prof. Dr. Ph. E.V.A. van Kerrebroeck, you gave me the opportunity to become a Ph.D. student at the Department of Urology. For this, I would like to express my eternal gratitude.

Prof. Dr. Paulo C.R. Palma, Department of Urology, State University of Campinas, Brazill. Dr. Palma your dynamic approach and scientifc knowledge were the motive for my interest in urogynecology.

Dr. Gommert van Koeveringe, how lucky I was to meet you. I thank you very much for your advilice, assistence and enthousiastic cooperation in the different projects that we carried out at the department of urology. I hope we can continue the cooperation.

Prof. Dr. Aalt Bast, Department of Pharmacology and Toxicology, thank you very much for working in your laboratory, for the discussions, the hospitality, your support and your friendship.

Prof. Dr. Jo De Mey, Department of Pharmacology and Toxicology, thank you for the opportunity to work at your department, for the good soclal and research atmosphere.

Bary Berghmans, epidemiologist and health sicientist ${ }_{n}$ Universilty Hospital Maastrichl. Thank you for your advice, support and friendship.

Rik de Jongh, thank you very much for your criticisms that gave me an extra stimulus to finish the experiments. It was very nice to have known you and to have shared ideas and friendship. 
Arico $C$, van Voskullen, I would like to thank you very much for your help, friendship and patience. You made life in Holland much easier because you were present in many difficult moments of my life and helped me to resolve all of them.

Luba Drossaert and Kelly Hoenjet, I thank you for your very helpfful contribution, the good social events and friendship.

Dr. Eduardo Villamor, thank you for your long-time support, advice, assistance and friendship.

I would like to express my gratitude to all members of the staff of Urology Department, Dr. C. Van de Beek, Dr. G.O.N. Oosterhof, Dr. E.H.J. Weil, Dr. P. Callewaert, Dr. H.J. Rollema, Dr. E.C. Wessels and residents in training.

Helme Voets. I would like to thank you for your help and friendship. The good dinners in your house were a lot of fun.

The secretaries of the department of Urology, Anja, Cindy, Joan, Jose and Marion, I thank you for your help and kind assistence.

Gert-Jan den Hartog, Department of Pharmacology and Toxicology, thank you for your help, assistance and patience.

I would like to thank Chantall GM Heijnen for your assistance and help.

I thank all researchers from the Department of Pharmacology and Toxicology who helped me since my first day working in the laboratory. Thank you for your stimulating research influence. 
Eu gostaria de dizer muito obrigada aos meus colegas e amigos do Departamento de Urologia da Universidade Estadual de Campinas, especialmente Rogério de Fraga que me apoiou na decisto de realizar o doutorado em um país desconhecido e por conseqüencia enfrentar as dificul|clades de adaptaçäo no novo ambiente de trabalho e convivio social.

Não poderia deixar de prestar meu agradecimento especial ao amigo José Tadeu Tamanini pelo apoio incondicional e amizade fraterna que foram fundamentais durante toda a realizaça deste projeto.

Aos meus pais, Odila e Sivietto, meus irmãos, Mara Célia e Márcio, que tiverarn paciência $\theta$ apoiaram-me nas minhas decisões, permitindo que o sonho de estar aqui hoje se tornasse realidade.

I thank the European Community, Joint co-operation in REBEC (Project Number QLG5-CT-200100822) and the WAMU foundation Maastricht for the financial support which was essential for this thesis. 


\section{Curriculum Vitae}

Miriam Dambros

\section{Education, training and positions held}

$\begin{array}{lll}\text { Bachelor in Medicine } & \text { Fundlaçäo Federal de Medicina, RS, Br } & \text { Mar 90-Dec 95 } \\ \text { Resident in General Surgery } & \text { Hospital Santa Casa de Porto Alegre, RS, Bir } & \text { Jan 96 - Dec 97 } \\ \text { Resident in Urology } & \text { Hospital Santa Casa de Porto Alegre, RS, Br } & \text { Jan 98 - Dec 99 } \\ \text { Master's Degree in Urology } & \text { Universidade Estadual de Campinas, SP, Br } & \text { Mar 00- Oct 01 } \\ \text { Doctorate in Urology } & \text { Universidade Estadual de Campinas, SP, Br } & \text { Mar 02 - Dec 04 } \\ \text { Urologist } & \text { Hospital Mário Gattl, SP, Br } & \text { Agu 00-Dec 02 } \\ \text { Research Fellow } & \text { Hospital Universitário San Carlos, Madrid, ES } & \text { Jlan 03-April 03 } \\ \text { Research Fellow } & \text { University Hospital Maastricht, Depart. of Urology May 03 - Dec 04 } \\ \text { Prof. Depart. Surgery } & \text { Universidade de São Francisco, SP, Br } & \text { Mar 05- } \\ \text { Urogynaecol Research } & \text { Universidade Estadual de Campinas, SP, Br } & \text { Mar 05- }\end{array}$

\section{Awards}

- First rank among BO medical graduates (AD 1995), Federal Faculty of Medical Sciences, Porto Alegre, Rs, Brazil .

- Best basic research study in 1998 in the fleld of infertility, judged by Brazilian Society of Urology. "Testicular Trauma in rats - Impact on the reproductive function" "Porto Alegre, RS, Brazil.

- Best scientific study presented at the VABEI Congress - April, 1999: "Hypercholesterolemia in rabbits - Harmful effects on the penile tunica albuginea ", São Paulo, Brazil.

- Best study presented as a poster at the $2^{\text {nd }}$ Gaucha symposium in Urology - September .1999:

"Effects of testicular trauma on spermatogenesis - experimental study" ${ }_{4}$ Porto Alegre, RS, Brazil 
- First prize at the $2^{\text {nd }}$ Gaucha symposium - September , 1999: "Cystometric findings in rats surgically castrated with or without estrogen replacement "', Porto Alegre, RS, Brazil

- Second prize at the Paulista Urology Congress - June, 2000: "Comparison between the effects of unilateral open testicular biopsy and puncture in spermatogenesis - experimental study", São Paulo, Brazil.

- Best scientific study published at "Urodinámica Aplicada" between 2002 and 2004. "The role of estradiol on the bladder disfunction: an experimental study in rats". Prize received during the SINUG Congress, September 2004, Isla de La Toja, Spain.

\section{Publications}

Dambros $M$, de Jongh $R$, van Koeveringe $G$ et al. Galangin protects pig detrusor nerves from repetitive field stimulation and anoxia/glucopenia injury. Urology $66(6): 1327-31,2005$.

Casado JS, Zurbano JM, Dambros $\mathrm{M}$ et al. Factores de descompensación miccionall y cistocele. Arch Esp Urol 58(4): 3»6-323, 2005.

Zurbano JM $\mathrm{M}_{n}$ Casado JS, Dambros $M$ et all. Alteraciones de la fase de llenado vesical y cistocele. Arch Esp Urol 58 (4): 309-315, 2005.

Zurbano JM $\mathrm{J}$ Casado JS, Dambros M et al. Urodynamics of the bladder diverticulum in the adult male. Arch Esp Urol 58(7):641-9, 2005

Dambras $M$, de Jongh $R_{\mathrm{u}}$ van Koeveringe $G$ et al. Multiple-signaling pathways are involved in the inhibitory effects of galangin on urinary bladder contractility. Neurourol Urodyn 24(4):369-73, 2005.

Dambros $M_{*}$ van Deutekorn $M_{*}$ de Jongh $R$ et al. The ïnhibitory effect of the flavonoid galangin on urinary bladder smooth muscle contractility is mediated in part by modulation of $\mathrm{Ca}^{2+}$ release from intracellular stores. Plan Med 71(10):962-4, 2005. 
Dambros $M$, de Jongh $R_{r}$ Koeveringe $G$ et al. Flavonoid galangin prevents smooth muscle fatigue of pig urinary bladder. J Pharm Pharmacol 57(5):617-22, 2005.

Thiel $M$, Palma PCR, Dambros $M$ et al. A stereological analysis of fibrosis and inflammatory reaction induced four different synthetic slings. BJU Inter 95(6):833-7, 2005.

Palma PCR, Dambros M, Riccetto $C L Z$ et al. Uretrolisis transvaginal tras cirugía correctora de la incontinencia urinaria de esfuerzo. Actas Uroll Esp 29(2): 207-211, 2005.

Palma PCR, Riccetto CLZ, Dambros M et al. Transobturator correction of cystocele. Actas Urol Esp $29(1): 89-92,2005$.

Palma PCR, Dambros $M_{n}$ Riccetto $C L Z$ et al. The lbero-American experience with a re-adjustable minimally invasive sling. BJU Inter 95(3): 341-345, 2005.

Tamanini JTN Dambros $\mathrm{M}_{4}$ D'ancona $\mathrm{CAL}$ et al. Concurrent validity, internal consistency and Responsivenessof the portuguese version of the king's health questionnaire (KHQ) in women after stress Urinary incontinence surgery. Braz J Urol 30(60):479-486, 2004.

Palma PCR, Riccetto CLZ, Dambros M et al. Safyre. A new concept for adjustable minimally invasive sling for female urinary stress incontinence. Actas Urol Esp 28(10):749-755, 2004. (article in Spanish)

Palma PCR, Dambros $M$, Thilel $M$ et al. Readjustable Transobturator Sling: A Novel Sling Procedure for Male Urinary Incontinence. Urol Inter 73:354-356, 2004.

Dambros $M$, Koeveringe $G$, Bast $A$ et al. Relaxant effects of estradiol through non-genomic 
pathways in male and female pig bladder smooth muscle. Pharmacology, $72(2): 121-7,2004$.

Palma PCR, Thiel $M$, Dambros $M$ et al. Resiniferaxotin for detrusor instability refractory to anticholinergics. Inter Braz J Urol.30:53-58, 2004.

Tamanini JTN, Dambros M, D'ancona CL et al. Validation of the International Consultation on Incontinence Questionnaire - Short Form (ICIQ-SF) for Portuguese. Revista de Saúde Pública 38: $1-6,2004$.

Palma PCR, Vidal $B_{n}$ Dambros $M$ et al. Effect of purified collagen on lipograft survival: experimental basis for periurethral lipoinjections. J Endourol 17:255-259, 2003.

Palma PCR, Riccetto CLZ, Dambros M et al. Pre-pubic Sparc: A promising alternative for selected cases of urinary stress incontinence. Urologla Panamericana:15:19-21, 2003.

Palma PCR, Riccetto CLZ, Dambros $M$ et al. Safyre: A readjustable minimally invasive sling forfemale urinary stress incontinence. Inter Braz J Urol 29: 353-359, 2003.

Dambros M, Palma PCR, Lacerda CM et al. The effect of ovariectomy and estradiol replacement on collagen and elastic fibers in the bladder of rats. Inter Urogynecol $J 14: 108-112,2003$.

Palma PCR, Riccetto CLZ, Dambros $M$ et al. Is the anterior vaginal wall silling a good alternative for intrinsic sphincteric insufficiency? Inter Braz J Urol 28: 349-355, 2002.

Palma PCR, Riccetto CLZ, Dambros $M$ et al. Sabre: Preliminay experience with a new synthetic absorbable self-anchoring sling for female stress urinary incontinence. Revista Urologia Panamericana 14: 19-22, 2002. 
Palma PCR, Riccetto $\mathrm{CLZ}$, Dambros $M$ et al. Tension-firee vaginal tape (TVT): minimally invasive technique for stress urinary incontinence. Inter Braz J Urol 28: 458-463, 2002.

Palma PCR, Thiel M. Dambros $M$ et al. The Bologna procedure for the treatment of cystocele in association with stress urinary incontinence. Inter Braz J Urol 28: 140-142, 2002.

Palma PCR, Maques PC, Dambros $M$ et al. Histopathological alternations resulting from subcutaneous implant of collagen and autologous aponeuroticfiascia: a comparative study in dogs. Inter Braz J Urol 27: 171-177, 2001.

Teloken $C$, Dambros $M$, Bohnenberger D et al. Hypercholesterolemia in rabbit induces increase in thickness of the penile tunica albuginea. Inter Braz J Urol 26: 535-540, 2000.

Teloken $C_{\text {, Rodhen }}$, Dambros M et al. Therapeutic effects of high dose Yahimbine Hydrochloride on organic erectile dysfunction. J Urol 159: 122-124, 1998. 